\title{
The More the Poorer? Resource Sharing and Scale Economies in Large Families
}

Rossella Calvi, Jacob Penglase, Denni Tommasi and Alexander Wolf

December 2020

Working Paper 46/20 


\title{
The More the Poorer? Resource Sharing and Scale Economies in Large Families
}

\author{
Rossella Calvi* $\quad$ Jacob Penglase $^{\dagger} \quad$ Denni Tommasi ${ }^{\ddagger} \quad$ Alexander Wolf $^{\S}$
}

November 2020

\begin{abstract}
The structure of a family may have important consequences for the material well-being of its members. For example, in large families, an individual must share resources with many others, but she may benefit from economies of scale in consumption. In this paper, we study individual consumption in different types of households, with a focus on family structures that are common in developing countries. Based on a collective household model, we develop a new methodology to identify the intra-household allocation of resources and the extent of consumption sharing. We apply our methodology using data from Bangladesh and Mexico, and use the model estimates to compute poverty rates for men, women, and children. Contrary to existing poverty calculations that ignore either intra-household inequality or economies of scale in consumption, ours take into account both dimensions.
\end{abstract}

JEL Codes: D13, D11, D12, C31, I32.

Keywords: collective model, household bargaining, resource shares, scale economies, Barten scales, indifference scales, poverty.

\footnotetext{
${ }^{*}$ Rice University, Department of Economics, Kraft Hall 421, 6100 Main Street, Houston, TX 77005, USA (e-mail: rossella.calvi@rice.edu).

'San Diego State University, Department of Economics, 5500 Campanile Drive, San Diego CA, 92182 (e-mail: jpenglase@sdsu.edu).

Monash University, Department of Econometrics and Business Statistics, Level 5, Building H, Caulfield Campus 900 Dandenong Road Melbourne, VIC 3145 (e-mail: denni.tommasi@monash.edu).

${ }^{\S}$ Compass Lexecon, Square de Meeûs 23, 1000 Brussels, Belgium (email: alexfwolf@gmail . com).

We thank Samson Alva, Arthur Lewbel, Omer Sozbir, and seminar participants at the Bordeaux Applied Economics Workshop. Jacob Penglase gratefully acknowledges support from the Center for Health Economics and Policy Studies and San Diego State University. All errors are our own.
} 


\section{Introduction}

The composition of households may have important consequences for the well-being of their members. Contrary to developed countries, where the vast majority of households comprise either single adults or nuclear families with a small number of children, households in the developing world are large and typically include several generations and many children. ${ }^{1}$ In these countries, the welfare state is often limited and families are the primary providers of material and non-material support to their members. In such contexts, understanding the relationship between family structure and individuals' welfare is of primary importance.

In this paper, we develop a framework to study the material well-being of individuals in different types of households, with a specific focus on family structures that are prevalent in developing countries. We aim to identify important aspects of intra-household consumption in order to answer the following questions: What is the income adjustment that would make an only child just as well off as if she was living in a larger household? How much income would a member of an extended family require to attain the same standard of living that she would have if she was living in a nuclear family? In larger households, individuals are allocated a smaller share of the household budget, but they tend to benefit from scale economies: food waste per person, for example, is likely lower in larger households, and more people jointly consume goods that can be shared (such as energy goods). Quantifying this trade-off is necessary to compare individuals' well-being across households and may be important for the correct measurement of poverty and inequality.

Consumption data are typically collected at the household level. Therefore, it is difficult to observe how goods are allocated across individuals within families and the extent to which these goods are shared. Recent works have used the collective household model to overcome this limitation and estimate critical aspects of intra-household consumption that researchers usually do not observe. Beginning with the seminal work by Chiappori $(1988,1992)$, this literature has modeled households as a collection of individuals, rather than a single economic unit, under the assumption that households are Pareto efficient in their allocation of goods.

Our paper builds on these seminal papers as well as more recent contributions by, e.g., Lewbel and Pendakur (2008), Bargain and Donni (2012), and Browning et al. (2013), who devised approaches to identify the allocation process and consumption sharing from household-level demand data. To recover the intra-household allocation of resources and scale economies in consumption, these works (which have mostly focused on couples) impose preference stability between single and married individuals. Stated differently, to identify resource allocation and economies of scale, the existing identification methods rely on the observability of consumption choices of single individuals and on the assumption that any change in consumption behavior between living alone and in a couple can be attributed to jointness of consumption and resource sharing rather than to changes in individual preferences. ${ }^{2}$

While effective, this approach has several drawbacks that we wish to avoid. First, as noted by Dunbar

\footnotetext{
${ }^{1}$ In 2017, the average household size in the United States and Canada was 2.5. The Netherlands ranked last for household size, with only 2.2 members per family, on average. By contrast, families in South Asia and many African countries are much larger: Indian and Ethiopian households, e.g., consist of 5 members, on average; in Senegal, where the practice of polygamy is common, the average household size equals 9 (Household Size and Composition Around the World 2017). Figure A1 in the Appendix shows the distribution of household size in selected countries.

${ }^{2}$ Parallel to our work, Lewbel and Lin (2020) and Donni and El Badaoui (2020) provide identification results that, at least partly, rely on preference stability between singles and individuals in couples or price variation. Alternative methods achieve set-identification of resource shares using axiomatic revealed preference methods (Cherchye et al., 2011, 2015, 2016, 2017).
} 
Figure 1: Household Types in Selected Countries
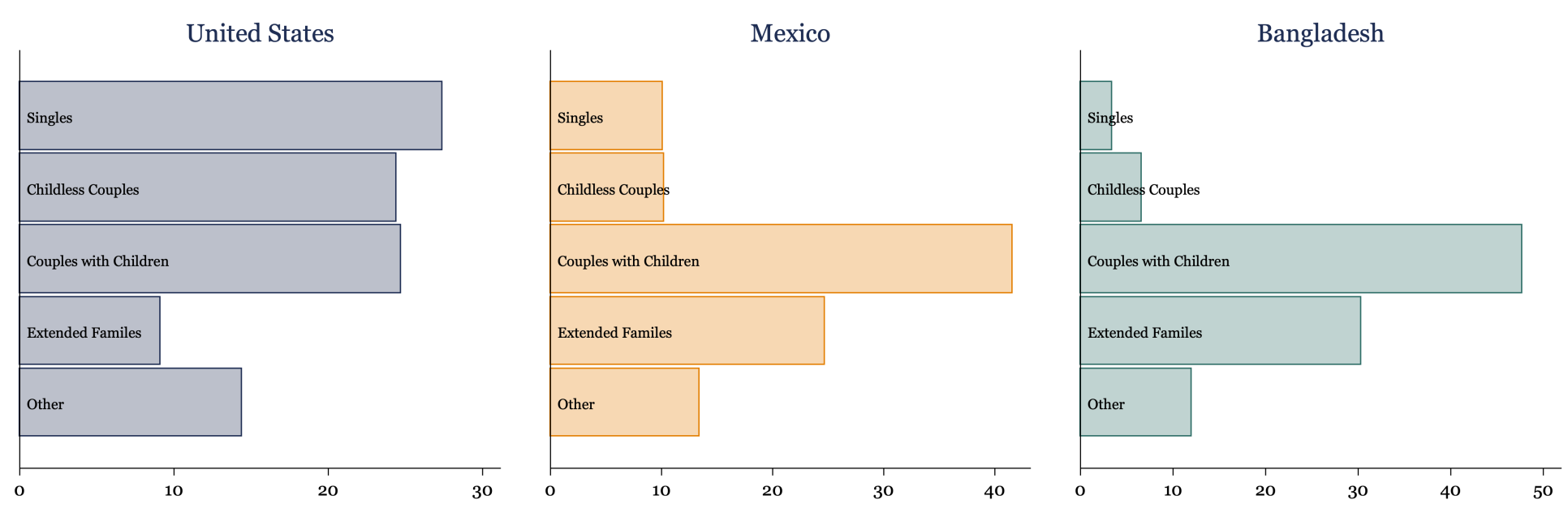

Notes: Authors' calculations based on the most recent IPUMS data (2010 for US, 2015 for Mexico, and 2011 for Bangladesh).

et al. (2013), it cannot be applied to study children's well-being, as they do not live alone. This is true both in developed and developing countries. Second, in developing countries (the focus of our study), single-person households are rare (see Figure 1). Cultural norms in specific regions of the world may also attach a strong social stigma to women living alone. So, observing the consumption choices of singles may be extremely challenging in many such contexts. Third, tastes over consumption goods may change upon marriage and individual preferences over some goods may be fundamentally different when living alone and when living in larger households.

Our identification method relies on four main assumptions. First, to identify the allocation process without the assumption of preference stability between single individuals and individuals in multi-person families, we impose semi-parametric restrictions on individual preferences over one private assignable good (Dunbar et al., 2013). ${ }^{3}$ Second, we require the Engel curves of such goods to have a moderate degree of curvature (Lewbel and Pendakur, 2008; Blundell et al., 1998; Browning et al., 2013). Third, we assume that economies of scale in consumption can be summarized by a single parameter that inflates household expenditure (Blundell et al., 1998; Lewbel and Pendakur, 2008; Bargain and Donni, 2012). Fourth, we restrict how the allocation process and the extent of joint consumption vary with household expenditure (Pendakur, 1999; Lewbel and Pendakur, 2008; Bargain and Donni, 2012). Under these assumptions, we can identify both resource allocation and scale economies for each family member without observing the consumption choices of single-person households. Specifically, the structural parameters of interest are identified by comparing the Engel curves of private assignable goods across family members and household compositions.

We apply our method using data from Bangladesh and Mexico. The choice of these countries is motivated by our interest in understanding consumption sharing at various stages of development: in poorer countries like Bangladesh, where food (which is largely private) is a larger share of the budget, economies of scale are likely to be less important than in middle-income countries like Mexico (Deaton and Paxson, 1997, 1998). Moreover, countries may differ substantially in their traditional gender norms and their societal attitudes towards women. Studying Bangladesh and Mexico allows for these types of comparisons. In Bangladesh, we find a modest amount of consumption sharing, suggesting that ignoring economies of

\footnotetext{
${ }^{3} \mathrm{~A}$ good is private if it is not shared or consumed jointly. A good is assignable if it appears in just one (known) household member's utility function, and so is only consumed by that household member.
} 
scale is not likely to lead to a large degree of error in individual consumption estimates. By contrast, we estimate significant economies of scale in consumption in Mexico, which, on average, increase individual consumption in extended families or nuclear families with multiple children by 10 percent relative to nuclear families with one child. We also unveil a non-monotonic relationship between economies of scale in consumption and household size in Mexico, which is driven by differences in the relative consumption of private and shareable goods across household types. Finally, we find that women in Mexican families are allocated a larger fraction of household resources relative to women in Bangladesh. In both countries, children command the smallest share of household resources, but their disadvantage is more pronounced in Bangladesh. ${ }^{4}$ These results have policy-relevant implications for the measurement of poverty, which we illustrate in Section 5.

Based on the model estimates, we construct indifference scales (Browning et al., 2013), which measure the income adjustment applied to a person living in a household of a particular demographic composition to be just as well off as if they were living in a household with a different demographic composition. Indifference scales can be used in applied welfare analysis to answer questions related to the measurement of poverty, inequality, or cost of living indices. Moreover, indifference scales do not suffer from many of the problems inherent to equivalence scales, such as ignoring intra-household inequality and relying on untestable assumptions related to utility comparisons across households. ${ }^{5}$ To this point, existing literature have applied indifference scales to compare the welfare of adults living alone or in a couple. We add to this literature by introducing child indifference scales, which are defined as the income adjustment applied to a child living in a household with multiple children that would allow her to reach the same indifference curve as if she was an only child. Moreover, we generalize the concept of adult indifference scales by considering the income adjustment required to make adults living in an extended family be just as well off as if they were living in a nuclear family.

In our application, we use indifference scales to construct empirically grounded poverty thresholds and compare them to commonly-used equivalence scales. Our poverty estimates improve upon recent works (Dunbar et al., 2013; Tommasi, 2019; Sokullu and Valente, 2019; Brown et al., 2019; Lechene et al., 2019; Bargain et al., 2018; Calvi, 2020; Penglase, 2020), who compute individual-level poverty rates, but are unable to account for consumption sharing within the household. Closer to our work is Bargain et al. (2014), who apply the methodology of Bargain and Donni (2012) to estimate the intra-household allocation process and adult economies of scale in Côte d'Ivoire. We depart from their framework by estimating both adult and children economies of scale and not relying on singles' data. More broadly, our results shed light on the relationship between household size and poverty (Lanjouw and Ravallion, 1995), and on the relative merits of per-capita poverty measures, commonly used equivalence scales, and model-based poverty estimates.

The rest of the paper is organized as follows. In Section 2, we set out a collective household model. In Section 3, we present our identification results. In Section 4, we describe our empirical applications and estimation results. In Section 5, we conduct an individual-level poverty analysis based on the model

\footnotetext{
${ }^{4}$ Previous estimates of individual consumption for Bangladesh and Mexico that account for intra-household allocation but not economies of scale are provided by Brown et al. (2019), Bargain et al. (2018), and Lewbel and Pendakur (2020), and Tommasi (2019), Sokullu and Valente (2019), and Hoehn-Velasco and Penglase (2019), respectively.

${ }^{5}$ See Chiappori (2016) and Pendakur (2018) for a detailed discussion of the relative merits of indifference scales and equivalence scales. See Fisher (1987) for a more general discussion of the limitations of using demand analyses to make interpersonal welfare comparisons.
} 
estimates. Section 6 concludes. Detailed proofs and additional material are in an online Appendix.

\section{Theoretical Model}

In this section, we set up a collective household model for extended families. Our model builds on Browning et al. (2013), Lewbel and Pendakur (2008), and Dunbar et al. (2013), but allows for more flexible living arrangements and for the presence of a large number of decision makers (Brown et al., 2019; Calvi, 2020).

We model households as collections of individuals who jointly purchase and consume goods. A household consists of $N$ members. Each member belongs to one of $J$ categories (indexed by $j$ ), such as women, men, children, or the elderly. The number of household members of each category $j$ is denoted by $n_{j}$ so that $N=\sum_{j=1}^{J} n_{j}$. A household's composition or type is defined by the number of individuals in each category. Accordingly, we denote a household type by $\tau=\left(n_{1}, \ldots, n_{J}\right)$. For simplicity, we assume that all household members of a specific category have identical, well-behaved preferences over consumption goods and are treated equally. ${ }^{6}$ As in Browning et al. (2013), we allow for altruism, so that one's utility may depend on the utility of other household members. However, for identification purposes, we rule out direct consumption externalities.

Household members have preferences over $K$ goods with $\log$ market prices $p=\left(p^{1}, \ldots, p^{K}\right)$. Let $z_{\tau}=$ $\left(z_{\tau}^{1}, \ldots, z_{\tau}^{K}\right)$ be the vector of observed quantities of goods purchased by each household of type $\tau$ at log total household expenditure $x$ and $\tilde{z}_{j, \tau}=\left(\tilde{z}_{j, \tau}^{1}, \ldots, \tilde{z}_{j, \tau}^{K}\right)$ be the vector of quantities of goods consumed by each individual of category $j$ in a household of type $\tau$ (that is, her private good equivalents). We model joint consumption using Barten scales, which effectively increase the quantities of the goods available for consumption by the household members. Specifically, we consider a consumption technology function that can be summarized by a diagonal $K \times K$ matrix $A_{\tau}$, such that $z_{\tau}=A_{\tau} \sum_{j=1}^{J} n_{j, \tau} \tilde{z}_{j, \tau}$. The diagonal entries of $A_{\tau}$ are the Barten scales and indicate to what extent, if at all, the sum of private good equivalents of a good $k$ exceeds the purchased quantity $z_{\tau}^{k}$. They also indicate how much cheaper each good is to household members relative to market prices. ${ }^{7}$

Let $\alpha_{\tau}=\left(\alpha_{\tau}^{1}, \ldots, \alpha_{\tau}^{K}\right)$ be the vector of $\log$ Barten scales. Then, $\alpha_{\tau}+p$ is the vector of log shadow prices faced by the household members. Note that Barten scales are common to all household members and depend on the nature of good $k$ : if good $k$ is a private good (i.e., not jointly consumed), then the $k^{\text {th }}$ diagonal element of $A_{\tau}$ is equal to one, $\alpha_{\tau}^{k}=0$, and its shadow price equals its market price; if good $k$ is jointly consumed (or at least partly shared), then $\alpha_{\tau}^{k}<0$ and the shadow prices is lower than the market price.

We denote by $W_{\tau}^{k}\left(p, x, \alpha_{\tau}\right)$ the household-level budget share for good $k$ as a function of log prices, $\log$ expenditure and Barten scales, and by $w_{j, \tau}^{k}\left(p, x, \alpha_{\tau}\right)$ the individual-level budget share of each member of type $j$ (that is, the budget share function of a household consisting just of one person of type $j$ ). Browning

\footnotetext{
${ }^{6}$ In our empirical application, we allow households to differ along a wider set of observable attributes, including individual characteristics of their members. To reduce notational clutter, we omit these for now.

${ }^{7}$ Note that this framework allows for a simple household production technology with constant returns to scale through which market goods are transformed into household commodities.
} 
et al. (2013) show that the household-level budget shares take the following form:

$$
W_{\tau}^{k}\left(p, x, \alpha_{\tau}\right)=\sum_{j} n_{j, \tau} \eta_{j, \tau}\left(p, x, \alpha_{\tau}\right) w_{j, \tau}^{k}\left(p+\alpha_{\tau}, x+\ln \eta_{j, \tau}\left(p, x, \alpha_{\tau}\right)\right)
$$

where $\eta_{j, \tau}$ are resource shares, i.e., the fraction of the total household expenditure allocated to each member of category $j$ in a household of type $\tau$.

Now consider a private good that is assignable, in the sense that is not shared and is exclusively consumed by household members of known category $j$. Then, the household-level budget shares for the assignable goods $k_{j}$ are simpler than Equation (1) and as follows (Dunbar et al., 2013):

$$
W_{\tau}^{k_{j}}\left(p, x, \alpha_{\tau}\right)=n_{j, \tau} \eta_{j, \tau}\left(p, x, \alpha_{\tau}\right) w_{j, \tau}^{k_{j}}\left(p+\alpha_{\tau}, x+\ln \eta_{j, \tau}\left(p, x, \alpha_{\tau}\right)\right),
$$

Note that Equations (1) and (2) follow directly from the central assumption of collective models, that the intra-household allocation of goods is Pareto efficient. Applying duality theory and decentralization welfare theorems, the household decision process can be decomposed in two stages: in a first stage, resources are allocated among family members; in a second stage, each household member chooses $\tilde{z}_{j, \tau}$ as if they maximized their own utility function given a fraction $\eta_{j, \tau}$ of the household's total expenditure and facing $\log$ shadow prices $\alpha_{\tau}+p .^{8}$ Note that one cannot just use $W_{\tau}^{k_{j}}$ as a measure of $\eta_{j, \tau}$ as different household members may have different tastes for their private assignable good.

Generalized Indifference Scales. Our objective is to shed light on the relationship between family structure (or household type, in the sense we defined above) and individual well-being. When comparing the well-being of individual $j$ living in small versus large families, there are two factors to consider: in larger households there may be more economies of scale in consumption, but resources are by construction allocated in smaller proportions. To better quantify this tradeoff, we consider indifference scales (Browning et al., 2013), i.e., the income adjustment applied to a person living in a household of a particular type to be just as well off as if they were living in household with a different type. Note that Browning et al. (2013) introduced indifference scales to compare the welfare of an individual living alone versus living in a couple. ${ }^{9}$ We expand their definition to carry out more general welfare comparisons.

Suppose a household of type $\tau$ has Barten scales $\alpha_{\tau}$ and each person in that household has resource share $\eta_{j, \tau}$. The indifference scales for an individual of type $j$ in a household of type $\tau=t^{\prime}$ relative to a household of type $\tau=t$ are given by the solutions to the following equation:

$$
V_{j}\left(\alpha_{t^{\prime}}+p, x+\ln \eta_{j, t^{\prime}}-\ln I_{j, t, t^{\prime}}\right)=V_{j}\left(\alpha_{t}+p, x+\ln \eta_{j, t}\right)
$$

\footnotetext{
${ }^{8}$ While some papers provide evidence in favor of Pareto efficiency (see e.g. Attanasio and Lechene (2014) for Mexico and Brown et al. (2019) for Bangladesh), some others cast doubt on this assumption (see e.g. Udry (1996) and De Vreyer et al. (2020) for Burkina Faso). Note that most rejections of Pareto efficiency are based on decisions about production, not consumption. As discussed in Rangel and Thomas (2019), confounding these two aspects may be misleading. Rangel and Thomas (2019) show that in nuclear families in Burkina Faso, resource allocations are consistent with efficiency. In more complex household structures, including polygynous households, efficiency in allocations is not rejected in models (like ours) that allow more than two decision makers. Finally, Lewbel and Pendakur (2019) develop a collective household model where households behave inefficiently, but show that this does not have a large effect on the estimates of resource shares in Bangaldesh.

${ }^{9}$ In Browning et al. (2013) as well as in Lewbel and Pendakur (2008) and Bargain and Donni (2012), indifference scales are defined as $V_{j}\left(p, x+\ln I_{j}\right)=$ $V_{j}\left(p+\alpha, x+\ln \eta_{j}\right)$ and represent the amount of income needed by an individual living alone to make her as well-off as if she were living in a couple. Intuitively, the indifference scale between household types $t$ and $t^{\prime}$ is equivalent to the ratio of the indifference scale between household types $t$ and single-person household and the indifference scale between household $t^{\prime}$ and single-person household.
} 
If a person in category $j$ living in a household of type $t^{\prime}$ was given an amount of income equal to $\eta_{j, t^{\prime}} e^{x} / I_{j, t, t^{\prime}}$, then she would be able to buy a bundle of goods that lies on the same indifference curve as the bundle of goods that she consumes as a member of a household of type $t$ with total expenditure $e^{x}$ and resource share $\eta_{j, t}$. This accounts for both the intra-household allocation of resources and the household economies of scale in consumption. If indifference scales were to equal 1 , then the individual would be indifferent between living in household $t$ or in household $t^{\prime}$, and no income adjustment would be necessary. By contrast, if indifference scales were lower (greater) than 1 , then household income $e^{x}$ for an individual in household $t^{\prime}$ would need to be scaled up (down) to be just as well off as if they were living in household $t$ with household income $e^{x}$.

Note that the definition of indifference scales provided in Equation (3) relies on the assumption that individuals' preferences, and hence indifference curves, are independent of household types (i.e., $V_{j}$ has no $\tau$ subscript). This preference stability assumption is necessary for indifference scales (which rely on welfare comparisons) to have a meaningful interpretation. As we discuss in the next section, however, it is not required for the identification of resource shares and economies of scale in consumption. Moreover, as noted by Lewbel and Pendakur (2008), if preferences change in an identified manner, indifference scales can still maintain a valid interpretation.

\section{Identification}

Our goal is to identify the intra-household allocation process and the extent of joint consumption separately from individual preferences over consumption goods. Below, we summarize our identifying assumptions. Next, we present our identification results, starting with the simple case of nuclear households with children and then proceeding to more complex settings. Our main theorem builds on a set of assumptions that have been used by previous works. Our contribution lays in how we combine and apply these assumptions to identify resource shares and economies of scale in consumption from householdlevel demand data without relying on price variation nor data on singles (both of which are typically not available in a developing country context). Table 1, which we describe in details later on, summarizes how our methodology relates to previous works.

\subsection{Setup}

As in Dunbar et al. (2013) and Bargain and Donni (2012), we require the observability of household-level expenditures on private assignable goods. Consistent with what is available in many household consumption surveys (which typically collect expenditures that can be assigned to categories of individuals, such as women, men, or children, but not the identity of each consumer), we posit that all household members of a specific category have identical preferences over their assignable good and they consume the same amount of it. In principle, this restriction can be relaxed with richer data.

Assumption 1. The econometrician observes the household-level budget shares for private assignable goods, $W_{\tau}^{k_{j}}\left(\alpha_{\tau}+p, x\right)$, for all categories $j=1, \ldots, J$. 
Note that private assignable goods provide a number of advantages over goods that are jointly consumed. First, by construction, their demand is only driven by the preferences of those household members who consume them; so, if we observe a household consuming more of women's clothing, we can exclude men's preferences for women's clothing as a potential determinant of this difference. ${ }^{10}$ Moreover, as a consequence of them being privately consumed, their shadow prices do not vary across household sizes and are equal to market prices; so, their demand functions do not directly depend on the specifics of the consumption technology function.

Assumption 2. Let $y=e^{x}$ be the household total expenditure, and $\omega_{j, \tau}^{k_{j}}(y)$ be the individual-level budget share equations for the private assignable goods as a function of total expenditure in one price regime. $\omega_{j, \tau}^{k_{j}}(y)$ are twice continuously differentiable with respect to $y$ and, when evaluated at $y=0$, are such that:
i. $\nabla_{y}^{2} \omega_{j, \tau}^{k_{j}}(0)=\nabla_{y}^{2} \omega_{j}^{k_{j}}(0)$ and $\nabla_{y} \omega_{j, \tau}^{k_{j}}(0)=\nabla_{y} \omega_{j}^{k_{j}}(0)$,
(Similarity Across Types)
ii. $\left.\nabla_{y}^{2} \omega_{j, \tau}^{k_{j}}(0)=\nabla_{y}^{2} \omega_{j^{\prime}, \tau}^{k_{j^{\prime}}}(0)\right)$,
(Similarity Across People)
iii. $\nabla_{y}^{2} \omega_{j, \tau}^{k_{j}}(0) \neq 0$.
(Non-linearity)

A few important aspects of Assumption 2 deserve mention. First, this assumption does not require observing budget shares at zero expenditure. Rather, it imposes restrictions on the limits of the derivatives of the budget share functions in the neighborhood of zero. One reason the assumption is written in terms of expenditure (as opposed to log expenditure) is so that this limit exists. Second, as shown in Table 1, existing identification methodologies typically rely on stronger preference stability requirements. Lewbel and Pendakur (2008) and Bargain and Donni (2012), for instance, constrain individuals' preferences over goods to be the same whether they are single or in a couple, so that changes in consumption behavior between living alone and with another person can be attributed to jointness of consumption and resource sharing rather than changes in preferences. We do not impose stability of preferences for adults across marital statuses. Instead, we require that individuals have similar (but not identical) preferences across household types (Assumption 2.i). So, e.g., mothers of two children have preferences over their clothing that are similar to those of mothers of three children. In this regard, our assumption aligns more closely with the identification restrictions proposed by Dunbar et al. (2013) (although they require the first derivative to be independent of household type, while we require this both for first and second derivatives). Third, while Assumption 2.ii posits similarity of preferences across different people, it allows for some degree of heterogeneity in individuals' preferences over their private assignable good. We later show how this assumption can be weakened if the data includes childless couples or in the case of specific types of preferences (e.g., the Quadratic Almost Ideal Demand System of Banks et al. (1997)). Assumption 2.ii is crucial to identify preference parameters and resource shares without relying on singles data. Dunbar et al. (2013) achieve identification of resource shares by imposing an analogous assumption on the first derivatives of the budget share equations. However, they do not identify economies of scale for children and adults. To this aim, we impose Assumption 2.iii, which requires a certain degree of non-linearity in the demand functions of the private assignable goods, as in Lewbel and Pendakur (2008), Bargain and Donni (2012), and Browning et al. (2013).

\footnotetext{
${ }^{10}$ This is true in absence of direct consumption externalities, which is one of the assumptions of our model (see Section 2 for details).
} 
We also require our main objects of interest (resource shares and economies of scale) to satisfy some common properties, which we summarize in Assumption 3 and Assumption 4 below.

Assumption 3. There exists a scalar-valued, differentiable function $s_{j, \tau}\left(\alpha_{\tau}, p\right)$, such that the following equality holds:

$$
V_{j}\left(\alpha_{\tau}+p, x\right)=V_{j}\left(p, x-\ln s_{j, \tau}\left(\alpha_{\tau}, p\right)\right) .
$$

This assumption is the independence of base assumption of Blundell et al. (1998) and Lewbel and Pendakur (2008). The function $s_{j, \tau}\left(\alpha_{\tau}, p\right)$ can be interpreted as a measure of the cost-savings that person $j$ experiences when living in a family instead of herself due to economies of scale. More accurately, we should expect $1 / s_{j, \tau}$ to increase as economies of scale in consumption increase. Note that $s_{j, \tau}\left(\alpha_{\tau}, p\right)$ is independent of $x$, so economies of scale are assumed to be independent of the expenditure at which they are evaluated. If there are economies of scale in consumption, $s_{j, \tau}\left(\alpha_{\tau}, p\right)<1$ and $\ln s_{j, \tau}\left(\alpha_{\tau}, p\right)<0$; if all goods are private, then $s_{j, \tau}\left(\alpha_{\tau}, p\right)=1$ and $\ln s_{j, \tau}\left(\alpha_{\tau}, p\right)=0$.

Applying Roy's identity to Equation (4) yields individual-level budget share functions (as functions of $\log$ shadow prices and $\log$ expenditure) for good $k$ in a household of type $\tau$ that are as follows:

$$
w_{j, \tau}^{k}\left(\alpha_{\tau}+p, x\right)=\lambda_{j, \tau}^{k}+w_{j, \tau}^{k}\left(p, x-\ln s_{j, \tau}\left(\alpha_{\tau}, p\right)\right),
$$

where $\lambda_{j, \tau}^{k}=\frac{\partial \ln s_{j, \tau}\left(\alpha_{\tau}, p\right)}{\partial p^{k}}$. Thus, $j$ 's budget share function for good $k$ has the same shape when evaluated at $\log$ market prices or at $\log$ shadow prices $\alpha_{\tau}+p$. The only difference is that they are translated horizontally by $\ln s_{j, \tau}(\alpha, p)$ and vertically by $\lambda_{j, \tau}^{k}$.

Assumption 4. Resource shares are independent of $x$, so that $\eta_{j, \tau}\left(p, \alpha_{\tau}, x\right)=\eta_{j, \tau}\left(p, \alpha_{\tau}\right)$.

This assumption mirrors Assumption A.1 of Dunbar et al. (2013). ${ }^{11}$ Empirical evidence supporting this assumption is provided by Menon et al. (2012), who show that for Italian households resource shares do not exhibit much dependence on household expenditure, Bargain et al. (2018), who find similar results in Bangladesh, and Cherchye et al. (2015), who use detailed data on Dutch households to show that revealed preferences bounds on women's resource shares are independent of total household expenditure. Importantly, this restriction still permits resource shares to depend on other variables related to expenditure, such as wealth and assets.

Under the assumption that the structural components $\eta_{j, \tau}\left(\alpha_{\tau}, p\right)$ and $s_{j, \tau}\left(\alpha_{\tau}, p\right)$ are independent of expenditure, the indifference scales of individuals $j$ across two household types $\tau$ and $\tau^{\prime}$ are also independent of expenditure, and are defined according to the following Lemma.

Lemma 1. Let Assumptions 3 and 4 hold. Then, indifference scales for an individual of group $j$ in a household of type $\tau=t^{\prime}$ relative to a household of type $\tau=t$ are independent of $x$ and are given by:

$$
I_{j, t, t^{\prime}}\left(p, \alpha_{t^{\prime}}, \alpha_{t}\right)=\frac{\eta_{j, t^{\prime}}\left(p, \alpha_{t^{\prime}}\right)}{\eta_{j, t}\left(p, \alpha_{t}\right)} \frac{s_{j, t}\left(p, \alpha_{t}\right)}{s_{j, t^{\prime}}\left(p, \alpha_{t^{\prime}}\right)} .
$$

Proof. See Appendix A.1.

Lemma 1 implies that, once two of the three objects of interest (resource shares, economies of scale, and indifference scales) are identified, the third one can be immediately recovered.

\footnotetext{
${ }^{11}$ While Assumption 4 needs to be satisfied for low levels of household expenditure only, for simplicity, we assume it holds for all values of $x$.
} 


\subsection{Identification in Nuclear Households with Children}

While our approach easily generalizes to extended households with multiple women and multiple men (see Section 3.3 for details), for simplicity we start by illustrating identification for nuclear households with children. This is a special case of the general model presented in Section 2, with three categories of individuals $j=m, w, c$ (men, women, and children) and $n_{m}=n_{w}=1$. In nuclear families, the man is the children's father and the woman is the mother, and a household type is determined by the number of children, so that $\tau=n_{c}=n$.

Suppose that demand data are observed in a unique price regime, as in cross-sectional data, so that the vector of prices $p$ is constant. Suppose also that there are no singles and that we do not observe a sufficient number of couples without children to identify $s_{j, 1}$, for $j=m, w, c$. Theorem 1 below shows that, under appropriate normalizations, the structural components of the model, such as $\eta_{j, n}$ and $s_{j, n}$, are identified for $j=m, w, c$ and $n=1, \ldots, N$. First, we normalize $s_{j, 1}=1$, so that $s_{j, n}$ with $n>1$ and $j=m, w$ measures the cost-savings from economies of scale experienced by adults when living as a couple with with $n>1$ children relative to living as a couple with one child. Second, we normalize $s_{c, 1}=1$. Thus, $s_{c, n}$ with $n>1$ measures the cost-savings from economies of scale experienced by a child when living with her parents and siblings relative to being an only child in a nuclear family. Note that recovering relative (as opposed to absolute) scale economies may be sufficient for many policy applications of our method, such as specifying relative poverty thresholds. The poverty line for individuals in a reference household (a nuclear households with one child) is arbitrary. But, for a chosen poverty line for these individuals, the poverty line in larger households is not arbitrary, but rather dependent on economies of scale in consumption. Therefore, if one were to set a per-capita poverty line of US $\$ 1.90$ or US\$3.10 (which are common poverty lines used by the World Bank) for individual living in a nuclear household with one child, then she would be able to determine how this line should change across household types (as we do in Section 5).

Theorem 1. Consider a population of couples with $n=1, \ldots, N$ children. Let Assumptions 1-4 hold with $\tau=n$ and set $s_{j, 1}=1$ for $j=m, w, c$. Then, resource shares $\eta_{j, n}$ and economies of scale $s_{j, n}$ are identified for $j=m, w, c$, with household-level demand data under a single price regime.

Proof. See Appendix A.2.

The proof of Theorem 1 can be summarized in two steps. In a first step, we use reference households (nuclear households with one child) and the semi-parametric restrictions discussed before to identify individual preferences over the assignable good. In the second step, we exploit variation in consumption patterns across people and household types to identify resource shares and economies of scale. The nonlinearity of the budget share equations enables us to separately identify intra-household allocation from the extent of joint consumption.

Now consider the same child in two different living situations: (1) as an only child ( $n=1)$, and (2) as a child in a nuclear household with multiple children $(n>1)$. We define a child's indifference scales $I_{c, 1, n}$ as the income adjustment applied to a child in a nuclear household with $n$ children (including herself) 
that would allow her to reach the same indifference curve as if she was an only child:

$$
V_{c}\left(\alpha_{n}+p, x+\ln \eta_{c, n}-\ln I_{c, 1, n}\right)=V_{c}\left(\alpha_{1}+p, x+\ln \eta_{c, 1}\right)
$$

More generally, we can define indifference scales for individual $j$ as the income adjustment needed for the individual living in a nuclear household with $n>1$ children that would allow her to reach the same indifference curve as if she was living in a nuclear household with one child:

$$
V_{j}\left(\alpha_{n}+p, x+\ln \eta_{j, n}-\ln I_{j, 1, n}\right)=V_{j}\left(\alpha_{1}+p, x+\ln \eta_{j, 1}\right)
$$

With economies of scale and resource shares identified by Theorem 1, we can use Lemma 1 to recover indifference scales for each individual category $j$ across different household types.

\subsection{Identification in Extended Families}

As discussed in the previous sections, extended families (that is, non-nuclear families) are widespread in developing countries. In Bangladesh and Mexico, the focus of our empirical application, one in three and one in four families, respectively, include other relatives (such as grandparents, aunts, or uncles) in addition to the nuclear family. In other countries, particularly in Africa, polygamy is a common marriage practice. The identification results presented in the previous sections apply to nuclear households with children, but can be easily extended to a more general framework, in line with the model of extended households of Section 2. Note that in this case, household size and household type do not necessarily coincide. Moreover, the cost-savings from economies of scale may depend on composition and not only on household size, as some goods may be more likely to be shared by similar individuals, i.e., individuals in the same category. ${ }^{12}$

Theorem 2. Consider a population of households of type $\tau=1, \ldots, T$. Let Assumptions 1-4 hold for all $\tau$. Then, under appropriate normalizations, resource shares $\eta_{j, \tau}$ and economies of scale $s_{j, \tau}$ are identified for $j=1, \ldots, J$, with household-level demand data under a single price regime.

Proof. See Appendix A.3.

Theorem 2 essentially says that the allocation process and the extent of joint consumption in extended families can be recovered from household-level demand data without price variation and without relying on singles' consumption choices nor assuming perfect preference stability across household types. Note that, as above, economies of scale are not absolute but relative to a reference household. The choice of reference household is ultimately arbitrary, but in the proof of Theorem 2 we select households with exactly one individual in each category $j=1, \ldots, J$. Stated differently, our reference household is of type $\tau=(1, \ldots 1)$ and economies of scale are defined relative to this type of households. ${ }^{13}$ With $s_{j, \tau}$

\footnotetext{
${ }^{12}$ For instance, electricity or heating are more likely and more often shared by individuals who spend substantial time at home. In contexts where, e.g., female labor force participation is low, we could expect the degree of joint consumption of such goods to be larger, the higher is the number of women in the family. So, given two households with equal household sizes, the cost-savings coming from economies of scale in consumption may be larger in the family with a larger share of female household members.

${ }^{13}$ This definition presupposes that there exists a household where all person types are present. This assumption is likely to hold in all empirical applications as the exact definition of the categories of family members to be considered is arbitrary and can be set by researcher based on data availability.
} 
and $\eta_{j, \tau}$ identified for all household types $\tau$ and individual categories $j$, Lemma 1 identifies indifference scales for each family member across different household types. In this context, it is convenient to define indifference scales for individual $j$ as the income adjustment needed for the individual living in nonreference that would allow her to reach the same indifference curve as if she was living in the reference household. If indifference scales were less than one, then household income would then need to be scaled up by $1 / I_{j, 1, \tau}$ for the individual in the non-reference household to be just as well off as if they were living in the reference household. By contrast, if indifference scales were above one, then household income would then need to be scaled down by $1 / I_{j, 1, \tau}$. So, indifference scales help quantify the trade-off between consumption sharing and intra-household resource allocation across household types.

To conclude this section, we briefly discuss how the identification results presented thus far contribute to the literature and how they relate to previous works. In Table 1, we compare our assumptions and results to four existing papers, listed chronologically based on their publications date. ${ }^{14}$ The papers closest to ours are Dunbar et al. (2013) and Bargain and Donni (2012). Like Dunbar et al. (2013) and unlike Bargain and Donni (2012), we impose preference similarity restrictions across individuals to avoid relying on singles data. Note that these preference restrictions are quite weak, as they involve only preferences over the private assignable goods and not all goods and only the first and second derivatives of the budget share functions. Dunbar et al. (2013) impose similarity of preferences across types or across people, while we impose both. Like Bargain and Donni (2012) and unlike Dunbar et al. (2013), we identify both resource shares and economies of scale in consumption. Since we do not require observing the consumption choices of people living alone, we identify economies of scale not only for adults, but also for children. As discussed previously, we identify economies of scale relative to a reference household. Note that our method could be applied to identify absolute economies of scale for adults if singles data were available.

\subsection{Additional Identification Results}

Before turning to the empirical applications, we discuss some extensions to our main identification results. Recall that Assumption 2.ii requires preferences for the assignable good to be similar across people. Specifically, we require that the second derivatives of the individual-level budget share functions for such goods do not vary across household members. This assumption, which may be violated for some categories of assignable goods in some contexts, ${ }^{15}$ can be weakened or even disposed of with additional data or specific types of preferences. Below we describe extensions to Theorem 1 (i.e., nuclear families with children, with $\tau=n$ ). It is straightforward to apply these extensions to Theorem 2 .

\footnotetext{
${ }^{14}$ Other recent identification approaches include Dunbar et al. (2017), who identify resource shares for women, men, and children with distribution factors (i.e., factors that impact the decision making process, but not preferences nor the budget constraint) instead of similarity restrictions on preferences, Sokullu and Valente (2018), who weaken the preference restrictions of Dunbar et al. (2013) by using panel data, Brown et al. (2019), who do so by using multiple assignable goods, and Penglase (2018), who identifies resource shares using private goods and are only partially assignable. Lewbel and Pendakur (2020) relax the assumption of Pareto efficiency and introduce cooperation factors (i.e., factors that affect resource allocation and the households consumption technology, but not indifference curves). The authors compare households of the same type that happen to choose different resource shares and Barten scales based on cooperation factors. By contrast, we compare resource allocation and economies of scale across household types $\tau$. So, similar to a cooperation factor, $\tau$ may impact resource allocation and joint consumption; differently from a cooperation factor, preferences can vary with $\tau$ (though in a restrictive way as in Assumption 2).

${ }^{15}$ The empirical evidence on the validity of the Similarity Across People restriction of Dunbar et al. (2013) (which requires that first derivative of the individual-level budget share functions for such goods not to vary across household members) is mixed. Using data from Malawi, Dunbar et al. (2017) find evidence supporting this restriction with clothing expenditures as the assignable good. Bargain et al. (2018) analyze data from Bangladesh and reject this restriction both for clothing and food expenditures; Sokullu and Valente (2018) find similar results for clothing expenditures in Mexico and Brown et al. (2019) for expenditures on specific food items in Bangladesh.
} 
Table 1: Comparison to Existing Literature: Assumptions and Identification

\begin{tabular}{|c|c|c|c|c|c|c|}
\hline & \multirow[t]{2}{*}{$\begin{array}{l}\text { Lewbel- } \\
\text { Pendakur } \\
\text { (2008) }\end{array}$} & \multirow[t]{2}{*}{$\begin{array}{l}\text { Bargain- } \\
\text { Donni } \\
(2012)\end{array}$} & \multirow[t]{2}{*}{$\begin{array}{c}\text { Browning- } \\
\text { Chiappori- } \\
\text { Lewbel (2013) }\end{array}$} & \multicolumn{2}{|c|}{$\begin{array}{l}\text { Dunbar-Lewbel- } \\
\text { Pendakur } \\
\text { (2013) }\end{array}$} & \multirow{2}{*}{$\begin{array}{c}\text { This paper } \\
\text { Theorems } 1 \& 2\end{array}$} \\
\hline & & & & Theorem 1 & Theorem 2 & \\
\hline \multicolumn{7}{|l|}{ A) Assumptions } \\
\hline Observability of Assignable Goods (A1) & & $\checkmark$ & & $\checkmark$ & $\checkmark$ & $\checkmark$ \\
\hline Preference Similarity Across Types (A2.i) & $\checkmark$ & $\checkmark$ & $\checkmark$ & & $\checkmark$ & $\checkmark$ \\
\hline Preference Similarity Across People (A2.ii) & & & & $\checkmark$ & & $\checkmark$ \\
\hline Non-linearity (A2.iii) & $\checkmark$ & $\checkmark$ & $\checkmark$ & & & $\checkmark$ \\
\hline Independence of Base (A3) & $\checkmark$ & $\checkmark$ & & & & $\checkmark$ \\
\hline Expenditure Invariance (A4) & $\checkmark$ & $\checkmark$ & & $\checkmark$ & $\checkmark$ & $\checkmark$ \\
\hline Preference Stability Across Types & $\checkmark$ & $\checkmark$ & $\checkmark$ & & & \\
\hline Observability of Singles' Data & $\checkmark$ & $\checkmark$ & $\checkmark$ & & & \\
\hline Observability of Price Variation & & & $\checkmark$ & & & \\
\hline \multicolumn{7}{|l|}{ B) Identified Objects } \\
\hline Resource Shares for Adults & $\checkmark$ & $\checkmark$ & $\checkmark$ & $\checkmark$ & $\checkmark$ & $\checkmark$ \\
\hline Scale Economies for Adults & $\checkmark$ & $\checkmark$ & $\checkmark$ & & & $\checkmark$ \\
\hline Indifference Scales for Adults & $\checkmark$ & $\checkmark$ & $\checkmark$ & & & $\checkmark$ \\
\hline Resource Shares for Children & & $\checkmark$ & & $\checkmark$ & $\checkmark$ & $\checkmark$ \\
\hline Scale Economies for Children & & & & & & $\checkmark$ \\
\hline Indifference Scales for Children & & & & & & $\checkmark$ \\
\hline
\end{tabular}

Notes: This table summarizes how our identification results contribute to the literature and how they relate to previous works. One important detail about this set of assumptions is the following. Similarity Across Types is a weaker version of Preference Stability Across Types. So, any approach that requires Preference Stability Across Types implicitly imposes the Similarity Across Type assumption. While both involve restrictions on how preferences vary across household compositions, Similarity Across Types does not require preferences to be identical across household types. Browning et al. (2013) require non-linearity in either the consumption technology function or preferences, but not necessarily both.

Corollary 1. Consider a population of couples with $n=1, \ldots, N$ children, with at least three household sizes. Let Assumptions 1, 2.i, 2.iii, 3, and 4 hold with $s_{j, 1}=1$. Moreover, let $w_{j, n}\left(p, x, \alpha_{n}\right)$ be polynomials of degree $l \geq 2$ in $x$. Then, resource shares $\eta_{j, n}$ and economies of scale economies $s_{j, n}$ are identified for $j=m, w, c$, with household-level demand data under a single price regime.

Proof. See Appendix A.4.

Corollary 1 states that, if the individual-level budget share functions for the private assignable goods in Equation (2) are polynomial functions of second (or higher) degree, then Assumption 2.ii (that preferences for the assignable good are similar between men, women, and children) can be dropped. This result is easily illustrated in the case of a Quadratic Almost Ideal Demand System (QUAIDS) of Banks et al. (1997), which we later use in our empirical applications. QUAIDS is a commonly used demand system with indirect utility function as follows:

$$
V_{j}(p, x)=\left(\frac{P_{j}^{2}(p)}{x-\ln P_{j}^{1}(p)}+P_{j}^{3}(p)\right)^{-1}
$$

where $P^{1}, P^{2}$, and $P^{3}$ are defined so that the property of the indirect utility function $V$ are satisfied. Using Roy's identity, the individual-level budget share functions for the private assignable goods $k_{j}$ are rank 
three quadratic in log expenditure: ${ }^{16}$

$$
\begin{aligned}
w^{k_{j}}(p, x) & =-\frac{1}{P_{j}^{1}(p)} \frac{\partial P_{j}^{1}(p)}{\partial p}+\frac{\partial P_{j}^{2}(p)}{\partial p} \frac{\left(x-\ln P_{j}^{1}(p)\right)}{P_{j}^{2}(p)}+\frac{\partial P_{j}^{3}(p)}{\partial p} \frac{\left(x-\ln P_{j}^{1}(p)\right)^{2}}{P_{j}^{2}(p)} \\
& =a_{j}(p)+b_{j}(p) x+c_{j}(p) x^{2} .
\end{aligned}
$$

Substituting the QUAIDS individual-level budget share functions into Equation (2) and imposing the assumptions of Corollary 1 result in Engel curves for the private assignable goods $k_{j}$ in a household of type $n$, with resource shares $\eta_{j, n}$ and scale economies $s_{j, n}$, that are as follows:

$$
W_{n}^{k_{j}}(x)=\eta_{j, n}\left[a_{j, n}+\lambda_{j, n}+b_{j}\left(x+\ln \eta_{j, n}-\ln s_{j, n}\right)+c_{j}\left(x+\ln \eta_{j, n}-\ln s_{j, n}\right)^{2}\right]
$$

The second derivatives of Equation (10) with respect to $x$ for $j=m, w, c$ identify resource shares and the preference parameters for the private assignable good $b_{j}$ and $c_{j}$, while the first derivative identifies the scale economies parameters $s_{j, n}$. With $s_{j, n}$ and $\eta_{j, n}$ identified for all household types and individual categories, indifference scales are identified by Lemma 1.

Assumption 2.ii can also be weakened when the consumption choices of couples without children are observable. While not extremely common in developing countries, childless couples do exist in many contexts. With childless couples, individual preferences for the assignable goods need to only be similar among adults, but not among adults and children. This requirement can be formalized as follows:

Assumption 5. Let $y=e^{x}$ be total expenditure, and $\omega_{j, n}^{k_{j}}(y)$ be the individual-level budget share equations for the private assignable goods as a function of total expenditure in one price regime. $\omega_{j, n}^{k_{j}}(y)$ are twice continuously differentiable with respect to $y$ and $\nabla_{y}^{2} \omega_{w}^{k_{w}}(y)=\nabla_{y}^{2} \omega_{m}^{k_{m}}(y)$.

In many cases, this may be a more attractive assumption than Assumption 2.ii . Adults' preferences for their assignable goods can then be identified using childless couples, while children's preferences, adults' and children's resource shares, and economies of scale would be identified following a strategy analogous (and hence omitted here) to that used to prove Theorem 1. A formal description of this result is provided by Corollary 2 below.

Corollary 2. Consider a population of couples with $n=0, \ldots, N$ children. Let Assumptions 1, 2.i, 2.iii, 3, 4, and 5 hold for all $n$, and set $s_{j, 0}=1$ for $j=m, w$ and $s_{c, 1}=1$. Then, resource shares $\eta_{j, n}$ and scale economies $s_{j, n}$ are identified for $j=m, w, c$, with household-level demand data under a single price regime.

\section{Empirical Application}

\subsection{Data}

We apply the approach described in the previous section using data from Bangladesh and Mexico. These countries differ along a number of dimensions. First, the two countries are at different stages of economic development. For example, the large majority of Bangladeshi households live in rural areas, compared

\footnotetext{
${ }^{16}$ Lewbel (1991) defines the rank of any demand system to be the dimension of the space spanned by its Engel curves.
} 
to a smaller fraction of Mexican households. Furthermore, in poorer countries like Bangladesh, food (which is largely private) typically represents a large share of the household budget. In these contexts, joint consumption may not play a critical role (Deaton and Paxson, 1997). By contrast, in middle-income countries like Mexico, the consumption of shared goods like energy or fuel for transportation may be more prevalent and economies of scale in consumption may be higher. Yet still, in poorer countries, households tend to be larger than in middle-income countries, which could result in more consumption sharing. Second, Mexico and Bangladesh differ substantially with respect to women's empowerment and societal attitudes towards women. According to the World Economic Forum's Gender Gap Index for 2020, e.g., Mexico ranked 25th out of 149 countries for gender equality, while Bangladesh ranked 50th. Our focus on these two countries is meant to shed light on how these differences can impact the assessment of individual well-being as well as the measurement of poverty.

Bangladesh. Data for Bangladesh come from the first two waves of the Bangladesh Integrated Household Survey (BIHS), which was conducted in 2011/12 and 2015. The survey was designed specifically to study issues related to intra-household inequality and is therefore ideal for our application. The data include detailed demographic information on all household members, a 24-hour recall module of individual dietary intakes and food weighing, a 7-day recall of household-level food expenditures, and an annual consumer expenditure module.

The survey collects information for two sets of private assignable goods: clothing and food items. Clothing expenditures for children are recorded separately; for adults, we assign expenditures on sarees, blouses, and petticoats to women, and expenditures on lungis, dhutis, and salwaars to men. To construct individual expenditures on food, we rely on the 24-hour recall module of dietary intakes. ${ }^{17}$ We compute total household expenditure based on the annual consumer expenditure module.

For computational reasons, we pool data from the two rounds of the BIHS dataset. We select a sample of 6,442 households as follows. To ensure comparability across household types, we exclude households with zero men, women, or children. To eliminate outliers, we exclude any households in the top or bottom one percent of total household expenditure, and households with more than eight adults or eight children. To avoid issues related to special events and food consumption, we drop households reporting having guests during the food recall day. A small number of households have individuals with food budget shares that take a value of zero due to illness, fasting, being an infant, or currently being away from the household. Households with such individuals are excluded from the analysis. Finally, households with missing data for any of the household characteristics or relevant expenditures are dropped from the sample. Table 2 presents descriptive statistics of the estimation sample. Households in Bangladesh are poor, with an average total expenditure of US $\$ 5,231$ (adjusted for PPP) over the year prior to the survey. Moreover, households spend a significant portion of their budget on food (65.3 percent). Households are large on average, with close to three adults and two children per household.

\footnotetext{
${ }^{17}$ To collect individual dietary intakes, a BIHS enumerator interviewed the woman in the household most responsible for food preparation. They asked her about the household's food consumption over the most recent typical data (which in almost all cases was the previous day). The enumerator determined which meals were served for breakfast, lunch, and dinner, as well as any snacks. For each meal, the survey respondent provided recipes, which include the cooked and uncooked weights of all ingredients. Finally, the respondent determined how much of each meal was served to each person in the household. Additional information collected include whether any guests were present, whether any food was left over or given to animals, and the reason(s) why any individual did not consume a given meal. For a more detailed discussion of how the data was collected, the overall quality of the data (e.g., measurement error), and how we construct budget shares, see Brown et al. (2019).
} 
Table 2: Descriptive Statistics: Bangladesh

\begin{tabular}{lcccc}
\hline \hline & Mean & Median & Std. Dev & Obs. \\
\hline & & & & \\
Household Expenditures: & & & & \\
Total Expenditure (PPP dollars) & 5,311 & 4660 & 2,608 & 6,442 \\
Food Budget Share & 0.662 & 0.675 & 0.114 & 6,442 \\
Men's Cereals, Pulses, Veg. Budget Share & 0.104 & 0.096 & 0.048 & 6,442 \\
Women's Cereals, Pulses, Veg. Budget Share & 0.094 & 0.088 & 0.042 & 6,442 \\
Children's Cereals, Pulses, Veg. Budget Share & 0.078 & 0.066 & 0.055 & 6,442 \\
& & & & \\
Household Composition: & & & & \\
Men & 1.399 & 1.000 & 0.676 & 6,442 \\
Women & 1.459 & 1.000 & 0.691 & 6,442 \\
Boys & 0.979 & 1.000 & 0.827 & 6,442 \\
Girls & 0.959 & 1.000 & 0.887 & 6,442 \\
& & & & \\
Household Characteristics: & & & & \\
Average Age Men & 38.791 & 37.000 & 11.281 & 6,442 \\
Average Age Women & 34.710 & 33.000 & 9.302 & 6,442 \\
Average Age Children & 7.345 & 7.500 & 3.501 & 6,442 \\
Average Education Men & 1.419 & 1.000 & 1.338 & 6,442 \\
Average Education Women & 1.442 & 1.500 & 1.211 & 6,442 \\
Working Men (share) & 0.870 & 1.000 & 0.269 & 6,442 \\
Working Women (share) & 0.632 & 1.000 & 0.415 & 6,442 \\
$\mathbb{1}($ Rural) & 0.826 & 1.000 & 0.379 & 6,442 \\
$\mathbb{1}$ (Dhaka) & 0.305 & 0.000 & 0.460 & 6,442 \\
Year=2011 & 0.529 & 1.000 & 0.499 & 6,442 \\
\hline \hline & & & & \\
\hline
\end{tabular}

Note: BIHS data (2011/12 and 2015). The table reports some descriptive statistics of the sample used in estimation. Expenditure data based on annual recall. Individual education ranges from 0 (no schooling) to 5 (completed secondary school). Indicators for employment equal 1 if individuals worked for pay during the week prior to the survey.

Mexico. Data for Mexico are from the 2018 wave of the Encuesta Nacional de Ingresos y Gastos de los Hogares (ENIGH). This biannual survey includes detailed measures of household income and expenditures, as well as standard demographic characteristics for all household members. Unlike BIHS, ENIGH does not collect assignable food consumption. We therefore use men's, women's, and children's clothing as private assignable goods. In this survey, expenditures on such goods are recorded separately for men, women, and children, so that we do not have to restrict our focus to gender-specific clothing items for adults (as we do for Bangladesh). We select a sample of roughly 36,000 households after removing those that have no men, women, or children, or are uncommonly large (more than eight adults or eight children). Moreover, we drop households that are in the top or bottom household expenditure percentile, and households with missing data for any of the variables included in estimation.

Table 3 presents descriptive characteristics for the Mexican sample. As expected, households in Mexico are wealthier than in Bangladesh, with an average annual expenditure of approximately US\$16,000 and a food budget share of 41 percent. Household size is similar to Bangladesh, with Mexican families on average consisting of three adults and two children. Note, however, that our definition of children is different in the Mexico sample relative to the Bangladesh sample. This choice is data-driven, since clothing expenditures are assigned to children aged 17 or younger in the ENIGH, while BIHS classifies children as individuals aged 14 or younger. As a result, the average age of children and adults is slightly higher in Mexico. 
Table 3: Descriptive Statistics: Mexico

\begin{tabular}{lcccc}
\hline \hline & Mean & Median & Std. Dev & Obs. \\
\hline & & & & \\
Household Expenditures: & & & & \\
Total Expenditure (PPP dollars) & 16,104 & 13,313 & 10,688 & 35,056 \\
Food Budget Share & 0.410 & 0.405 & 0.152 & 35,056 \\
Men's Clothing Budget Share & 0.006 & 0.000 & 0.014 & 35,056 \\
Women's Clothing Budget Share & 0.007 & 0.000 & 0.014 & 35,056 \\
Children's Clothing Budget Share & 0.014 & 0.007 & 0.021 & 35,056 \\
& & & & \\
Household Composition: & & & & \\
Men & 1.341 & 1.000 & 0.620 & 35,056 \\
Women & 1.406 & 1.000 & 0.661 & 35,056 \\
Boys & 0.993 & 1.000 & 0.831 & 35,056 \\
Girls & 0.940 & 1.000 & 0.823 & 35,056 \\
& & & & \\
Household Characteristics: & & & & \\
Average Age Men & 38.930 & 37.000 & 11.368 & 35,056 \\
Average Age Women & 37.230 & 36.000 & 9.805 & 35,056 \\
Average Age Children & 8.773 & 9.000 & 4.498 & 35,056 \\
Average Education Men & 0.710 & 1.000 & 0.454 & 35,056 \\
Average Education Women & 0.726 & 1.000 & 0.446 & 35,056 \\
Working Men (share) & 0.901 & 1.000 & 0.258 & 35,056 \\
Working Women (share) & 0.511 & 0.500 & 0.456 & 35,056 \\
$\mathbb{1}$ (Rural) & 0.326 & 0.000 & 0.469 & 35,056 \\
$\mathbb{1}$ (Mexico City) & 0.024 & 0.000 & 0.153 & 35,056 \\
\hline \hline
\end{tabular}

Note: ENIGH data (2018). The table reports some descriptive statistics of the sample used in estimation. Expenditure data based on annual recall. Individual education ranges from 0 (no schooling) to 1 (completed secondary school). Indicators for employment equal 1 if individuals worked for pay during the week prior to the survey.

\subsection{Estimation}

For our empirical application, we consider the Quadratic Almost Ideal Demand System of Banks et al. (1997). As discussed in Section 3.4, under QUAIDS, the budget share functions are quadratic in log total expenditure. Adding error terms, the system of Engel curves for the private assignable goods includes $J$ equations as follows:

$$
W_{h, \tau}^{k_{j}}=n_{j, h, \tau} \eta_{j, \tau}\left[d_{j, \tau}+b_{j}\left(x_{h, \tau}+\ln \eta_{j, \tau}-\ln s_{j, \tau}\right)+c_{j}\left(x_{h, \tau}+\ln \eta_{j, \tau}-\ln s_{j, \tau}\right)^{2}\right]+\epsilon_{h, \tau}
$$

where $W_{h, \tau}^{k_{j}}$ is the household-level budget share for the assignable good of each person $j$ in household $h$ of type $\tau, x_{h, \tau}$ is the household's log expenditure, and $n_{j, h, \tau}$ is the number of household members in each category $j$. Consistent with the requirements of Corollary 1 , the preference parameters $b_{j}$ and $c_{j}$ do not vary across household types. By contrast, $d_{j, \tau}=a_{j, \tau}+\lambda_{j, \tau}$ can vary freely both across household and individual types.

Let $X^{\tau}$ be a vector of household composition variables, such as the number of men, women, boys and girls, and $X$ be a vector containing a set of household socio-economic characteristics. These include the variables listed in Tables 2 and 3, such as age, education, the employment status of the household members, and place of residence. We model the resource shares $\eta_{j, \tau}$ and scale economies $s_{j, \tau}$ as linear functions of $X$ and $X^{\tau}$. Following Corollary 1 , the preference parameters $b_{j}$ and $c_{j}$ are specified as linear functions of $X$, but do not depend on the household composition variables. Since the error terms may be correlated across equations, we estimate the system of Engel curves using non-linear Seemingly Unrelated 
Regression, which is iterated until the estimated parameters and the covariance matrix settle. IteratedSUR with multivariate normal errors is equivalent to maximum-likelihood estimation. Consistent with the model, we impose a cross-equation restriction that the resource shares $\eta_{j, \tau}$ must sum to one.

We make four important simplifications to the system of Engel curves in (11) to ensure convergence. First, due to data limitations and for computational tractability, we focus on three categories of individuals: women, men, and children. Second, we specify $\eta_{j, \tau}$ and $s_{j, \tau}$ using an inverse logistic function that guarantees that they are bounded between zero and one. Third, we assume that preferences for the assignable goods are similar across people, i.e., $b_{j}=b$ and $c_{j}=c$. While not required for identification in the case of polynomial budget-share functions like QUAIDS, this restriction proved critical for the convergence of our estimation routine. Fourth, we estimate a single scale economy parameter for each household type, i.e., $s_{j, \tau}=s_{\tau}$. Stated differently, we assume that any gains from joint consumption are equally shared among all household members. ${ }^{18}$ As it is common in non-linear models, we noticed that the sum-of-squared residuals function has multiple local minima. This is true both when using the Bangladeshi data and the Mexican data. We therefore performed grid searches over a wide range of starting values and selected the estimates corresponding to the minimum sum-of-squared residuals.

Pre-Estimation Tests. Before presenting our empirical results, we briefly discuss a series of preestimation tests aimed at selecting which private assignable goods in our samples are likely to satisfy the identifying assumptions. Recall from Section 3 that we require the Engel curves for private assignable goods to have non-zero second derivatives with respect to household expenditure (or log household expenditure in the case of QUAIDS). Engel curves that are "too linear" do not provide enough variation to separately identify scale economies from resource shares and preferences. ${ }^{19}$ We implement two preestimation diagnostic tests to determine which assignable goods are likely to satisfy this condition.

First, we estimate household-level Engel curves for men's, women's and children's assignable goods using a linear regression model, which we estimate using ordinary least squares. Doing this helps us determine which goods in our samples have significantly non-linear Engel curves, on average. However, it may mask some important heterogeneity across households. Since our empirical model allows for heterogeneity in preferences, resources shares, and scale economies (which essentially means that we estimate different Engel curves for different household types and observable characteristics), we also estimate the following fully-interacted linear regression model:

$$
W_{h}^{k_{j}}=\alpha_{0}+\left(X_{h}, X_{h}^{\tau}\right)^{\prime} \alpha+\left(X_{h}, X_{h}^{\tau}\right)^{\prime} \beta x_{h}+\left(X_{h}, X_{h}^{\tau}\right)^{\prime} \gamma x_{h}^{2}+\epsilon_{h},
$$

where $X_{h}$ and $X_{h}^{\tau}$ are vectors of household composition variables and socio-economic characteristics, respectively, and $x_{h}$ is the household's log expenditure. This approach allows us to compute slope coefficients and curvature parameters for all household types and test that they are significantly different from zero conditional on household characteristics.

The full set of results are presented in Table A1 in the Appendix, which reports the estimates of simple

\footnotetext{
${ }^{18}$ This is admittedly a strong assumption that we impose to guarantee a successful convergence of our estimation routine. Relaxing this assumption led to estimation problems with the data from Mexico, but not from Bangladesh. For Bangladesh, we estimated separate economies of scale in consumption for women, men, and children, and found them not to be largely different from each other. The full set of results is available upon request.

${ }^{19}$ In a similar spirit, Tommasi and Wolf (2018) point out that the identification approach of Dunbar et al. (2013) implicitly requires Engel curves for the private assignable goods to have a large non-zero slope. Our tests address this issue too.
} 
household-level linear regression models as well as descriptive statistics of the empirical distributions of t-statistics of the slope coefficients and curvature parameters in Equation (12). The dataset from Mexico only records expenditures for assignable clothing, whose Engel curves display enough non-linearity to make it suitable for our approach. In Bangladesh, we find that cereals, pulses, and vegetables exhibit the highest degree of curvature among potential assignable goods. For proteins (meat, fish, and milk products) as well as assignable clothing, the Engel curves are essentially linear for the vast majority of households, which makes them ill-suited for our application. So, in what follows, we present estimates obtained using assignable food (cereals, pulses, and vegetables) for Bangladesh and assignable clothing for Mexico. Note that the specific empirical properties of the budget share functions may vary substantially by context and assignable good. For this reason, we recommend testing the validity of the identifying assumptions whenever possible.

\subsection{Results}

Table 4 below presents selected summary statistics for the estimated children's, women's and men's resources shares as well as economies of scale and indifference scales. Recall that these are estimated conditional on a set of observable household characteristics and composition variables. The coefficients for each variable and the corresponding heteroskedasticity-robust standard errors are presented in Tables A2 and A3 in the Appendix, while the empirical distributions of the estimated resource shares and scale economies are plotted in Figure A2. In Table A4, we also report estimated resource shares and scale economies in a representative non-reference household, defined as non-reference household with all preference factors and household type variables at their median value (see Tables 2 and 3 for a list of these values). The associated standard errors are quite small (especially for Bangladesh), indicating that the parameters of interest are precisely estimated. ${ }^{20}$

Panel A of Table 4 reports the mean, median, and standard deviation for the share of household consumption allocated to each child, woman, or man. In line with Brown et al. (2019) and Lewbel and Pendakur (2020), who also estimate resource allocation in Bangladesh, we find that in Bangladeshi families men consume significantly more than women, who in turn consume more than children. Our estimates are also consistent with the observed resource shares provided by Bargain et al. (2018). ${ }^{21}$ Specifically, our estimates indicate that women on average are allocated only 77 percent of the resources allocated to men, while each child receives 37 percent of a man's share. In Mexico, women consume a larger share of the household budget on average, which is consistent with previous estimates by Sokullu and Valente (2019) and Hoehn-Velasco and Penglase (2019). ${ }^{22}$

\footnotetext{
${ }^{20}$ In Table A5 in the Appendix, we report descriptive statistics for the estimated resource shares and scale economies from specifications that account for endogeneity of household type (due, e.g., to selection) and endogeneity of household expenditure (related, e.g., to measurement error). In a first specification, we augment each Engel curve equation with an inverse Mills ratio (IMR) to address selection. Specifically, the IMR is obtained from the estimation of probit selection equation with an indicator for non-reference households as dependent variable and a community-level measure of prevalence of non-reference households ass the excluded instrument. In a second specification, we follow previous literature (Dunbar et al., 2013; Attanasio and Lechene, 2014) and instrument household total expenditure with household income (for Mexico) and the total value of household assets (for Bangladesh). These results are largely in line with our baseline estimates.

${ }^{21}$ Bargain et al. (2018) use a different dataset from Bangladesh, the Household Income and Expenditure Survey, that exceptionally contains individualized (private only) expenditure for all the members of 1,039 households in year 2004.

${ }^{22}$ By contrast, Tommasi (2019) estimates women's resource shares that are slightly lower than men's in Mexico. As discussed in Sokullu and Valente (2019), this difference can be attributed to the initial values used in the two estimation routines: while Tommasi (2019) uses values based on selfreported control over resources, Sokullu and Valente (2019) use values based on a grid search. Recall that these previous works estimate intra-household allocation but not economies of scale in consumption.
} 
Table 4: Estimated Resource Shares, Scale Economies, and Indifference Scales

\begin{tabular}{|c|c|c|c|c|c|c|c|c|}
\hline & \multicolumn{4}{|c|}{ Bangladesh } & \multicolumn{4}{|c|}{ Mexico } \\
\hline & Obs. & Mean & Median & Std. Dev. & Obs. & Mean & Median & Std. Dev. \\
\hline & (1) & (2) & (3) & (4) & (5) & (6) & (7) & (8) \\
\hline \multicolumn{9}{|l|}{ A) Resource Shares: $\widehat{\eta}_{j, \tau}$} \\
\hline Children & 6,442 & 0.132 & 0.117 & 0.063 & 36,075 & 0.156 & 0.123 & 0.088 \\
\hline Women & 6,442 & 0.274 & 0.301 & 0.089 & 36,075 & 0.337 & 0.388 & 0.116 \\
\hline Men & 6,442 & 0.354 & 0.380 & 0.102 & 36,075 & 0.288 & 0.312 & 0.085 \\
\hline B) Scale Economies: $\widehat{s}_{\tau}$ & 5,407 & 0.962 & 0.990 & 0.075 & 29,893 & 0.909 & 0.955 & 0.116 \\
\hline \multicolumn{9}{|l|}{ C) Indifference Scales: $\widehat{I}_{j, 1, \tau}$} \\
\hline Children & 5,407 & 0.543 & 0.507 & 0.241 & 29,893 & 0.655 & 0.468 & 0.608 \\
\hline Women & 5,407 & 0.770 & 0.848 & 0.321 & 29,893 & 0.856 & 0.967 & 0.318 \\
\hline Men & 5,407 & 0.846 & 0.931 & 0.271 & 29,893 & 0.936 & 0.984 & 0.286 \\
\hline
\end{tabular}

Notes: Selected summary statistics for the estimated children's, women's, men's resources shares as well as economies of scale and indifference scales. Estimates are conditional on a set of observable household characteristics and composition variables. Coefficients for each variable and the corresponding heteroskedastic-robust standard errors are presented in Tables A2 and A3 in the Appendix, while the empirical distributions of the estimated resource shares and scale economies are plotted in Figure A2. Panel A reports the mean, median, and standard deviation for the share of household consumption allocated to each child, woman, or man. Panel B presents summary statistics for the estimated scale parameters. Panel C reports the computed indifference scales. Note that mean and median of resource shares do not need to sum to one because there can be more than one individual of the same type in each family. Indifference scales are calculated as $\widehat{I}_{j, 1, \tau}=\frac{\widehat{s}_{j, 1}}{\widehat{s}_{j, \tau}} \frac{\widehat{\eta}_{j, \tau}}{E\left[\widehat{\eta}_{j, 1}\right]}$, where $\widehat{s}_{j, 1}$ equals one and $E\left[\widehat{\eta}_{j, 1}\right]$ is the average resource share for person type $j$ across the reference households.

In Panel B of Table 4, we present summary statistics for the estimated scale parameters $\widehat{s}_{\tau}$. Recall that scale economies measure the cost-savings experienced by individuals from living in a household of composition $\tau$ relative to living in a reference household (i.e., in households with one man, one woman, and one child), and lower values imply greater consumption sharing. By construction, scale economies will equal one in the reference household, so we omit those households from the presentation of the results. In Bangladesh, we find that relative to a nuclear family with one child, the total household expenditure in non-reference families is scaled up by approximately 4 percent (1/0.962), on average. This implies that the cost of living faced by an individual in the average non-reference household is 96 percent of what is faced by an individual living in the reference household. In Mexico, we estimate larger economies of scale in consumption, with the total household expenditure in non-reference families being scaled up by approximately 10 percent relative to reference households. Note that scale economies in consumption may vary across household types due to household size (by construction public or shareable goods are consumed by a larger number of people in larger families), but also due to differences in the relative consumption of private and shareable goods across family compositions. We will come back to this point later on. ${ }^{23}$

Finally, in Panel C of Table 4, we compute generalized indifference scales, which measure the scale to household expenditure required for an individual living in a (typically larger) household of type $\tau$ to be just as well off as if they were living in the reference household $(\tau=1)$. So, we compute indifference scales as $\widehat{I}_{j, 1, \tau}=\frac{\widehat{s}_{j, 1}}{\widehat{s}_{j, \tau}} \frac{\widehat{\eta}_{j, \tau}}{E\left[\widehat{\eta}_{j, 1}\right]}$, where $\widehat{s}_{j, 1}$ equals one and $E\left[\widehat{\eta}_{j, 1}\right]$ is the average resource share for person type $j$ across the reference households. Recall that if indifference scales were to equal one, then the individual

\footnotetext{
${ }^{23}$ While there are no previous estimates of scale economies in Mexico and Bangladesh to compare ours to, we indirectly check the validity of our estimates by examining the correlation between scale economies and the consumption of public goods. In Figure A4 in the Appendix, we report the results of non-parametric regressions of the estimates $\widehat{s}_{\tau}$ on the budget share on public goods (energy, rent, and other housing expenses). It is reassuring that we estimate larger scale economies (lower $\widehat{s}_{\tau}$ ) when the budget share on public goods is large.
} 
would be indifferent between living in the non-reference household and the reference household: in this case, the consumption gains from living in the larger household or from any reallocation of resources exactly offset the decline in consumption due to the smaller resource share. If indifference scales are less than one, then the benefit of increased consumption sharing is outweighed by the "cost" associated with a smaller resource share; household expenditure would then need to be scaled up by $1 / \widehat{I}_{j, 1, \tau}$ for the individual in the non-reference household to be just as well off as if they were living in the reference household.

On average, we estimate indifference scales that are less than one. Since economies of scale are limited in Bangladesh, indifference scales are quite low, indicating that the expenditure adjustment for individuals living in non-reference households to be just as well off as they would be if they lived in a reference household would have to be quite high. Specifically, for a given expenditure level, on average, children, women and men in non-reference households would need to have their household's expenditure scaled up by 84 percent (1/0.543), 30 percent, and 18 percent, respectively, to be just as well off as they would be in a nuclear family with one child. In Mexico, indifference scales are higher due to the greater degree of consumption sharing. We find that, for a given expenditure level, children in non-reference households would need to have their households' expenditure scaled up by 53 percent, on average, to be just as well off as they would be in the reference household. By contrast, the average expenditure adjustment for women and men would amount to 17 and 7 percent, respectively.

Estimates by Household Type. In Table 4, we analyzed the distribution of estimated resource shares for children, women and men for all households in the Mexican and Bangladeshi samples as well as scale economies and indifference scales for non-nuclear households or nuclear households with multiple children relative to nuclear households with one child. We now examine how these estimates vary with household size (Figure 2) and composition (Figures A5 and A6 in the Appendix).

Three main features emerge from Figure 2, which plots the average estimated $\widehat{\eta}_{j, \tau}, \widehat{s}_{\tau}$, and $\widehat{I}_{j, \tau}$ by household size. First, as expected, the share of resources devoted to each child, woman, or man decreases with household size, as resources need to be shared between more people in larger families. While the decline for children is similar across the two countries, the decline in women's share in Mexico is much steeper than in Bangladesh, suggesting that resource allocation among women and men is more equitable in larger households, on average. ${ }^{24}$

Second, scale economies increase (that is, $\widehat{s}_{\tau}$ decreases) with household size in Bangladesh, which is consistent with larger families benefiting the most from the joint consumption of public goods. By contrast, we estimate a non-monotonic relationship between scale economies and household size in Mexican families. Note that, for a given composition of the household budget (i.e., for given budget shares for private versus jointly consumed goods), we would expect scale economies to increase as the number of family members increases. So, scale economies that are decreasing in household size for families with more than four members could arise from differences in the relative consumption of private and sharable goods across household sizes. To test this hypothesis, we leverage the detailed breakdown of expenditures provided by the ENIGH and explore how the budget shares on private and public (or partially shared)

\footnotetext{
${ }^{24}$ Note that this may mask non-trivial inequality among women or among men. Given data limitations, however, we cannot analyze this possibility further.
} 
Figure 2: Resource Shares, Economies of Scale, and Indifference Scales by Household Size

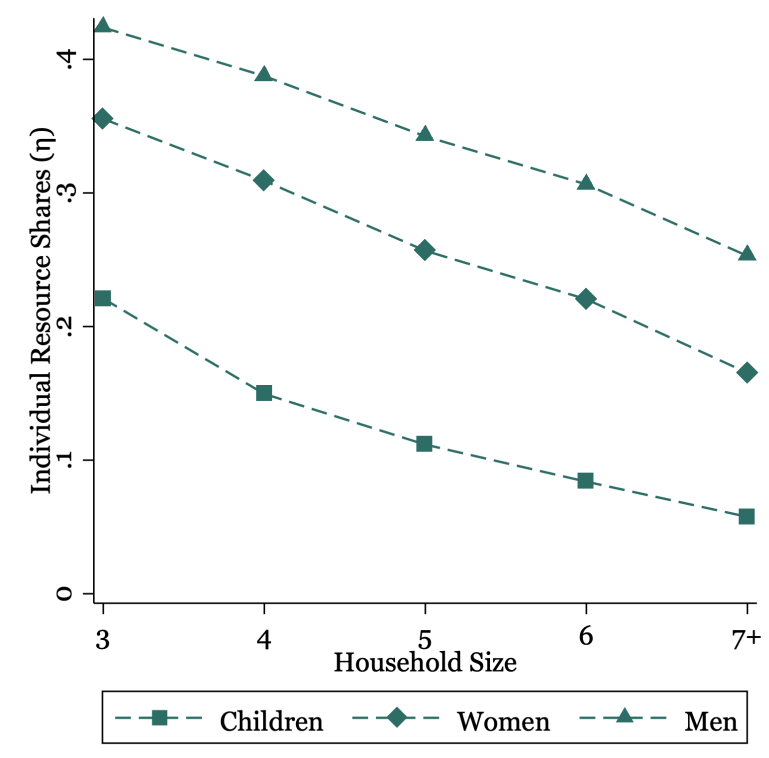

(A.1) Bangladesh: Resource Shares $\left(\widehat{\eta}_{j, \tau}\right)$

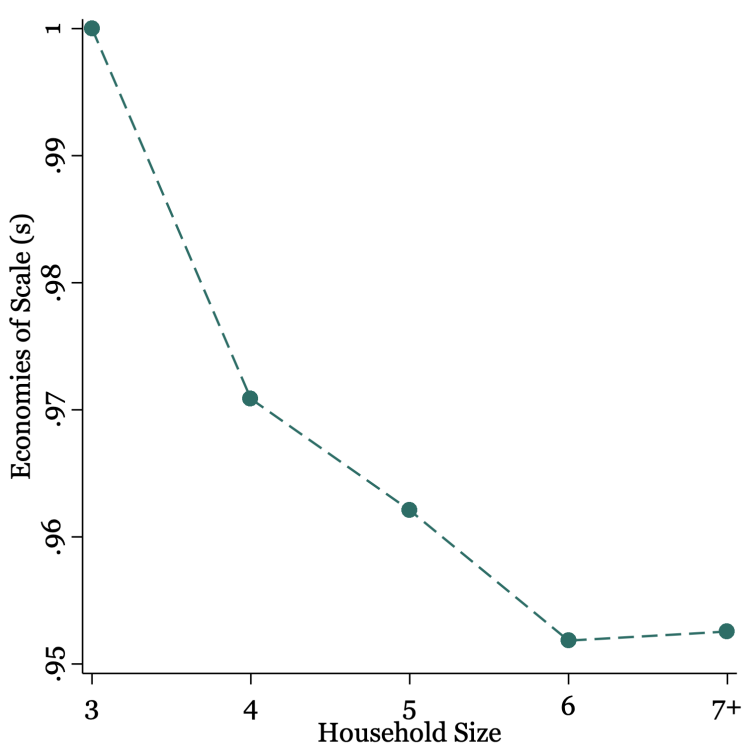

(B.1) Bangladesh: Economies of Scale $\left(\widehat{s}_{\tau}\right)$

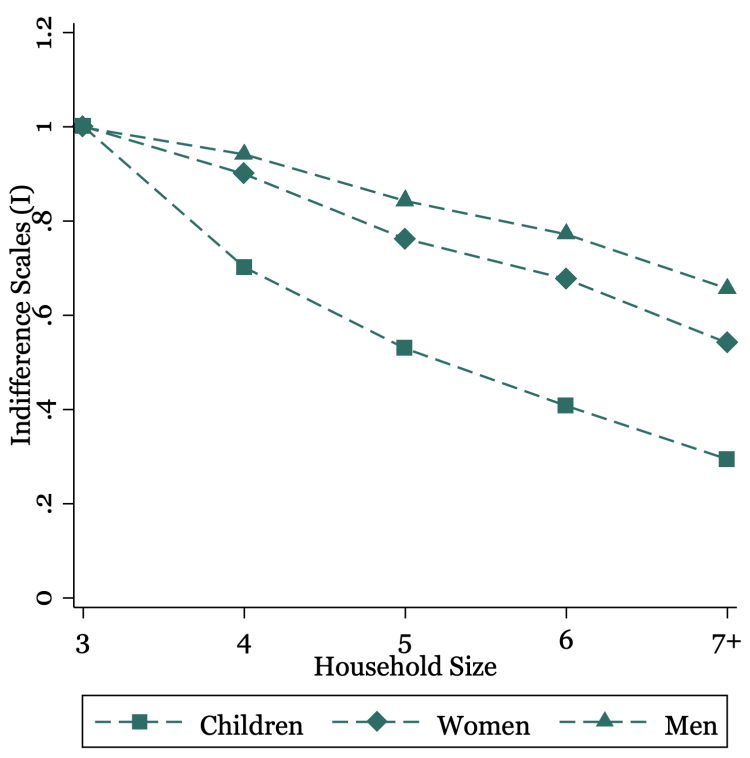

(C.1) Bangladesh: Indifference Scales

$$
\left(\widehat{I}_{j, 1, \tau}\right)
$$

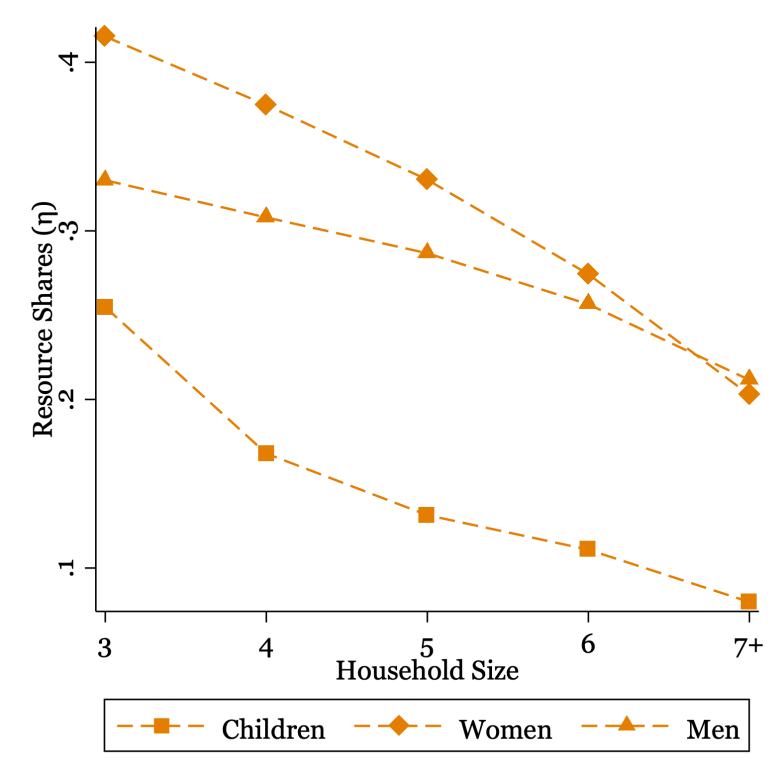

(A.2) Mexico: Resource Shares $\left(\widehat{\eta}_{j, \tau}\right)$

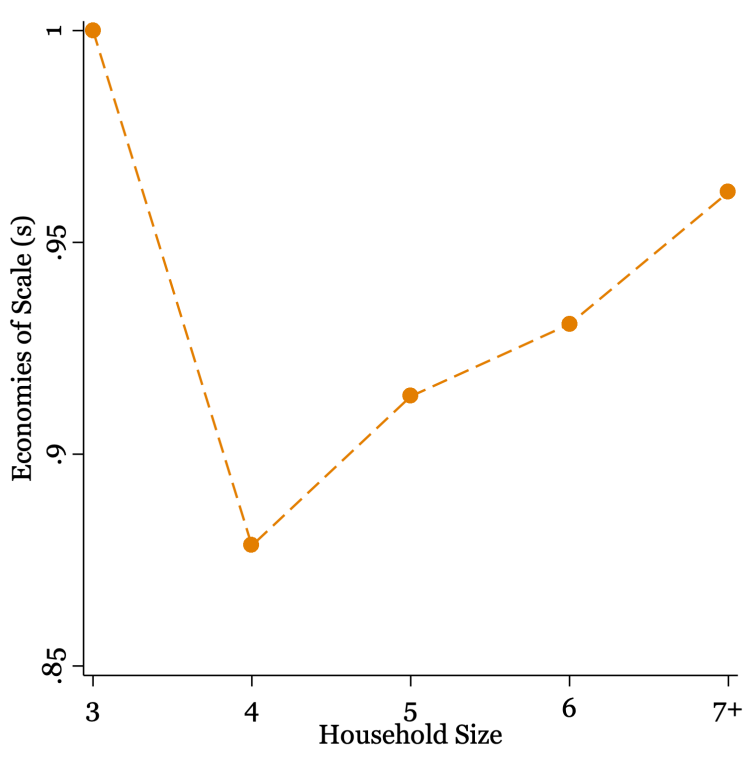

(B.2) Mexico: Economies of Scale $\left(\widehat{s}_{\tau}\right)$

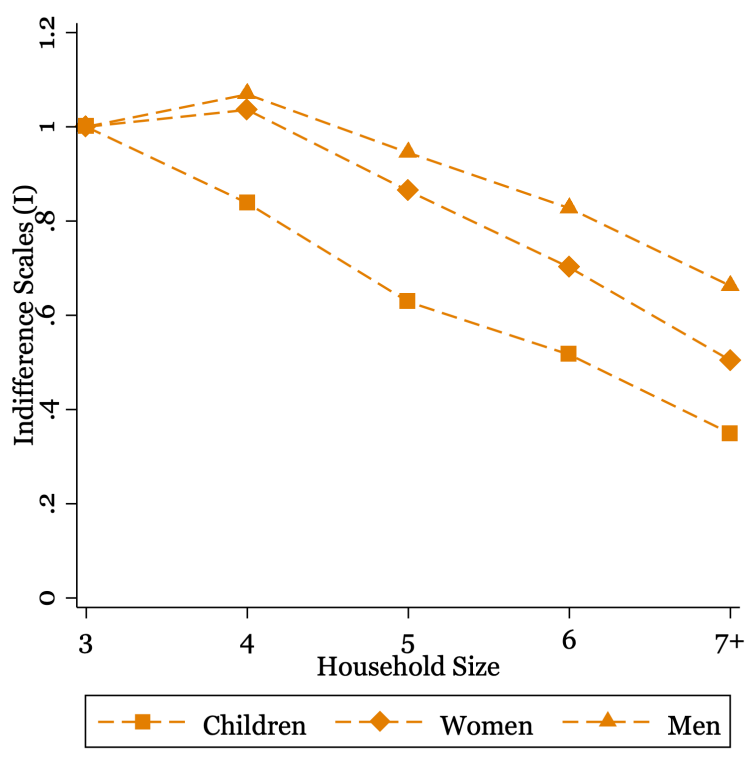

(C.2) Mexico: Indifference Scales

$$
\left(\widehat{I}_{j, 1, \tau}\right)
$$

Note: The figure shows how resource shares, scale economies and indifference scales for children, women and men vary with household size. Indifference Scales are computed following Lemma 1. The reference household is defined as having one of each person type (here, this implies one man, one woman, one child). Scale economies in the reference household are set to one. Resource shares in the reference household are set to the average across all reference households. 
goods change with household size. As shown in Figure A3 in the Appendix, the share of budget allocated to private goods (food, clothing, and personal accessories) is the lowest and the budget share of partly shared goods (fuel for transportation and other vehicle expenses, excluding purchase) is the highest in Mexican families of size four compared to smaller or larger families. This non-monotonicity helps rationalize the higher economies of scales in families of size four relative to larger or smaller families.

Third, while the estimated indifference scales in Bangladesh are below one, on average, in all household sizes, in Mexico adults' indifference scales are slightly larger than one for households of size four. This means that for women, men, and children in Bangladeshi families, for children in Mexican families, and for adults in Mexican families with more than four members, the impact of scale economies on their consumption level (or of any reallocation of resources across household sizes) is outweighed by them having to share resources with more people as household size increases. So, their expenditure would need to be scaled up to be just as well off as if they were living in a nuclear household with one child with the same household expenditure level. By contrast, for adults in Mexican families of size four, the expenditure adjustment would be zero or possibly negative.

As previously discussed, in extended families, household size and household type may not coincide. To better understand how indifference scales vary with the composition of the family, in Figures A5 and A6 in the Appendix, we plot the average indifference scales by the number of children and adults in the family. In both countries, we find that adults' indifference scales decline substantially as the number of adults increases. By contrast, for a given number of adults, the decline is minimal as the number of children increases, suggesting that the amount of resources allocated to each adult does not vary significantly with the number of children. Turning to children, we estimate indifference scales that are decreasing in both the number of children and adults in Bangladesh, and decreasing in the number of children but not adults in Mexico. This means that any expenditure adjustment required to make a child in a non-reference household as well off as if she was an only child in a nuclear household increases with the number of children and adults in Bangladesh, and with the number of children (but not adults) in Mexico. ${ }^{25}$

\section{Poverty Analysis}

Standard methods for measuring poverty (e.g., World Bank per-capita measures) entirely ignore intrahousehold allocation and economies of scale. Other approaches (e.g., OECD equivalence scales) deal with economies of scale in largely atheoretical ways and do not account for intra-household inequality. With very few exceptions, previous methods that rely on collective household models to estimate individuallevel poverty rates successfully tackle the issue of intra-household allocation, but not of joint consumption. In what follows, we begin by summarizing various existing methods to measure poverty. We then use the structural estimates presented in Section 4.3 to conduct an individual-level poverty analysis that takes into account both the intra-household allocation of consumption and scale economies. We conclude by comparing poverty estimates based on different methods and by discussing some policy implications.

\footnotetext{
${ }^{25}$ With the available data, it is not possible to fully understand what drives this difference. Mexico, however, is "more nuclear" than Bangladesh, in the sense that the vast majority of individuals are identified in the household roster as mother, father, or child. So, a substantial fraction of the third or fourth adults in Mexico are adult children (of age higher than 17), living with their parents. It is unclear that this helps explain the pattern of indifference scales by household types, but it is a difference worth noting.
} 
Per-capita Poverty Rates. The World Bank primarily relies on per-capita measures of poverty (World Bank, 2015). Accordingly, an individual is classified as poor if their household per-capita expenditure is below a poverty line (e.g., US\$1.90/day). This approach implicitly assumes that everyone is allocated the same share of total household expenditure, and that there is no consumption sharing. Importantly, the poverty line does not vary across household sizes: an individual living alone faces the same threshold as an individual living an a larger household. A single-person household spending US\$2/day, e.g., is assumed to be just as well off as if she was living in a five-person household that together spend US\$10/day. Even in absence of intra-household inequality in how resources are allocated among family members, this would not be the case if the five-person household consumed any public goods or any goods that can be jointly consumed. ${ }^{26}$ So, while per-capita expenditure is equal across household sizes, per-capita consumption may be substantially different. Poverty calculations based on household per-capita expenditures are unable to account for this important difference. Moreover, when using such an approach, either everyone in a household lives below the poverty line or no one does, which may be unrealistic when intra-household inequality is high.

Equivalence Scale-Adjusted Poverty Rates. An alternative approach to measuring poverty is to adjust household expenditure across household compositions using equivalence scales. An equivalence scale is a way of transforming expenditure in a multi-person household into an equivalent expenditure in a one-person household, by accounting for both household size and differences in needs between children and adults. Alternatively, it can be defined as the ratio of a sub-utility function for some group of goods to the corresponding sub-utility function in a reference household (Lewbel, 1989). As discussed in Chiappori (2016) and Pendakur (2018), equivalence scales suffer from important weaknesses. First, they ignore intra-household allocations. Second, they are generally constructed based on ad hoc assumptions. Third, since an equivalence scale is defined as the expenditure of the household divided by the expenditure of a single person that enjoys the same standard of living (i.e., the same utility level) as the household, the concept of equivalence scales relies on comparisons between individual and household utilities. This is troublesome in theory because it is individuals, not households, who have preferences and hence utility functions. ${ }^{27}$ Nevertheless, equivalence scales have been widely used for the measurement of poverty both in developed and developing countries. A common example of equivalence scales is the OECD scale (or Oxford scale), which equals 1 for the first adult household member, plus 0.7 for each additional adult, plus 0.5 for each child. So, a typical family of four, with two parents and two children, would be assigned an equivalence scale of 2.7. An alternative three-parameter equivalence scale is used in the United States (Betson, 2007; Garner and Short, 2010). ${ }^{28}$

Model-Based Poverty Estimates. Individual-level consumption is typically not available in most surveys. To overcome this limitation, an increasing number of papers have used the collective household

\footnotetext{
${ }^{26}$ To see this, suppose households divide their expenditures equally between a single purely private good, and a second good that is purely public. In the single-person household, the US $\$ 2$ expenditure results in US\$2 consumption. In the five-person household, the US $\$ 10$ expenditure (US\$5 spent on the public good and US\$5 spent on the private good), results in a total consumption of US\$30 for all individuals, or US\$6 per person (assuming no intra-household inequality).

${ }^{27}$ Equivalence scales also suffer from serious econometric identification issues, which are discussed in, e.g., Deaton and Muellbauer (1980), Blundell and Lewbel (1991), and Lewbel (1997).

${ }^{28}$ The OECD scale converts household expenditure in an $n$-person household to a single-person household by taking total household expenditure and dividing by $1+0.7\left(n_{a}-1\right)+0.5 n_{c}$, where $n_{a}$ is the number of adults and $n_{c}$ is the number of children. The three-parameter equivalence scale used in the US is given by $\left(1+0.8+0.5\left(n_{c}-1\right)\right)^{0.7}$ for single-parent households, and by $\left(n_{a}+0.5 n_{c}\right)^{0.7}$ for households with multiple adults.
} 
model to structurally estimate the intra-household allocation of resources and to overcome the deficiencies of per-capita and equivalence scale-based approaches to measure poverty. For example, Dunbar et al. (2013) estimate poverty in Malawi separately for men, women, and children, and find that child poverty rates are substantially understated when ignoring inequality within the household. Subsequent applications and extensions of Dunbar et al. (2013) provide estimates of individual-level poverty rates that account for intra-household resource allocation for several countries around the world. Penglase (2020), for example, estimates higher poverty rates for foster children relative to non-foster children in Malawi. Calvi (2020) shows that poverty rates for women in India are substantially higher than for men, especially at older ages, while Brown et al. (2019) find that, as a result of intra-household inequality, one third of poor individuals in Bangladesh live in families with per-capita expenditure above the poverty line. Tommasi (2019) and Sokullu and Valente (2019) study changes in poverty for men, women and children in Mexico following the introduction of PROGRESA in the late 1990s. Lechene et al. (2019) confirm previous estimates of individual poverty rates for Bangladesh and Malawi, and compute poverty rates for men, women, and children in Albania, Iraq, and Bulgaria, unveiling substantial heterogeneity across countries.

While Dunbar et al. (2013) and all the other aforementioned applications provide individual-level poverty rates that are adjusted for intra-household inequality, they do not account for scale economies in consumption. ${ }^{29}$ Ignoring scale economies, however, may result in an over-estimation of poverty rates. The novelty of our method is that it delivers individual-level poverty estimates for women, men, and children, that account for both intra-household inequality and scale economies.

A simple example may help illustrate how individual-level poverty rates are affected by intra-household resource allocation and economies of scale. Consider two households with household expenditure $y$ equal to US $\$ 10 /$ day: a reference household with one man, one woman, and one child, and no economies of scale in consumption; ${ }^{30}$ and a (possibly larger) non-reference household of type $\tau$. Suppose the woman's resource share in the reference household, $\eta_{w, 1}$, is 0.30 , so that her individual expenditure equals US $\$ 3 /$ day; also, suppose each woman's resource share in the non-reference household is 0.17 , so that their individual expenditure is US\$1.70/day. If there were no economies of scale in consumption and $s_{\tau}=1$ (e.g., if consumption in both households was limited to private goods), the amount of expenditure allocated to each woman would coincide with how much she consumes. So, the woman in the reference household would not be classified as poor (based on the US\$1.90/day threshold), while each woman in the non-reference household would. However, if the non-reference household experienced economies of scale from the joint consumption of public goods, each woman's actual level of consumption would exceed US\$1.70. Specifically, if $s_{\tau}=0.80$, each woman's consumption in the non-reference household would amount to US\$1.70/0.80 = US\$2.13, and she would not be classified as poor.

To implement our approach, we first select a poverty line for the reference household. This is the level of per-capita consumption below which the reference household as a whole is classified as poor based on standard per-capita poverty measures. Admittedly, this choice is quite arbitrary. Even when relying on a standard poverty line, the assumption that this is the relevant poverty line for a nuclear family with one child cannot be easily tested. This issue, however, is mostly irrelevant when focusing on the relative poverty rates of men, women, and children, and on poverty rates relative to a reference household. In

\footnotetext{
${ }^{29}$ The underlying model of Dunbar et al. (2013) accounts for scale economies, but that component of the model is not identified or estimated.

${ }^{30}$ For a detailed discussion of relative scale economies and the normalization required for identification in our framework, see Section 3.
} 
what follows, we use the absolute poverty line of US\$1.90/day and apply the same poverty threshold for men, women, and children. In the Appendix, we provide alternative poverty rates in Table A6, where we adjust individual poverty lines for age-specific needs, ${ }^{31}$ and Table A7, where we use a poverty line equal to 50 percent of median per-capita expenditure in each country. Next, we compute each household member's individual consumption, which accounts both for resource allocation and the extent of economies of scale in consumption relative to the reference household. Specifically, for each individual in our sample, we compute her individual consumption as $\widehat{\eta}_{j, \tau} y / \widehat{s}_{\tau}$. Note that this is different from previous works that, by ignoring scale economies in consumption, cannot distinguish between individual expenditure (i.e., $\left.\widehat{\eta}_{j, \tau} y\right)$ and individual consumption. Also, note that since we are only estimating scale economies relative to a reference household, individual consumption and individual expenditure would coincide in nuclear families with one child. ${ }^{32}$ Finally, we classify individuals as poor if their individual consumption is below the poverty line: the shares of women, men or children below the poverty line yield individual-level poverty rates that are adjusted for intra-household inequality and scale economies.

Alternatively, one could first adjust the poverty line for different household types for economies of scale in consumption and then compare individual expenditures $\widehat{\eta}_{j, \tau} y$ to the adjusted poverty lines. Clearly, both approaches yield the same poverty estimates. Figure A8 in the Appendix shows how the poverty lines for Bangladesh (Panel A) and Mexico (Panel B) should vary by number of children and adults to account for joint consumption based on our estimates. In the figure, for each household composition, the US\$1.90/day poverty line is multiplied by the average level of scale economies $\widehat{s}_{\tau}$.

Table 5 presents poverty rates computed using the four approaches described above. ${ }^{33}$ In Column (1), poverty rates are based on household per-capita expenditure, so they ignore both intra-household allocation and scale economies. In Column (2), we compute poverty using the popular OECD equivalence scale; when using this approach, we divide household expenditure by $1+0.7\left(1-n_{a}\right)+0.5 n_{c}$. In Column (3), poverty rates account for resource allocation among family members, but not economies of scale. In Column (4), we provide poverty rates that account for both dimensions.

As expected, poverty rates for Bangladesh are much higher than for Mexico. Beyond this observation, there are a number of other features that emerge from Table 5. First, poverty rates are significantly higher for children and for women in Bangladesh when intra-household inequality is accounted for (in Columns (3) and (4)). In Mexico, there is essentially no difference between the share of women and men who live in poverty, while children's poverty is more prevalent. Note that any difference between children's, women's, and men's poverty rates in Column (1) and (2) must be driven by differences in household compositions between poor and non-poor families and not by intra-household allocation. Second, the per-capita approach substantially underestimates children's poverty and overestimates adults' poverty in both countries. Third, although economies of scale are limited in Bangladesh, since many individuals live quite close to the poverty line, the poverty estimates based on individual expenditure are quite different from those based on individual consumption. By contrast, although economies of scale are higher in Mexico, the rates of extreme poverty are so low that we cannot detect substantial differences between

\footnotetext{
${ }^{31}$ Specifically, we set the child poverty line to be 60 percent of the adult poverty line and we set the elderly poverty line to be 80 percent of the prime-age adult line Brown et al. (2019).

${ }^{32}$ If there were scale economies in reference households, we would overestimate poverty. This bias, however, would be smaller than if economies of scale in consumption were ignored altogether.

${ }^{33}$ Figure A7 in the Appendix presents the empirical distributions of household per-capita expenditure, household expenditure adjusted using the OECD equivalence scale, model-based individual expenditure and model-based individual consumption for Bangladesh and Mexico.
} 
Table 5: Poverty Rates By Measure

\begin{tabular}{l}
\hline \hline Obs. \\
\cline { 2 - 5 }
\end{tabular}

Columns (3) and (4) (slightly larger differences emerge when we compute relative poverty rates instead of absolute poverty rates; see Table A7 in the Appendix). Fourth, the OECD equivalence scale delivers much lower poverty rates compared to the per-capita approach (which is expected) and to the approach based on individual consumption, suggesting that this scale may overcorrect for economies of scale, particularly in countries like Bangladesh where more than two thirds of the household budget consists of private goods (mostly food).

Next, we study the extent of poverty misclassification (Brown et al., 2019), i.e., how many people with individual consumption below the poverty line would be classified as not poor based on their per-capita expenditure, equivalent expenditure, and individual expenditure (or vice-versa). To this aim, we plot our estimates of individual consumption against household per-capita expenditure (Panels A.1 and A.2 of Figure 3), household equivalent expenditure (Panels B.1 and B.2), and individual expenditure (Panels C.1 and C.2). Analogous graphs focused on women, men, and children are provided in Figures A9 A10 and A11 in the Appendix. We partition each graph into four regions based on whether one's estimated individual consumption, per-capita expenditure, equivalent expenditure or individual expenditure is above or below the US\$1.90/day poverty threshold. For individuals falling in the lower left or upper right quadrants, the two measures of poverty in each graph coincide. In other words, accounting for intrahousehold inequality and economies of scale does not impact their categorization as living above or below the poverty threshold. By contrast, individuals falling in the lower right quadrant would be considered poor according to the alternative measure, despite having an estimated level of individual consumption below the standard poverty line. Similarly, individuals in the upper left quadrant would be considered poor according to the alternative measures, despite having an estimated level of individual consumption above the standard poverty line.

In Bangladesh, 68.7 percent of individuals who are poor using individual consumption are misclassified as non-poor using the per-capita approach. The rate of misclassification is much higher (97.6 percent) 
Figure 3: Per-capita Expenditure, Equivalent Expenditure, Individual Expenditure vs. Individual Consumption

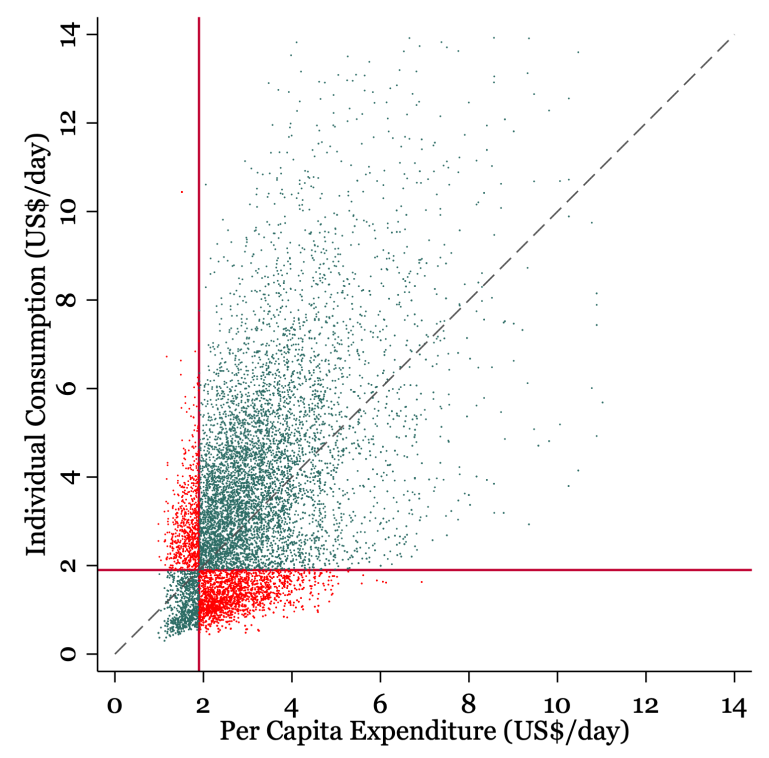

(A.1) Bangladesh: $\widehat{\eta}_{j, \tau} y / \widehat{s_{\tau}}$ vs. $y / n$

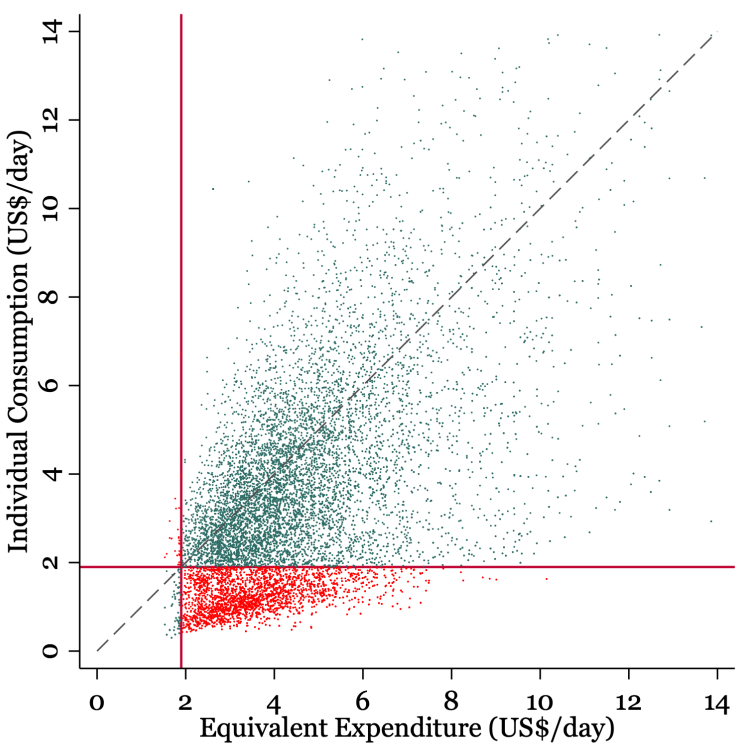

(B.1) Bangladesh: $\widehat{\eta}_{j, \tau} y / \widehat{s}_{\tau}$ vs. $y / n_{e q}$

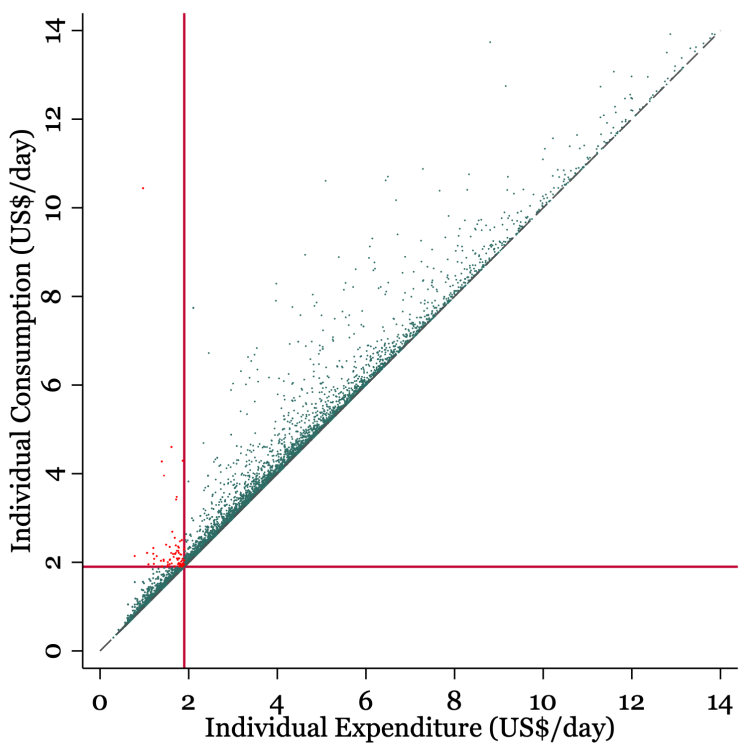

(C.1) Bangladesh: $\widehat{\eta}_{j, \tau} y / \widehat{s}_{\tau}$ vs. $\widehat{\eta}_{j, \tau} y$

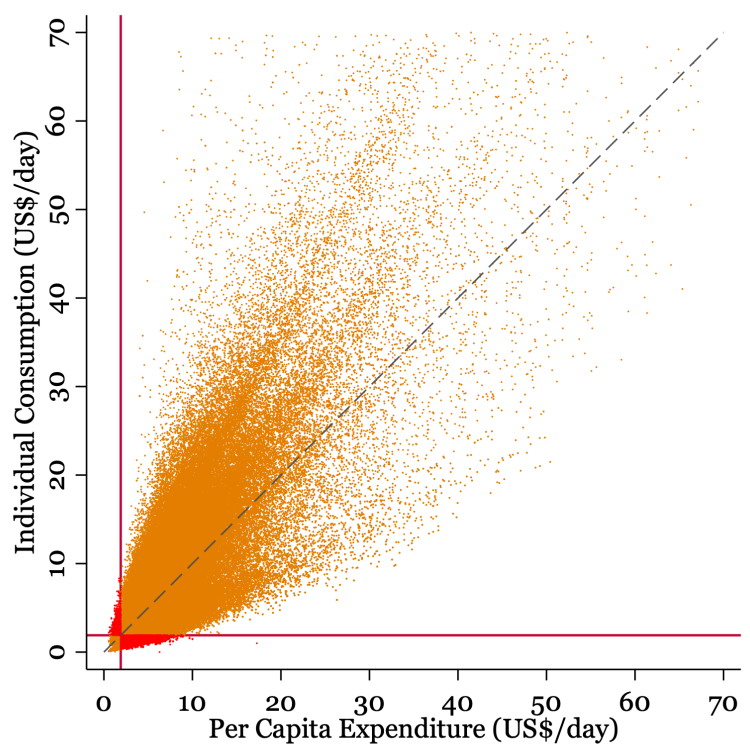

(A.2) Mexico: $\widehat{\eta}_{j, \tau} y / \widehat{s}_{\tau}$ vs. $y / n$

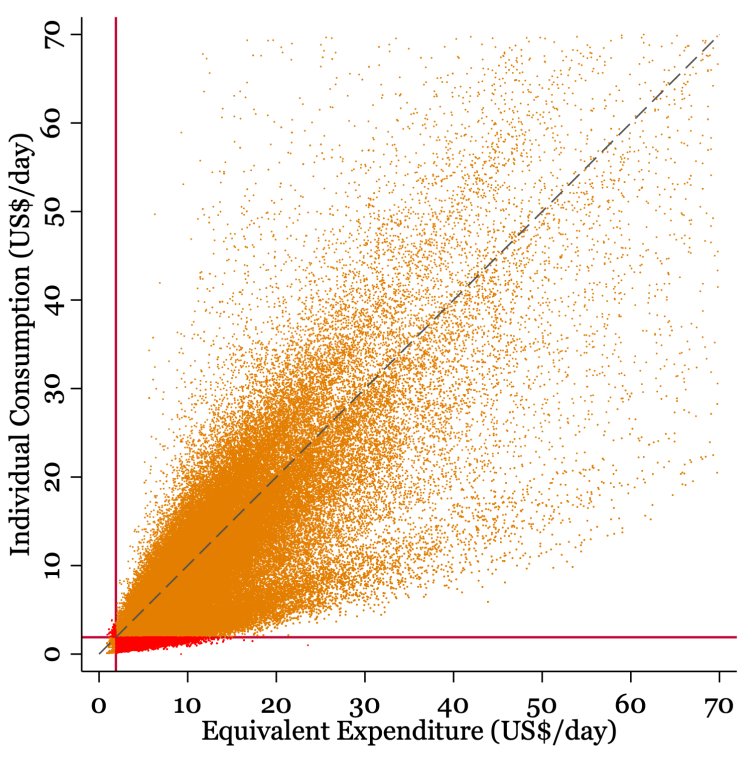

(B.2) Mexico: $\widehat{\eta}_{j, \tau} y / \widehat{s}_{\tau}$ vs. $y / n_{e q}$

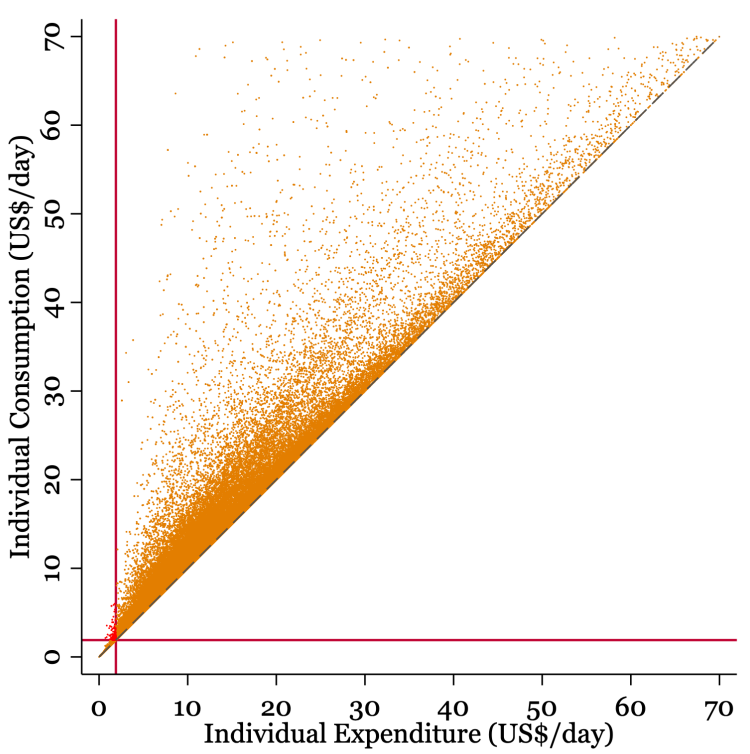

(C.2) Mexico: $\widehat{\eta}_{j, \tau} y / \widehat{s}_{\tau}$ vs. $\widehat{\eta}_{j, \tau} y$

Note: The figure shows the extent of poverty misclassification, i.e., how many people with individual consumption below the poverty line would be classified as not poor based on their per-capita expenditure, equivalent expenditure, and individual expenditure (or vice-versa). Panels A.1 and A.2 report our estimates of individual consumption against household per-capita expenditure. Panels B.1 and B.2 against household equivalent expenditure. Panels C.1 and C.2 against individual expenditure. Analogous graphs focused on women, men, and children separately are provided in Figures A9, A10 and A11 in the Appendix. Individual expenditure is obtained multiplying total annual household expenditure (PPP dollars) by individual resource shares. Individual consumption is obtained by dividing individual expenditure by scale economies. In Bangladesh, only households surveyed in 2015 are included. Reference lines correspond to the 1.90 dollar/day poverty line. Dash lines identify the 45 degree lines. 
using the OECD equivalence scale. As we do not estimate any diseconomies of scale, any individual classified as poor using individual consumption is also poor using individual expenditure. Turning to Mexico, we find similar patterns, although the misclassification rates are minimal just because the US\$1.90/day threshold is very low in this context. Based on a relative poverty line (50 percent of median per-capita expenditure), we find that roughly half of poor individuals in the Mexican sample are misclassified as nonpoor using the per-capita approach. We also examine misclassification in the opposite direction, that is individuals misclassified as poor despite having individual consumption above the poverty line. Focusing on individual expenditure, we find that approximately 2.5 percent of individuals who are non-poor using our consumption measure are misclassified as poor. This holds true both in Mexico and Bangladesh. We report total misclassification rates in Table A8 in the Appendix, as well as misclassification rates separately for men, women, and children.

\section{Conclusion}

We develop an identification method to recover intra-household resource allocation and economies of scale in consumption in a collective household framework. Our method requires the observability of household-level consumption choices over private assignable goods and relies on semi-parametric restrictions over individual preferences for such goods. We compute indifference scales for children and indifference scales for adults in extended households or nuclear families with multiple children, which help us shed light on how individual well-being may change across family structures that are most prevalent in developing countries.

To illustrate the relative importance of intra-household resource allocation and scale economies in countries at different stages of economic development, we estimate our model using data from Bangladesh and Mexico. We find a higher degree of scale economies in Mexico relative to Bangladesh, which is consistent with the importance of shared goods relative to private consumption in each country. Moreover, while scale economies are unambiguously increasing in household size in Bangladesh, we estimate a nonmonotonic relation between scale economies and household size in Mexico. Further, we show that women are allocated less resources than men in Bangladesh, while in Mexico the opposite holds true, on average. In both countries, children command the smallest share of household resources, but their disadvantage is more pronounced in Bangladesh. Based on the model estimates, we conduct a poverty analysis that accounts for both intra-household inequality and economies of scale in consumption. Existing methods, such as per-capita measures, equivalence scale-based measures, and previous model-based measures ignore one or both of these factors. Our results demonstrate that these are not harmless omissions in certain contexts.

Future work can apply our approach to various settings and policy areas. For example, one could use our estimates to improve the design of cash transfer programs, by determining how the size of the cash transfer payments should optimally vary across household sizes and compositions. Similarly, one could use our methodology to compute the size of child support payments following a divorce. Child support is often determined by the number of children being supported (Bartfeld, 2000). We provide a systematic way to assess how the size of these payments should vary across the number of children being supported, which may be important as divorce rates are increasing in many developing countries. 
There are some caveats to our analysis that deserve mention. First, while we can identify several important aspects of intra-household consumption, our model proved somewhat difficult to estimate, and has relatively demanding data requirements. Future work should investigate simplifications that facilitate estimation (in the spirit of Lechene et al. (2019)). Second, our analysis is primarily descriptive and does not examine why resources are allocated unequally within families. However, understanding the cultural, social, and economic reasons behind intra-household inequality is essential for policy design. Third, while we attempt to address estimation issues related to selection using conventional approaches (Heckman, 1979, 1990), future work may focus on explicitly modeling the household formation process. Finally, although our approach allows for a very simple production technology, it ignores more complex types of household production. Incorporating time use into the model is a promising avenue for future research.

\section{References}

Attanasio, O. P. And V. LeChene (2014): "Efficient Responses to Targeted Cash Transfers," Journal of Political Economy, 122, 178 - 222. [6], [19]

BAnks, J., R. Blundell, AND A. LeWbel (1997): "Quadratic Engel Curves and Consumer Demand," Review of Economics and statistics, 79, 527-539. [8], [13], [17]

BARGAin, O. AND O. DonNi (2012): "Expenditure on children: A Rothbarth-type method consistent with scale economies and parents' bargaining," European Economic Review, 56, 792-813. [2], [3], [4], [6], [7], [8], [12]

BARGain, O., O. Donni, AND P. KwEnda (2014): "Intrahousehold Distribution and Poverty: Evidence from Côte d'Ivoire," Journal of Development Economics, 107, 262-276. [4]

BARGAin, O., G. LACROIX, AND L. Tiberti (2018): "Validation of Collective Models for Individual Welfare Analysis using Direct Evidence on Sharing," mimeo. [4], [9], [12], [19]

BARTfeld, J. (2000): "Child Support and the Postdivorce Economic Well-Being of Mothers, Fathers, and Children," Demography, 37, 203-213. [29]

Betson, D. M. (2007): "Is Everything Relative? The Role of Equivalence Scales in Poverty Measurement," . [24]

Blundell, R., A. Duncan, And K. Pendakur (1998): "Semiparametric Estimation and Consumer Demand," Journal of applied econometrics, 13, 435-461. [3], [9]

Blundell, R. AND A. LEWBEL (1991): "The Information Content of Equivalence Scales," Journal of econometrics, 50, 49-68. [24]

Brown, C., R. CAlvi, And J. Penglase (2019): "Sharing the Pie: Undernutrition, Intra-household Allocation, and Poverty," Mimeo. [4], [5], [6], [12], [15], [19], [25], [26], [27]

Browning, M., P.-A. ChiAppori, AND A. LeWbel (2013): "Estimating Consumption Economies of Scale, Adult Equivalence Scales, and Household Bargaining Power," Review of Economic Studies, 80, 12671303. [2], [3], [4], [5], [6], [8], [13]

CALvi, R. (2020): "Why are older women missing in India? The age profile of bargaining power and poverty," Journal of Political Economy, 128, 2453-2501. [4], [5], [25]

Cherchye, L., B. De Rock, A. Lewbel, And F. Vermeulen (2015): "Sharing Rule Identification for General Collective Consumption Models," Econometrica, 83, 2001-2041. [2], [9] 
Cherchye, L., B. De Rock, And F. Vermeulen (2011): “The Revealed Preference Approach to Collective Consumption Behaviour: Testing and Sharing Rule Recovery," The Review of Economic Studies, 78, 176198. [2]

Cherchye, L., T. Demuynck, B. De Rock, F. Vermeulen, et Al. (2017): "Household Consumption When the Marriage Is Stable," American Economic Review, 107, 1507-1534. [2]

Cherchye, L., B. D. Rock, K. Surana, And F. Vermeulen (2016): "Marital matching, economies of scale and intrahousehold allocations," Review of Economics and Statistics, 1-45. [2]

CHIAPPORI, P.-A. (1988): "Rational Household Labor Supply,” Econometrica, 56, pp. 63-90. [2] [2]

(1992): “Collective Labor Supply and Welfare," Journal of Political Economy, 100, pp. 437-467.

CHIAPPORI, P. A. (2016): "Equivalence versus Indifference Scales," The Economic Journal, 126, 523-545. [4], [24]

De VReYer, P., S. LAmbert, AND M. RaVAllion (2020): “Unpacking Household Engel Curves,” Tech. rep., National Bureau of Economic Research. [6]

Deaton, A. And J. Muellbauer (1980): "An Almost Ideal Demand System," American Economic Review, 70, 312-26. [24]

DEATOn, A. And C. PAXson (1997): "Poverty Among Children and the Eldrely in Developing Countries," Working papers 226, Princeton, Woodrow Wilson School-Development Studies. [3], [15]

- (1998): "Economies of scale, household size, and the demand for food," Journal of political economy, 106, 897-930. [3]

Donni, O. AND E. El BADAOUI (2020): "Labor Supply in Extended Household: Economies of Scale, SelfSelection and the Intra Household Distribution of Resources in South Africa," Unpublished Manuscript. [2]

Dunbar, G. R., A. Lewbel, And K. Pendakur (2013): "Children's Resources in Collective Households: Identification, Estimation, and an Application to Child Poverty in Malawi," American Economic Review, 103, 438-71. [2], [3], [4], [5], [6], [7], [8], [9], [12], [18], [19], [25]

(2017): "Identification of Random Resource Shares in Collective Households Without Preference Similarity Restrictions," Mimeo. [12]

FISHER, F. M. (1987): "Household Equivalence Scales and Interpersonal Comparisons," The Review of Economic Studies, 54, 519-524. [4]

Garner, T. I. AND K. S. Short (2010): "Identifying the Poor: Poverty Measurement for the US from 1996 to 2005," Review of Income and Wealth, 56, 237-258. [24]

Heckman, J. (1990): "Varieties of selection bias," The American Economic Review, 80, 313-318. [30]

Heckman, J. J. (1979): "Sample selection bias as a specification error," Econometrica: Journal of the econometric society, 153-161. [30]

Hoenn-Velasco, L. AND J. Penglase (2019): "The impact of unilateral divorce in mexico: Bargaining power and labor supply," Unpublished Manuscript. [4], [19]

LANJOUW, P. AND M. RAVALLION (1995): "Poverty and Household Size," The Economic Journal, 105, 14151434. [4] 
Lechene, V., K. Pendakur, And A. Wolf (2019): "OlS Estimation of the Intra-Household Distribution of Consumption," Unpublished Manuscript. [4], [25], [30]

LEWBEL, A. (1989): "Identification and Estimation of Equivalence Scales under Weak Separability," The Review of Economic Studies, 56, 311-316. [24]

(1991): "The rank of demand systems: theory and nonparametric estimation," Econometrica: Journal of the Econometric Society, 711-730. [14]

(1997): "Consumer Demand Systems and Household Equivalence Scales," Handbook of Applied Econometrics, 2. [24]

LEWBEL, A. AND X. LIN (2020): "Identification of Semiparametric Model Coefficients, With an Application to Collective Households," Unpublished Manuscript. [2]

Lewbel, A. And K. Pendakur (2008): "Estimation of Collective Household Models with Engel Curves," Journal of Econometrics, 147, 350-358. [2], [3], [5], [6], [7], [8], [9]

_ (2019): "Ineffiecient Collective Households: Abuse and Consumption," . [6]

(2020): "Inefficient Collective Households: Cooperation and Consumption," Tech. rep., Boston College Department of Economics. [4], [12], [19]

Menon, M., K. Pendakur, And F. Perali (2012): “On the Expenditure-dependence of Children's Resource Shares," Economics Letters, 117, 739-742. [9]

PendAKuR, K. (1999): "Semiparametric Estimates and Tests of Base-Independent Equivalence Scales," Journal of Econometrics, 88, 1-40. [3]

- (2018): "Welfare analysis when people are different," Canadian Journal of Economics, 51, 321360. [4], [24]

Penglase, J. (2018): "Consumption Inequality among Children: Evidence from Child Fostering in Malawi," Unpublished Manuscript. [12]

(2020): "Consumption Inequality Among Children: Evidence from Child Fostering in Malawi," The Economic Journal, ueaa104. [4], [25]

Rangel, M. AND D. Thomas (2019): “Decision-Making in Complex Households,” Tech. rep., National Bureau of Economic Research. [6]

SoKullu, S. AND C. VAlEnte (2018): "Individual Consumption in Collective Households: Identification Using Panel Data with an Application to PROGRESA," Unpublished Manuscript. [12]

- (2019): "Individual Consumption in Collective Households: Identification Using Panel Data with an Application to PROGRESA," mimeo. [4], [19], [25]

Tommasi, D. (2019): "Control of Resources, Bargaining Power and the Demand of Food: Evidence from PROGRESA," Journal of Economic Behavior \& Organization, 161, 265-286. [4], [19], [25]

Tommasi, D. AND A. Wolf (2018): "Estimating Household Resource Shares: A Shrinkage Approach," Economics Letters, 163, 75-78. [18]

UDRY, C. (1996): "Gender, Agricultural Production, and the Theory of the Household," Journal of political Economy, 1010-1046. [6]

World BAnk (2015): A Measured Approach to Ending Poverty and Boosting Shared Prosperity: Concepts, Data, and the Twin Goals, Washington, DC: World Bank. [24] 


\section{Online Appendix for \\ The More the Poorer? Resource Sharing and Scale Economies in Large Families}

Rossella Calvi, Jacob Penglase, Denni Tommasi, and Alexander Wolf

\section{Contents}

A Proofs 2

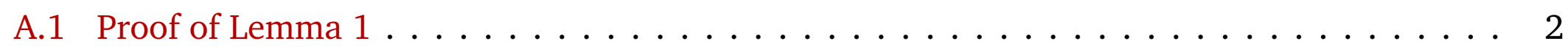

A.2 Proof of Theorem $1 \ldots \ldots \ldots \ldots \ldots \ldots \ldots \ldots \ldots \ldots$

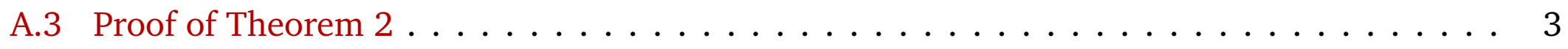

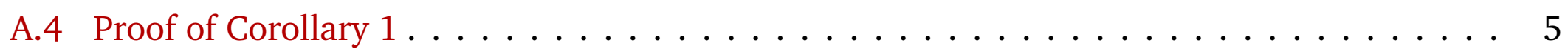

$\begin{array}{llr}\text { B Additional Tables and Figures } & 6\end{array}$ 


\section{A Proofs}

\section{A.1 Proof of Lemma 1}

From the definition of indifference scales in Equation (7),

$$
V_{j}\left(\alpha_{t}+p, x+\ln \eta_{j, t}\right)=V_{j}\left(\alpha_{t^{\prime}}+p, x+\ln \eta_{j, t^{\prime}}-\ln I_{j, t^{\prime}, t}\right)
$$

It follows from Equation (4) that

$$
V_{j}\left(\alpha_{t}+p, x+\ln \eta_{j, t}\right)=V_{j}\left(\alpha_{t^{\prime}}+p, x+\ln \eta_{j, t}-\ln s_{j, t}+\ln s_{j, t^{\prime}}\right)
$$

Thus,

$$
V_{j}\left(\alpha_{t^{\prime}}+p, x+\ln \eta_{j, t^{\prime}}-\ln I_{j, t^{\prime}, t}\right)=V_{j}\left(\alpha_{t^{\prime}}+p, x+\ln \eta_{j, t}-\ln s_{j, t}+\ln s_{j, t^{\prime}}\right) .
$$

For Equation (A1) to hold, the following needs to be true

$$
\ln I_{j, t^{\prime}, t}=\ln \eta_{j, t^{\prime}}-\ln \eta_{j, t}+\ln s_{j, t}-\ln s_{j, t^{\prime}}
$$

\section{A.2 Proof of Theorem 1}

We rewrite the Engel curves in terms of expenditure (instead of log expenditure). Let $y$ be household expenditure with $x=\ln y$. Define $\Omega_{j, n}^{k_{j}}(y)=W_{j, n}^{k_{j}}(x), \omega_{j, n}^{k_{j}}\left(y \eta_{j, n} / s_{j, n}\right)=w_{j, n}^{k_{j}}\left(x+\ln \eta_{j, n}-\ln s_{j, n}\right)$. Identification will come from the derivates of the Engel curves, so let $v_{j, n}^{k_{j}}(y)=\nabla_{y} \omega_{j, n}^{k_{j}}(y)$ and $\zeta_{j, n}^{k_{j}}(y)=\nabla_{y}^{2} \omega_{j, n}^{k_{j}}(y)$.

Consider a one-child household, i.e., a nuclear household with one adult man $m$, one adult woman $w$, and one child $c(n=1)$. From Equation (5),

$$
w_{j, 1}^{k_{j}}\left(\alpha_{1}+p, x+\ln \eta_{j, 1}\left(\alpha_{1}, p\right)\right)=\lambda_{j, 1}^{k_{j}}\left(\alpha_{1}, p\right)+w_{j, 1}^{k_{j}}\left(p, x+\ln \eta_{j, 1}\left(\alpha_{1}, p\right)-\ln s_{j, 1}\left(\alpha_{1}, p\right)\right) .
$$

for $j=m, w, c$. We use one-child households as the reference household for all person types. Under a single price regime, Assumption 4, and appropriate normalizations, the household-level budget shares for private assignable goods $k_{j}$ for one-child households are given by

$$
\Omega_{j, 1}^{k_{j}}(y)=\eta_{j, 1} \omega_{j, 1}^{k_{j}}\left(\eta_{j, 1} y\right)
$$

Recall that $\Omega_{j, 1}^{k_{j}}$ is observed. Given Assumptions 2.i and 2.ii, resource shares and the second derivatives of the individual budget shares are identified by the following set of four equations in four unknowns:

$$
\left.\nabla_{y}^{2} \Omega_{j, 1}^{k_{j}}(y)\right|_{0}=\eta_{j, 1} \zeta^{k_{j}}(0)
$$

for $j=m, w, c$ with $\eta_{c, 1}=1-\eta_{m, 1}-\eta_{w, 1}$. Then, taking the first derivative of Equation (A2) with respect to $y$ and applying Assumption 2.i yields:

$$
\left.\nabla_{y} \Omega_{j, 1}^{k_{j}}(y)\right|_{0}=\eta_{j, 1} v_{j}^{k_{j}}(0)
$$

which identifies $v_{j}^{k_{j}}(0)$, for $j=m, w, c$. 
Moving onto $n$-child couples with $n>1$ (nuclear households with one man $(m)$, one woman $(w)$, and $n>1$ children), the household-level budget shares for private assignable goods $k_{j}$ are given by:

$$
\Omega_{j, n}^{k_{j}}(y)=\eta_{j, n}\left[\lambda_{j, n}^{k_{j}}+\omega_{j, n}^{k_{j}}\left(\frac{\eta_{j, n} y}{s_{j, n}}\right)\right],
$$

for $j=m, w$, and

$$
\Omega_{c, n}^{k_{c}}(y)=n \eta_{c, n}\left[\lambda_{c, n}^{k_{c}}+\omega_{c, n}^{k_{j}}\left(\frac{\eta_{c, n} y}{s_{c, n}}\right)\right],
$$

for children. Differentiating Equations (A3) and (A4) with respect to $y$ :

$$
\left.\nabla_{y} \Omega_{j, n}^{k_{j}}(y)\right|_{0}=\frac{\eta_{j, n}^{2}}{s_{j, n}} v_{j}^{k_{j}}(0)
$$

for $j=m, w$, and for children

$$
\left.\nabla_{y} \Omega_{c, n}^{k_{c}}(y)\right|_{0}=n \frac{\eta_{c, n}^{2}}{s_{c, n}} v_{c}^{k_{c}}(0)
$$

Differentiating again yields:

$$
\left.\nabla_{y}^{2} \Omega_{j, n}^{k_{j}}(y)\right|_{0}=\frac{\eta_{j, n}^{3}}{s_{j, n}^{2}} \zeta^{k_{j}}(0)
$$

for $j=m, w$, and for children

$$
\left.\nabla_{y}^{2} \Omega_{c, n}^{k_{c}}(y)\right|_{0}=n \frac{\eta_{c, n}^{3}}{s_{c, n}^{2}} \zeta^{k_{c}}(0) .
$$

Since $v_{j}^{k_{j}}(0)$ and $\zeta_{j}^{k_{j}}(0)$ are known, the ratio of the second and first derivatives identifies $\kappa_{j, n}=\frac{\eta_{j, n}}{s_{j, n}}$ :

$$
\frac{\left.\nabla_{y}^{2} \Omega_{j, n}^{k_{j}}(y)\right|_{0}}{\left.\nabla_{y} \Omega_{j, n}^{k_{j}}(y)\right|_{0}}=\frac{\eta_{j, n} \zeta^{k_{c}}(0)}{s_{j, n} v_{j}^{k_{c}}(0)}=\kappa_{j, n} \frac{\zeta^{k_{c}}(0)}{v_{j}^{k_{c}}(0)}
$$

Substituting $\kappa_{j, n}$ into equations Equations (A5) and (A6) yields:

$$
\left.\nabla_{y} \Omega_{j, n}^{k_{j}}(y)\right|_{0}=\eta_{j, n} \kappa_{j, n} v_{j}^{k_{j}}(0)
$$

for $j=m, w$, and for children

$$
\left.\nabla_{y} \Omega_{c, n}^{k_{c}}(y)\right|_{0}=n \eta_{c, n} \kappa_{c, n} v_{c}^{k_{c}}(0),
$$

which identify $\eta_{j, n}$ and, in turn, $s_{j, n}$ from $\kappa_{j, n}$.

\section{A.3 Proof of Theorem 2}

Let $\tau=1$ denote the household where one of all $J$ person types are present. This will be our reference household. Scale economies will then be measured relative to this household. We start by proving identification in the reference household. Next, we prove identification in a household with a different composition and generalize this to all other household types. So, the structure of the proof follows closely the proof of Theorem 1. 
We rewrite the Engel curves in terms of expenditure as follows. Let $y$ be household expenditure with $x=\ln y$. Define $\Omega_{j, \tau}^{k_{j}}(y)=W_{j, \tau}^{k_{j}}(x), \omega_{j, \tau}^{k_{j}}\left(y \eta_{j, \tau} / s_{j, \tau}\right)=w_{j, \tau}^{k_{j}}\left(x+\ln \eta_{j, \tau}-\ln s_{j, \tau}\right)$. Identification will come from the derivates of the Engel curves, so let $v_{j, \tau}^{k_{j}}(y)=\nabla_{y} \omega_{j, \tau}^{k_{j}}(y)$ and $\zeta_{j, \tau}^{k_{j}}(y)=\nabla_{y}^{2} \omega_{j, \tau}^{k_{j}}(y)$.

Let $\tau=1$ denote the reference household, where all $J$ person types are present. From Equation (5),

$$
w_{j, 1}^{k_{j}}\left(\alpha_{1}+p, x+\ln \eta_{j, 1}\left(\alpha_{1}, p\right)\right)=\lambda_{j, 1}^{k_{j}}\left(\alpha_{1}, p\right)+w_{j, 1}^{k_{j}}\left(p, x+\ln \eta_{j, 1}\left(\alpha_{1}, p\right)-\ln s_{j, 1}\left(\alpha_{1}, p\right)\right)
$$

Under a single price regime, Assumption 4, and appropriate normalizations, the household-level budget share functions for private assignable goods $k_{j}$ for person type $j$ in the reference household is given by:

$$
\Omega_{j, 1}^{k_{j}}(y)=\eta_{j, 1} \omega_{j, 1}^{k_{j}}\left(\eta_{j, 1} y\right)
$$

Given Assumptions 2.i and 2.ii, resource shares and the second derivatives of the individual budget share functions are identified by the following set of $J+1$ equations in $J+1$ unknowns: $^{1}$

$$
\left.\nabla_{y}^{2} \Omega_{j, 1}^{k_{j}}(y)\right|_{0}=\eta_{j, 1} \zeta^{k_{j}}(0)
$$

with $\sum_{j} n_{j} \eta_{j, 1}=1$. Taking the first derivative of Equation (A9) with respect to $y$ and applying Assumption 2.i yields:

$$
\left.\nabla_{y} \Omega_{j, 1}^{k_{j}}(y)\right|_{0}=\eta_{j, 1} v_{j}^{k_{j}}(0)
$$

which identifies $v_{j}^{k_{j}}(0)$ for all $j$.

Turning to the non-reference households of types $\tau=t \neq 1$, the household-level budget shares for the private assignable goods $k_{j}$ are given by:

$$
\Omega_{j, t}^{k_{j}}(y)=n_{j} \eta_{j, t}\left[\lambda_{j, t}^{k_{j}}+\omega_{j, t}^{k_{j}}\left(\frac{\eta_{j, t} y}{s_{j, t}}\right)\right] .
$$

Differentiating Equation (A10) with respect to $y$ and imposing Assumption 2.i:

$$
\left.\nabla_{y} \Omega_{j, t}^{k_{j}}(y)\right|_{0}=n_{j} \frac{\eta_{j, t}^{2}}{s_{j, t}} v_{j}^{k_{j}}(0) .
$$

Note that $v_{j}^{k_{j}}(0)$ does not depend on $t$. Differentiating again yields:

$$
\left.\nabla_{y}^{2} \Omega_{j, t}^{k_{j}}(y)\right|_{0}=n_{j} \frac{\eta_{j, t}^{3}}{s_{j, t}^{2}} \zeta^{k_{j}}(0) .
$$

The ratio of the second and first derivatives above identifies $\kappa_{j, t}=\frac{\eta_{j, t}}{s_{j, t}}$ :

$$
\frac{\left.\nabla_{y}^{2} \Omega_{j, t}^{k_{j}}(y)\right|_{0}}{\left.\nabla_{y} \Omega_{j, t}^{k_{j}}(y)\right|_{0}}=\frac{\eta_{j, t} \zeta^{k_{j}}(0)}{s_{j, t} v_{j}^{k_{j}}(0)} .
$$

Substituting $\kappa_{j, t}$ into Equation (A11) for all $j=1, \ldots J$ identifies $\eta_{j, t}$ and $s_{j, t}$.

\footnotetext{
${ }^{1}$ Assumption $2 . \mathrm{i}$ is generalized such that the similarity across sizes is a similarity across all $\tau$ household types. Similarly, Assumption $2 . i \mathrm{i}$ is generalized such that the similarity in preferences across men, women, and children is now a similarity in preferences across all $J$ person types.
} 


\section{A.4 Proof of Corollary 1}

Let $w_{j, n}^{k_{j}}\left(\alpha_{n}+p, x+\ln \left(\eta_{j, n}\right)\right)$ be a polynomial of degree $l$ in $x$. Then there are a finite number (i.e., $\left.l\right)$ of non-zero derivatives. Let $\zeta_{j}^{k_{j}}=\nabla_{x}^{l} w_{j, n}^{k_{j}}(x)$, where $\zeta_{j}^{k_{j}}$ does not depend on $x$ or household type $n$. Furthermore, let $v_{j}^{k_{j}}=\nabla_{x}^{l-1} w_{j, n}^{k_{j}}(x)=\gamma_{j}^{k_{j}}+\zeta_{j}^{k_{j}} x$.

We take the $l^{\text {th }}$ derivative of $W_{j, n}^{k_{j}}(x)$ with respect to $x$ :

$$
\nabla_{x}^{l} W_{j, n}^{k_{j}}(x)=\eta_{j, n} \zeta_{j}^{k_{j}}
$$

With three household sizes (e.g., $n=1,2,3$ ), Equation (A12) results in a system of nine Engel curves with nine unknowns: three preference parameters $\zeta_{j}^{k_{j}}$ and six resource shares (since resource shares sum to one, we only need to identify two resource shares for households with children). We can then use Equation (A12) to identify $\zeta_{j}^{k_{j}}$ and $\eta_{j, n}$.

Given $\zeta_{j}^{k_{j}}$ and $\eta_{j, n}$, and under the appropriate normalizations to scale economies in the reference households, the $(l-1)^{t h}$ derivatives of $W_{j, n}^{k_{j}}(x)$ in one-child families identifies the preference parameters $\gamma_{j}^{k_{j}}$ for $j=m, w, c$ :

$$
\nabla_{x}^{l-1} W_{j, 1}^{k_{j}}(x)=\eta_{j, 1}\left[\gamma_{j}^{k_{j}}+\zeta_{j}^{k_{j}}\left(x+\ln \eta_{j, 1}\right)\right]
$$

Preference parameters $\gamma_{j}^{k_{j}}$ and $\zeta_{j}^{k_{j}}$ are both assumed to not vary across household type, and are therefore treated as known in the non-reference households. Moreover, resource shares are identified for all household types from Equation (A12). What is left to identify are scale economies in the non-reference households.

To identify $s_{j, n}$, we take the $(l-1)^{\text {th }}$ derivative of $W_{j, n}^{k_{j}}(x)$ with respect to $x$ :

$$
\nabla_{x}^{l-1} W_{j, n}^{k_{j}}(x)=\eta_{j, n}\left[\gamma_{j}^{k_{j}}+\zeta_{j}^{k_{j}}\left(x-\ln s_{j, n}+\ln \eta_{j, n}\right)\right]
$$

For each person type $j$ in a household of size $n>1$, Equation (A14) is one equation with one unknown. We can therefore solve for $s_{j, n}$. 


\section{B Additional Tables and Figures}

Table A1: Pre-Estimation Tests of Assignable Goods

\begin{tabular}{|c|c|c|c|c|c|c|c|c|}
\hline & \multicolumn{4}{|c|}{ Slope } & \multicolumn{4}{|c|}{ Curvature } \\
\hline & Estimate & |t-stat $\mid$ & Mean & Median & Estimate & |t-stat $\mid$ & Mean & Median \\
\hline \multicolumn{9}{|l|}{ Bangladesh: } \\
\hline Men's Food (Cereals, Pulse, Vegetables) & -0.159 & 5.032 & 3.454 & 3.482 & 0.004 & 3.281 & 2.993 & 3.025 \\
\hline Women's Food (Cereals, Pulse, Vegetables) & -0.086 & 2.810 & 3.371 & 3.351 & 0.002 & 1.214 & 2.958 & 2.928 \\
\hline Children's Food (Cereals, Pulse, Vegetables) & -0.123 & 4.082 & 2.434 & 2.262 & 0.004 & 2.779 & 2.100 & 1.913 \\
\hline Men's Food (Meat, Fish, Milk Products) & 0.076 & 2.016 & 1.781 & 1.519 & -0.002 & 1.130 & 1.675 & 1.435 \\
\hline Women's Food (Meat, Fish, Milk Products) & 0.010 & 0.306 & 1.536 & 1.247 & 0.001 & 0.605 & 1.416 & 1.123 \\
\hline Children's Food (Meat, Fish, Milk Products) & 0.077 & 2.054 & 1.725 & 1.594 & -0.002 & 1.166 & 1.607 & 1.474 \\
\hline Men's Food (All) & 0.019 & 0.306 & 0.946 & 0.857 & -0.002 & 0.624 & 0.966 & 0.892 \\
\hline Women's Food (All) & 0.041 & 0.734 & 1.123 & 0.943 & -0.002 & 0.931 & 1.126 & 0.949 \\
\hline Children's Food (All) & 0.012 & 0.206 & 1.557 & 1.380 & -0.001 & 0.208 & 1.551 & 1.379 \\
\hline Men's Clothing & 0.009 & 1.235 & 0.970 & 0.853 & -0.001 & 1.704 & 0.979 & 0.847 \\
\hline Women's Clothing & -0.041 & 4.995 & 1.430 & 1.266 & 0.002 & 4.503 & 1.340 & 1.189 \\
\hline Children's Clothing & -0.007 & 0.797 & 0.955 & 0.835 & 0.000 & 0.560 & 0.962 & 0.848 \\
\hline \multicolumn{9}{|l|}{ Mexico: } \\
\hline Men's Clothing & -0.012 & 4.376 & 1.116 & 0.967 & 0.001 & 5.197 & 1.167 & 1.027 \\
\hline Women's Clothing & -0.015 & 5.668 & 1.675 & 1.489 & 0.001 & 6.809 & 1.758 & 1.525 \\
\hline Children's Clothing & -0.018 & 4.336 & 1.592 & 1.300 & 0.001 & 4.743 & 1.602 & 1.308 \\
\hline
\end{tabular}

Notes: OLS estimates. Slope coefficients and curvature parameters of the fully-interacted linear regression model (12). We also report the t-statistics of the slope coefficients and curvature parameters as well as mean and median of the empirical distributions. The predicted values are obtained from a regression of the assignable good budget shares on preference factors $\left(X_{h}, X_{h}^{\tau}\right)^{\prime},\left(X_{h}, X_{h}^{\tau}\right)^{\prime} x_{h}$, and $\left(X_{h}, X_{h}^{\tau}\right)^{\prime} x_{h}^{2}$. We report the predicted curvature of the assignable good Engel curves evaluated at the mean values of $\left(X_{h}, X_{h}^{\tau}\right)^{\prime}$. 
Table A2: Resource Shares and Scale Economies: Bangladesh

\begin{tabular}{|c|c|c|c|c|c|c|}
\hline & \multicolumn{4}{|c|}{ Resource Shares } & \multicolumn{2}{|c|}{ Scale Economies } \\
\hline & \multicolumn{2}{|c|}{ Children } & \multicolumn{2}{|c|}{ Women } & \multirow[b]{2}{*}{ Estimate } & \multirow[b]{2}{*}{ SE } \\
\hline & Estimate & SE & Estimate & SE & & \\
\hline & (1) & (2) & (3) & (4) & (5) & (6) \\
\hline Number of Men & $-0.3107^{* * *}$ & $(0.0374)$ & $-0.0718 * * *$ & $(0.0181)$ & $1.1408 * * *$ & $(0.3673)$ \\
\hline Number of Women & $-0.3281 * * *$ & $(0.0353)$ & $0.1337 * * *$ & $(0.0229)$ & $1.5042 * * *$ & $(0.3719)$ \\
\hline Number of Children & $0.1636 * * *$ & $(0.0236)$ & $-0.0508 * * *$ & $(0.0137)$ & $-0.9428 * * *$ & $(0.0940)$ \\
\hline Average Age Men & $-0.0052 * * *$ & $(0.0019)$ & -0.0012 & $(0.0013)$ & 0.0122 & $(0.0104)$ \\
\hline Average Age Women & $-0.0095 * * *$ & $(0.0026)$ & $-0.0031^{\star}$ & $(0.0016)$ & $0.0827 * * *$ & $(0.0210)$ \\
\hline Average Age Children & $0.0596 * * *$ & $(0.0077)$ & $-0.0430 * * *$ & $(0.0045)$ & $-0.3789 * * *$ & $(0.0720)$ \\
\hline Head Woman Works & $-0.1977 * * *$ & $(0.0530)$ & 0.0289 & $(0.0334)$ & 0.276 & $(0.2270)$ \\
\hline Head Man Works & $-0.3587 * * *$ & $(0.0759)$ & $-0.1209 * * *$ & $(0.0427)$ & $1.5598 * * *$ & $(0.3537)$ \\
\hline Average Education Women & $-0.0664 * * *$ & $(0.0235)$ & $-0.0362^{* * * *}$ & $(0.0116)$ & 0.1593 & $(0.1091)$ \\
\hline Average Education Men & $-0.0863 * * *$ & $(0.0206)$ & -0.0034 & $(0.0114)$ & 0.1642 & $(0.1172)$ \\
\hline Urban & 0.0063 & $(0.0663)$ & -0.0024 & $(0.0392)$ & 0.1671 & $(0.2727)$ \\
\hline Dhaka & -0.0847 & $(0.0515)$ & 0.0093 & $(0.0286)$ & $0.7680 * * *$ & $(0.2783)$ \\
\hline Year $=2011$ & 0.0329 & $(0.0461)$ & $-0.0559 * *$ & $(0.0272)$ & 0.0983 & $(0.2364)$ \\
\hline- & & & & & & \\
\hline
\end{tabular}

Notes: BIHS data (2011/12 and 2015). NLSUR estimates conditional on a set of observable household characteristics and composition variables. Robust standard errors in parentheses. We specify resource shares and scale economies using an inverse logistic function that guarantees that they are bounded between zero and one. We restrict scale economies to be identical across men, women, and children. Age variables are divided by 10 to ease computation.

Table A3: Resource Shares and Scale Economies: Mexico

\begin{tabular}{|c|c|c|c|c|c|c|}
\hline & \multicolumn{4}{|c|}{ Resource Shares } & \multicolumn{2}{|c|}{ Scale Economies } \\
\hline & \multicolumn{2}{|c|}{ Children } & \multicolumn{2}{|c|}{ Women } & \multirow[b]{2}{*}{ Estimate } & \multirow[b]{2}{*}{$\mathrm{SE}$} \\
\hline & Estimate & SE & Estimate & SE & & \\
\hline & (1) & (2) & (3) & (4) & (5) & (6) \\
\hline Number of Men & -0.0238 & $(0.0637)$ & $-0.2210 * * *$ & $(0.0528)$ & -0.1980 & $(0.2595)$ \\
\hline Number of Women & 0.0669 & $(0.0530)$ & 0.0737 & $(0.0518)$ & 0.1270 & $(0.2797)$ \\
\hline Number of Boys & $-0.1189 * * *$ & $(0.0386)$ & $0.0652 * *$ & $(0.0325)$ & $1.2568 * * *$ & $(0.4324)$ \\
\hline Number of Girls & $-0.1241 * * *$ & $(0.0400)$ & 0.0148 & $(0.0339)$ & $1.3015 * * *$ & $(0.4861)$ \\
\hline Average Age Men & $0.1101^{* * *}$ & $(0.0385)$ & $0.1027 * * *$ & $(0.0324)$ & $-0.3784 * *$ & $(0.1517)$ \\
\hline Average Age Women & $-0.0924 *$ & $(0.0490)$ & $-0.1349 * * *$ & $(0.0390)$ & -0.1525 & $(0.2446)$ \\
\hline Average Age Children & $0.2853^{* * *}$ & $(0.1029)$ & -0.1181 & $(0.0843)$ & -0.3680 & $(0.3997)$ \\
\hline Head Woman Works & -0.0741 & $(0.0890)$ & $0.1397 * *$ & $(0.0670)$ & 0.1404 & $(0.4776)$ \\
\hline Head Man Works & -0.0121 & $(0.1586)$ & -0.1352 & $(0.1219)$ & 0.6907 & $(0.4891)$ \\
\hline Average Education Women & 0.0817 & $(0.1095)$ & 0.0447 & $(0.0855)$ & -0.4791 & $(0.5338)$ \\
\hline Average Education Men & $0.2195 * *$ & $(0.1042)$ & -0.0508 & $(0.0841)$ & 0.2224 & $(0.4441)$ \\
\hline Urban & -0.0467 & $(0.0825)$ & -0.0007 & $(0.0703)$ & -0.3926 & $(0.4332)$ \\
\hline Mexico City & 0.2776 & $(0.1776)$ & $-0.4154 * *$ & $(0.1696)$ & $-1.0679 *$ & $(0.6207)$ \\
\hline Constant & $-1.1538 * * *$ & $(0.2673)$ & -0.1882 & $(0.1890)$ & & \\
\hline Sample Size & 36,075 & & & & & \\
\hline
\end{tabular}

Notes: ENIGH data (2018). NLSUR estimates conditional on a set of observable household characteristics and composition variables. Robust standard errors in parentheses. We specify resource shares and scale economies using an inverse logistic function that guarantees that they are bounded between zero and one. We restrict scale economies to be identical across men, women, and children. Age variables are divided by 10 to ease computation. 
Table A4: Estimated Resource Shares and Scale Economies: Representative Household

\begin{tabular}{lccccc}
\hline \hline & \multicolumn{2}{c}{ Bangladesh } & & \multicolumn{2}{c}{ Mexico } \\
\cline { 2 - 3 } \cline { 5 - 6 } & Estimate & Std. Error & & Estimate & Std. Error \\
\cline { 2 - 3 } & $(1)$ & $(2)$ & & $(3)$ & $(4)$ \\
\hline A) Resource Shares: $\widehat{\eta}_{j, \tau}$ & & & & & \\
Children & 0.273 & 0.012 & & 0.249 & 0.024 \\
Women & 0.323 & 0.007 & & 0.417 & 0.021 \\
Men & 0.403 & 0.011 & & 0.334 & 0.018 \\
B) Scale Economies: $\widehat{s}_{\tau}$ & 0.969 & 0.012 & & 0.956 & 0.033 \\
\hline \hline
\end{tabular}

Notes: The table reports the estimated resource shares and scale economies in a representative non-reference household, defined as non-reference household with all preference factors and household type variables at their median value (see Tables 2 and 3 for a list of these values).

Table A5: Robustness Checks: Endogeneity and Selection

\begin{tabular}{|c|c|c|c|c|c|}
\hline & Mean & St. Dev. & Min. & Median & Max. \\
\hline & (1) & (2) & (3) & (4) & (5) \\
\hline \multicolumn{6}{|l|}{ A) Bangladesh } \\
\hline \multicolumn{6}{|l|}{ Endogeneity: Household Type } \\
\hline Children's Resource Share & 0.120 & 0.053 & 0.014 & 0.110 & 0.332 \\
\hline Women's Resource Share & 0.312 & 0.092 & 0.105 & 0.355 & 0.488 \\
\hline Men's Resource Share & 0.325 & 0.092 & 0.108 & 0.347 & 0.550 \\
\hline Scale Economies & 0.956 & 0.075 & 0.154 & 0.984 & 1.000 \\
\hline Endogeneity: Household Expenditure & 0.140 & 0.091 & 0.010 & 0.114 & 0.692 \\
\hline Children's Resource Share & 0.265 & 0.089 & 0.071 & 0.282 & 0.459 \\
\hline Women's Resource Share & 0.351 & 0.122 & -0.001 & 0.370 & 0.618 \\
\hline Men's Resource Share & Scale Economies & 0.063 & 0.170 & 0.989 & 1.000 \\
\hline \multicolumn{6}{|l|}{ B) Mexico } \\
\hline \multicolumn{6}{|l|}{ Endogeneity: Household Type } \\
\hline Children's Resource Share & 0.163 & 0.091 & 0.013 & 0.129 & 0.490 \\
\hline Women's Resource Share & 0.321 & 0.111 & 0.050 & 0.367 & 0.619 \\
\hline Men's Resource Share & 0.297 & 0.088 & 0.000 & 0.320 & 0.623 \\
\hline Scale Economies & 0.916 & 0.111 & 0.163 & 0.955 & 1.000 \\
\hline \multicolumn{6}{|l|}{ Endogeneity: Household Expenditure } \\
\hline Children's Resource Share & 0.150 & 0.091 & 0.007 & 0.119 & 0.513 \\
\hline Women's Resource Share & 0.333 & 0.127 & 0.035 & 0.375 & 0.709 \\
\hline Men's Resource Share & 0.294 & 0.083 & 0.000 & 0.297 & 0.648 \\
\hline Scale Economies & 0.971 & 0.076 & 0.024 & 0.994 & 1.000 \\
\hline
\end{tabular}

Notes: This table reported the estimated resource shares and scale economies from specifications that account for endogeneity of household type (e.g., selection) and endogeneity of household expenditure (e.g., measurement error). 
Table A6: Poverty Rates by Measure Using Absolute Poverty Line with Age Adjustment

\begin{tabular}{lccccc}
\hline \hline & Obs. & $\begin{array}{c}\text { Per-Capita } \\
\text { Expenditure } \\
(y / n)\end{array}$ & $\begin{array}{c}\text { Equivalent } \\
\text { Expenditure } \\
\left(y / n_{e q .}\right)\end{array}$ & $\begin{array}{c}\text { Individual } \\
\text { Expenditure } \\
\left(\eta_{j, \tau} y\right)\end{array}$ & $\begin{array}{c}\text { Individual } \\
\text { Consumption } \\
\left(\eta_{j, \tau} y / s_{\tau}\right)\end{array}$ \\
\cline { 2 - 5 } & $(1)$ & $(2)$ & $(3)$ & $(4)$ & $(5)$ \\
\hline A) Bangladesh & & & & & \\
Children & 5,827 & 0.004 & 0.000 & 0.398 & 0.352 \\
Women & 4,601 & 0.129 & 0.007 & 0.106 & 0.103 \\
Men & 4,373 & 0.118 & 0.006 & 0.028 & \\
B) Mexico & & & & & 0.023 \\
Children & 72,962 & 0.007 & 0.001 & 0.119 & 0.005 \\
Women & 51,343 & 0.014 & 0.003 & 0.007 & 0.004 \\
Men & 48,831 & 0.014 & 0.003 & 0.007 & \\
\hline \hline
\end{tabular}

Notes: The table presents poverty rates, using relative poverty line, for Bangladesh and Mexico computed using four approaches: household per-capita expenditure, household expenditure adjusted using the OECD equivalence scale, model-based individual expenditure and model-based individual consumption. Per-capita expenditure is obtained by dividing total household expenditure by the number of individuals in the household. Individual expenditure is obtained multiplying total annual household expenditure (PPP dollars) by individual resource shares. Individual consumption is obtained by dividing individual expenditure by scale economies. In Bangladesh, only households surveyed in 2015 are included. Reference lines correspond to the 1.90 dollar/day poverty line. We set the child poverty line to be 0.60 of the prime-age adult poverty line. Similarly, we scale the poverty line for individuals age 46 and older by 0.80 .

Table A7: Poverty Rates by Measure Using Relative Poverty Line

\begin{tabular}{lccccc}
\hline \hline & Obs. & $\begin{array}{c}\text { Per-Capita } \\
\text { Expenditure } \\
(y / n)\end{array}$ & $\begin{array}{c}\text { Equivalent } \\
\text { Expenditure } \\
\left(y / n_{\text {eq. }}\right)\end{array}$ & $\begin{array}{c}\text { Individual } \\
\text { Expenditure } \\
\left(\widehat{\eta}_{j, \tau} y\right)\end{array}$ & $\begin{array}{c}\text { Individual } \\
\text { Consumption } \\
\left(\widehat{\eta}_{j, \tau} y / \widehat{s}_{\tau}\right)\end{array}$ \\
\cline { 2 - 6 } & $(1)$ & $(2)$ & $(3)$ & $(4)$ & $(5)$ \\
\hline A) Bangladesh & & & & & \\
Children & 5,827 & 0.031 & 0.000 & 0.560 & 0.515 \\
Women & 4,601 & 0.021 & 0.000 & 0.028 & 0.025 \\
Men & 4,373 & 0.019 & 0.000 & 0.002 & 0.002 \\
B) Mexico & & & & & \\
Children & 72,962 & 0.152 & 0.050 & 0.527 & 0.509 \\
Women & 51,343 & 0.123 & 0.041 & 0.076 & 0.060 \\
Men & 48,831 & 0.122 & 0.041 & 0.075 & 0.054 \\
\hline \hline
\end{tabular}

Notes: The table presents poverty rates, using relative poverty line, for Bangladesh and Mexico computed using four approaches: household per-capita expenditure, household expenditure adjusted using the OECD equivalence scale, model-based individual expenditure and model-based individual consumption. Per-capita expenditure is obtained by dividing total household expenditure by the number of individuals in the household. Individual expenditure is obtained multiplying total annual household expenditure (PPP dollars) by individual resource shares. Individual consumption is obtained by dividing individual expenditure by scale economies. In Bangladesh, only households surveyed in 2015 are included. Reference lines correspond to the 50 percent of median per capita expenditure. We make no age adjustments to any poverty line. 
Table A8: Poverty Misclassification Rates

\begin{tabular}{|c|c|c|c|c|c|c|}
\hline & \multicolumn{3}{|c|}{ Poor Based on Individual Consumption $\left(\widehat{\eta}_{\tau, j} y / \widehat{s}_{\tau}\right)$} & \multicolumn{3}{|c|}{ Not Poor Based on Individual Consumption $\left(\widehat{\eta}_{\tau, j} y / \widehat{s}_{\tau}\right)$} \\
\hline & $\begin{array}{c}\text { Per-Capita } \\
\text { Expenditure } \\
(y / n)\end{array}$ & $\begin{array}{c}\text { Equivalent } \\
\text { Expenditure } \\
\left(y / n_{e q .}\right)\end{array}$ & $\begin{array}{c}\text { Individual } \\
\text { Expenditure } \\
\left(\widehat{\eta}_{j, \tau} y\right)\end{array}$ & $\begin{array}{c}\text { Per-Capita } \\
\text { Expenditure } \\
(y / n)\end{array}$ & $\begin{array}{c}\text { Equivalent } \\
\text { Expenditure } \\
\left(y / n_{e q .}\right)\end{array}$ & $\begin{array}{l}\text { Individual } \\
\text { Expenditure } \\
\left(\widehat{\eta}_{j, \tau} y\right)\end{array}$ \\
\hline & (1) & (2) & (3) & (4) & $(5)$ & $(6)$ \\
\hline \multicolumn{7}{|c|}{ A) Bangladesh } \\
\hline Children & 0.747 & 0.985 & 0.000 & 0.008 & 0.003 & 0.145 \\
\hline Women & 0.388 & 0.933 & 0.000 & 0.085 & 0.002 & 0.004 \\
\hline Men & 0.137 & 0.878 & 0.000 & 0.125 & 0.005 & 0.005 \\
\hline Total & 0.687 & 0.976 & 0.000 & 0.090 & 0.003 & 0.027 \\
\hline \multicolumn{7}{|c|}{ B) Mexico } \\
\hline Children & 0.711 & 0.903 & 0.000 & 0.010 & 0.002 & 0.038 \\
\hline Women & 0.113 & 0.499 & 0.000 & 0.075 & 0.012 & 0.018 \\
\hline Men & 0.057 & 0.403 & 0.000 & 0.075 & 0.009 & 0.022 \\
\hline Total & 0.628 & 0.843 & 0.000 & 0.057 & 0.008 & 0.025 \\
\hline
\end{tabular}

Notes: The table shows the extent of poverty misclassification, i.e., how many people with individual consumption below the poverty line would be classified as not poor based on their per-capita expenditure, equivalent expenditure, and individual expenditure (or vice-versa). Per-capita expenditure is obtained by dividing total household expenditure by the number of individuals in the household. Individual expenditure is obtained multiplying total annual household expenditure (PPP dollars) by individual resource shares. Individual consumption is obtained by dividing individual expenditure by scale economies. In Bangladesh, only households surveyed in 2015 are included. In Bangladesh, we us a 1.90 dollar / day poverty line. In Mexico, the poverty line corresponds to the 50 percent of median per capita expenditure. We make no age adjustments to any poverty line. 


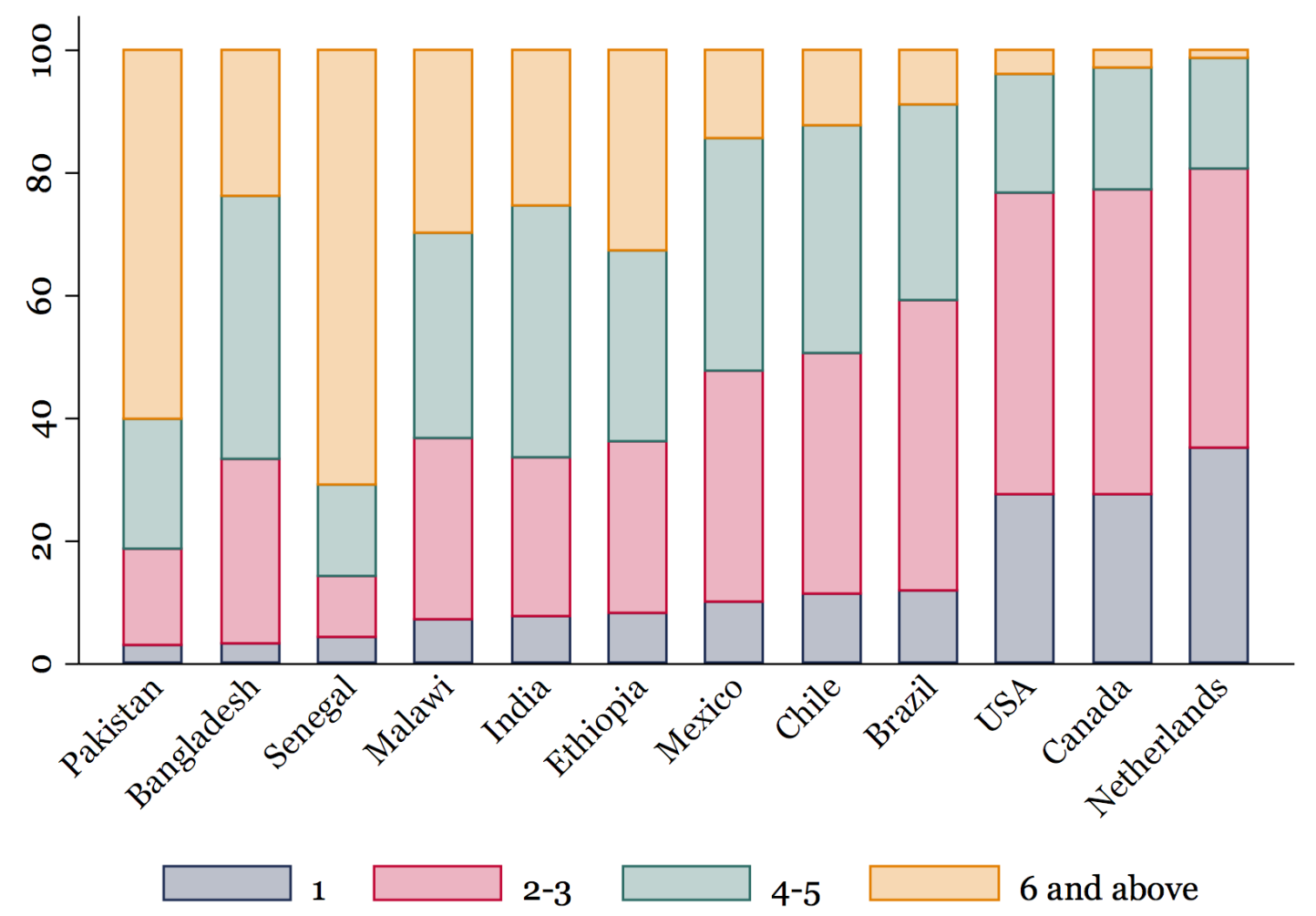

Figure A1: Household Sizes in Selected Countries

Notes: Authors' calculations based on the most recent IPUMS data. 
Figure A2: Estimated Resource Shares and Scale Economies: Empirical Distributions

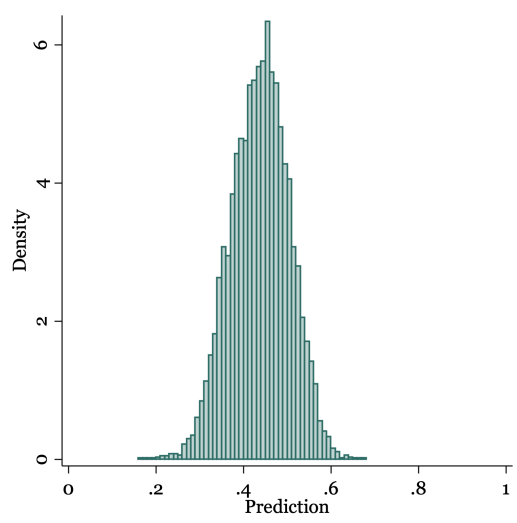

(A.1) Bangladesh: Men's Resource Shares $\left(M \eta_{m, \tau}\right)$

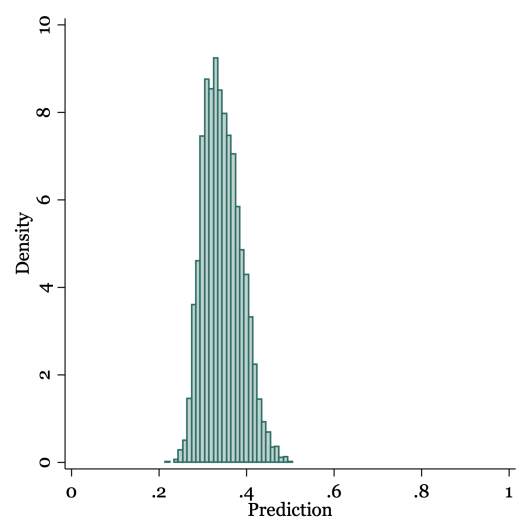

(B.1) Bangladesh: Women's Resource Shares $\left(W \eta_{w, \tau}\right)$

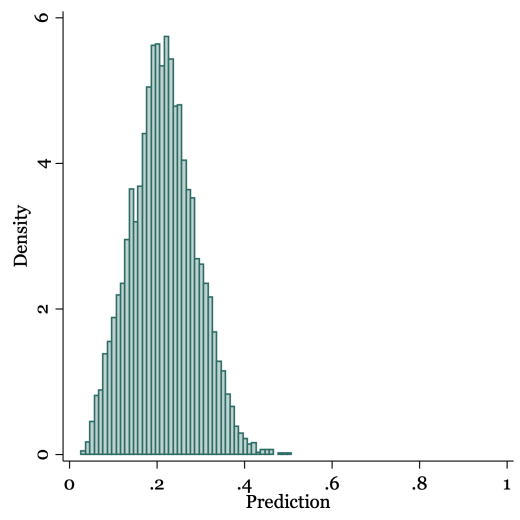

(C.1) Bangladesh: Children's Resource Shares $\left(C \eta_{c, \tau}\right)$

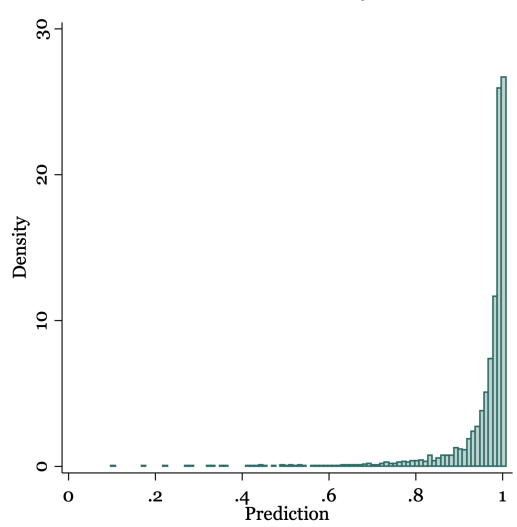

(D.1) Bangladesh:

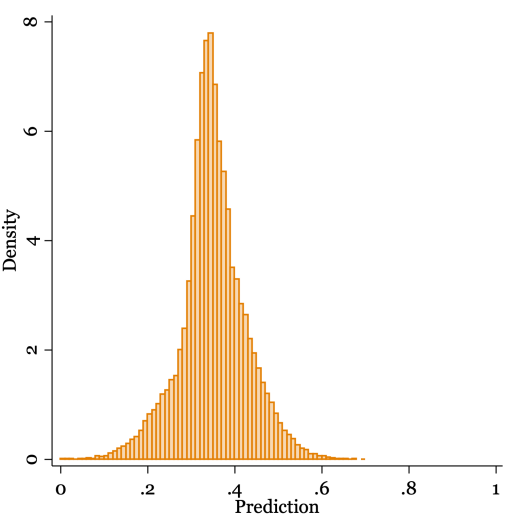

(A.1) Mexico: Men's

Resource Shares $\left(M \eta_{m, \tau}\right)$

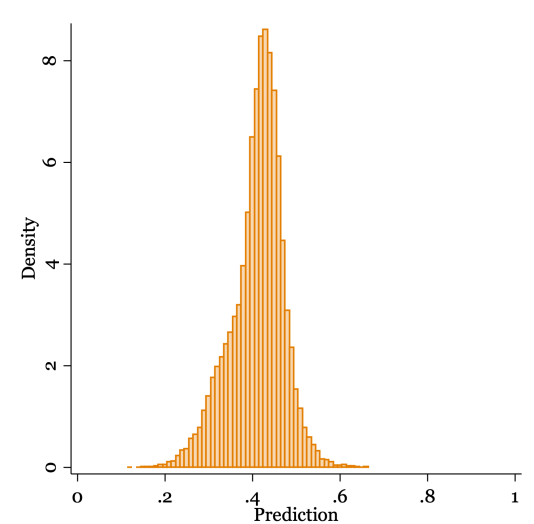

(B.1) Mexico: Women's Resource Shares $\left(W \eta_{w, \tau}\right)$

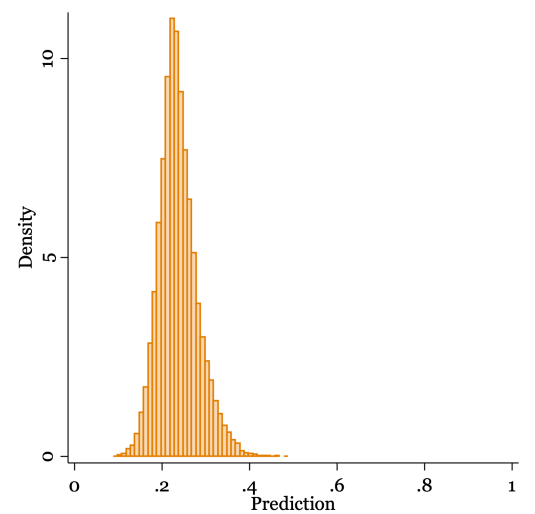

(C.1) Mexico: Children's Resource Shares $\left(C \eta_{c, \tau}\right)$

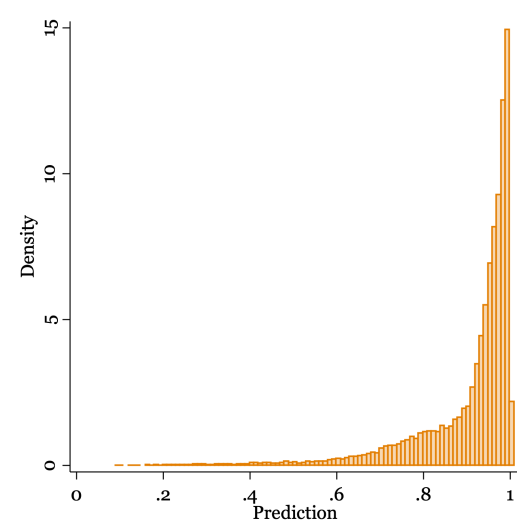

(D.2) Bangladesh:

Economies of Scale $\left(s_{\tau}\right) \quad$ Economies of Scale $\left(s_{\tau}\right)$

Note: Empirical distribution of the estimated resource shares and scale economies. The summary statistics are presented in Table 4. 
Figure A3: Budget Shares on Private, Public, and Sharable Goods: Mexico

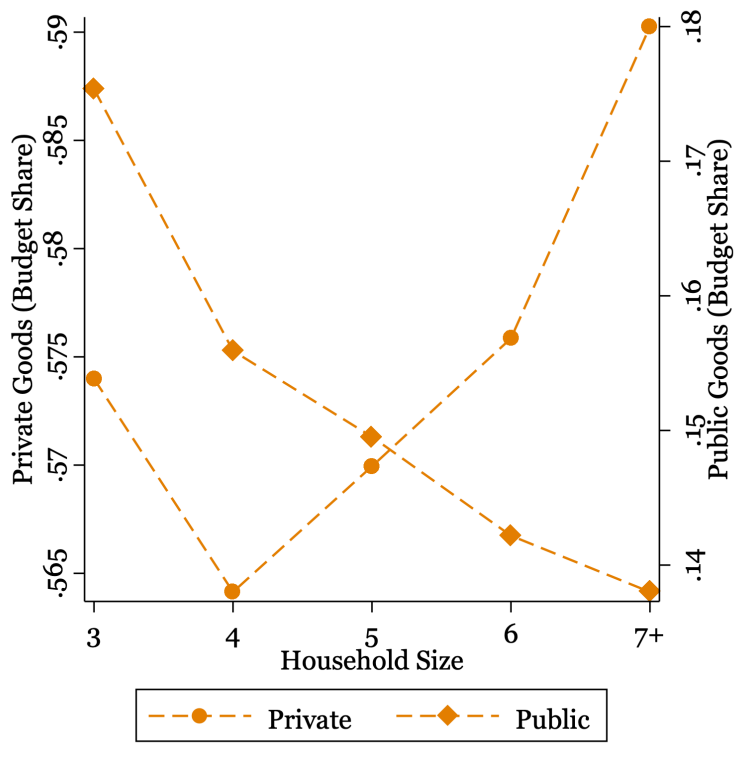

(A) Public and Private Goods

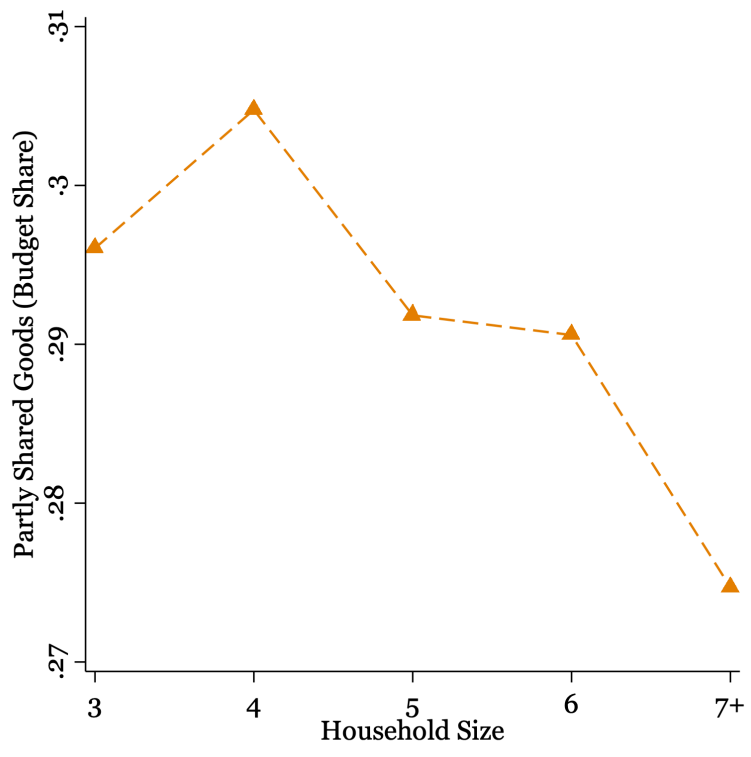

(B) Sharable Goods

Note: Share of budget allocated to private and public goods in Mexico. Private goods include food, clothing, footwear, and personal accessories. Public goods include rent, house/residence expenditure, and energy. Sharable goods include fuel for transportation and other expenses on vehicles (excl. purchase).

Figure A4: Public Goods and Estimated Economies of Scale

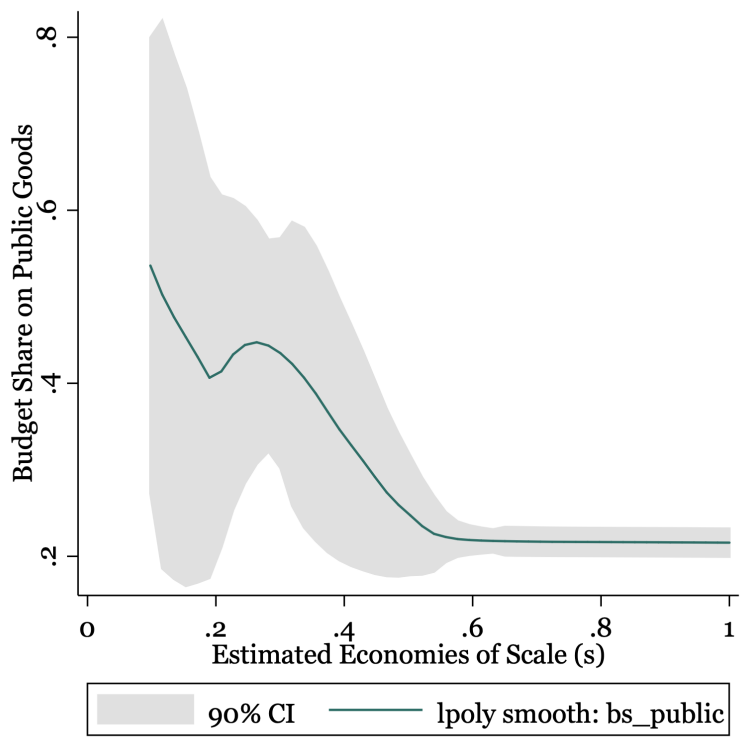

(A) Bangladesh

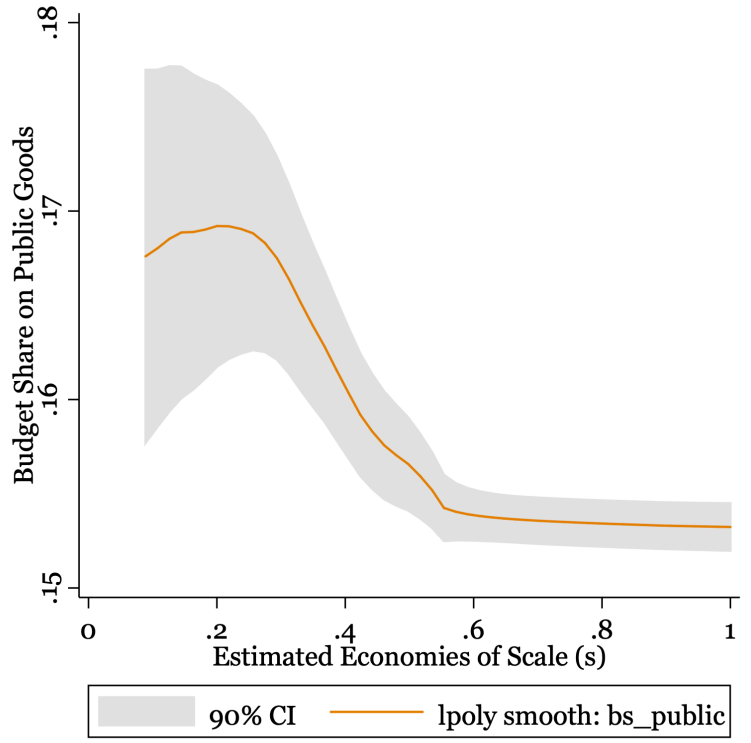

(B) Mexico

Note: Local polynomial regressions to examining the correlation between scale economies and the consumption of public goods. Public goods include rent, house/residence expenditure, and energy. It is reassuring that we estimate larger scale economies (lower $\widehat{s}_{\tau}$ ) when the budget share on public goods is large. 
Figure A5: Indifference Scales by Household Composition: Bangladesh

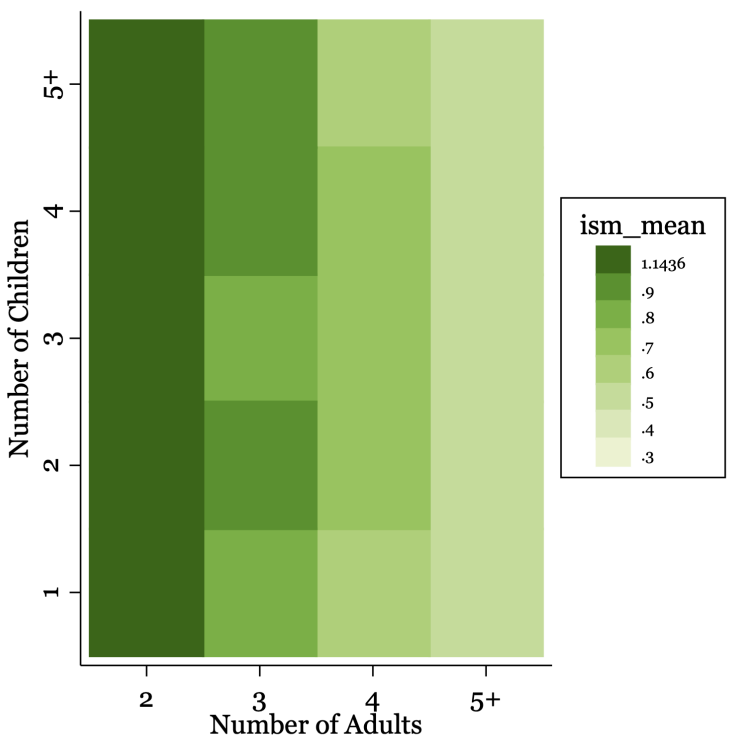

(A) Men

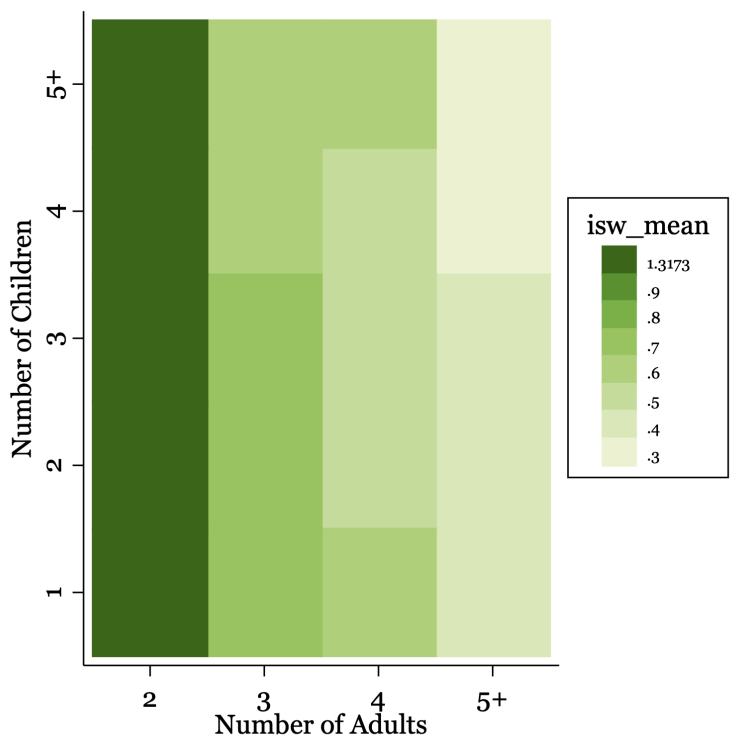

(B) Women

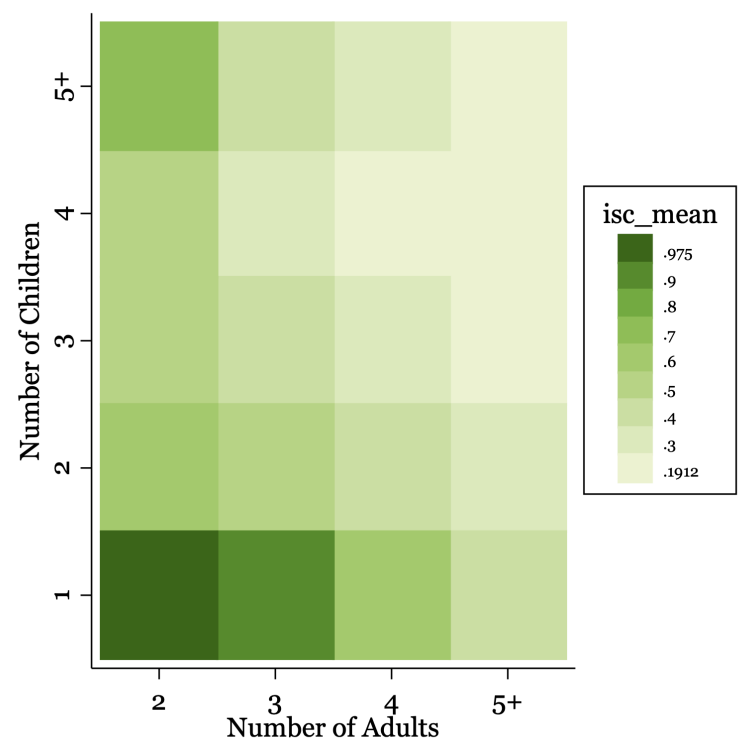

(C) Children

Note: The figure shows how the average indifference scales for children, women and men vary by the number of children and adults in the family. Indifference Scales are computed following Lemma 1. The reference household is defined as having one of each person type (here, this implies one man, one woman, one child) Adults' indifference scales decline substantially as the number of adults increases. By contrast, for a given number of adults, the decline is minimal as the number of children increases. Children's indifference scales decline in both the number of children and adults. 
Figure A6: Indifference Scales by Household Composition: Mexico

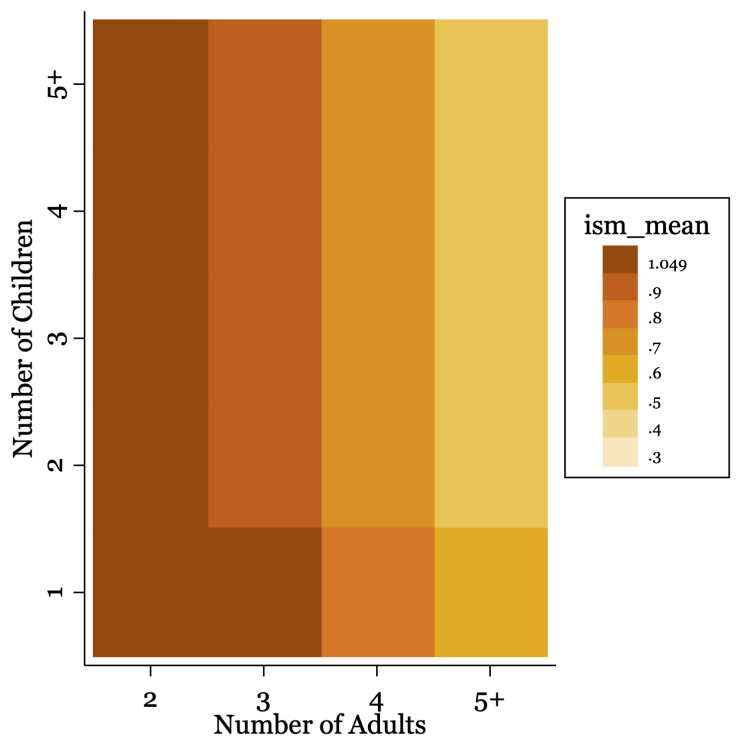

(A) Men

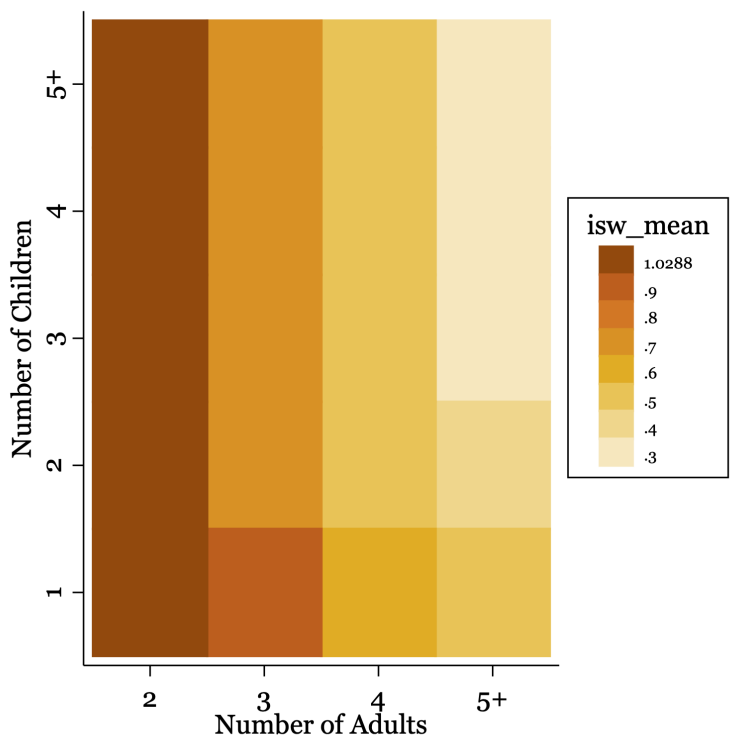

(B) Women

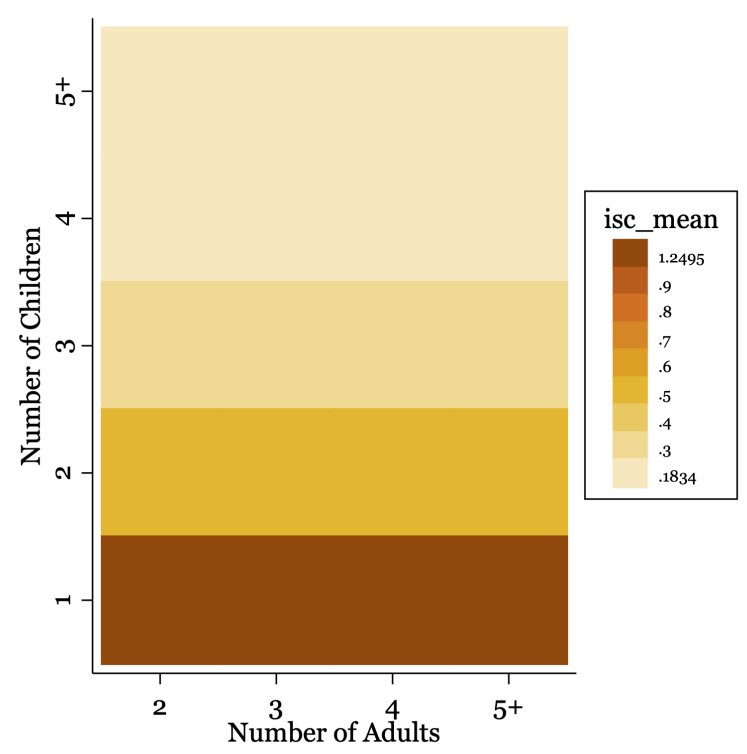

(C) Children

Note: The figure shows how the average indifference scales for children, women and men vary by the number of children and adults in the family. Indifference Scales are computed following Lemma 1. The reference household is defined as having one of each person type (here, this implies one man, one woman, one child) Adults' indifference scales decline substantially as the number of adults increases. By contrast, for a given number of adults, the decline is minimal as the number of children increases. Children's indifference scales decline in the number of children. 
Figure A7: Empirical Distributions

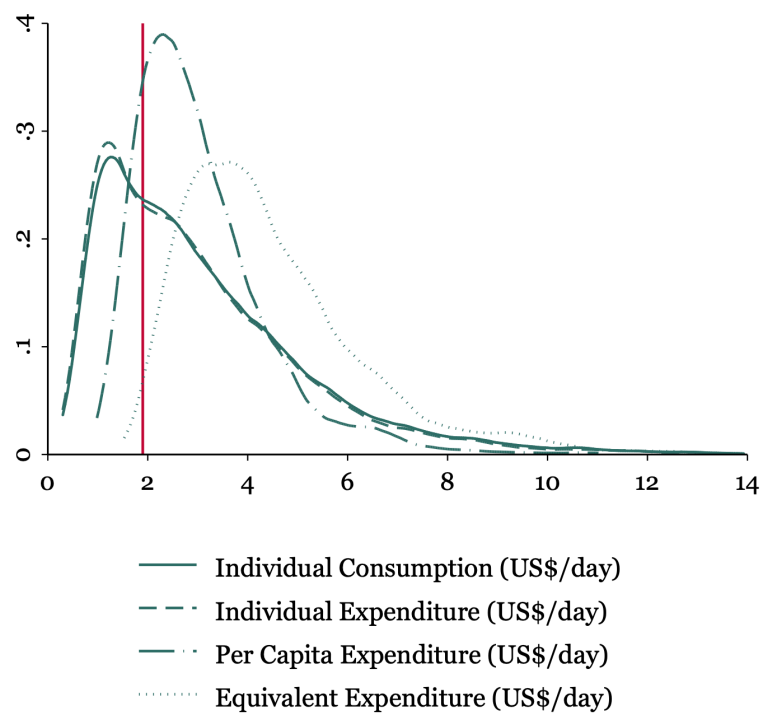

(A) Bangladesh

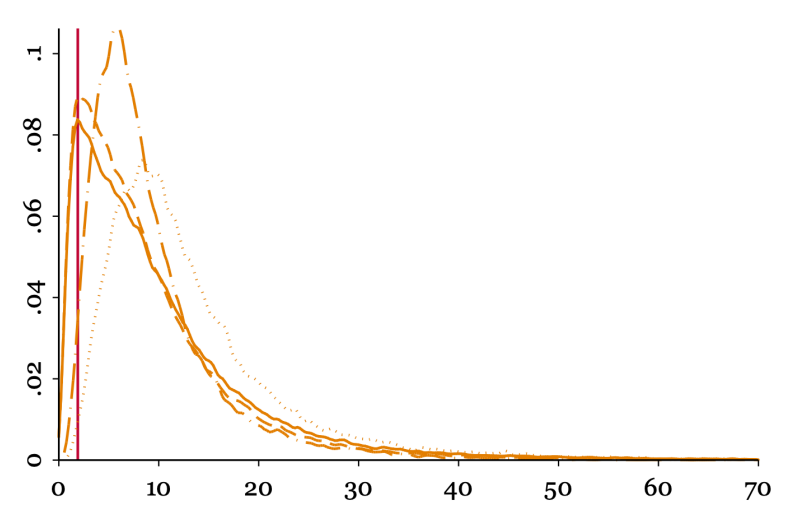

— Individual Consumption (US\$/day)

- - - Individual Expenditure (US\$/day)

- Per Capita Expenditure (US\$/day) Equivalent Expenditure (US\$/day)

Figure A8: Model-based Poverty Lines: US\$/day Adjusted for Scale Economies

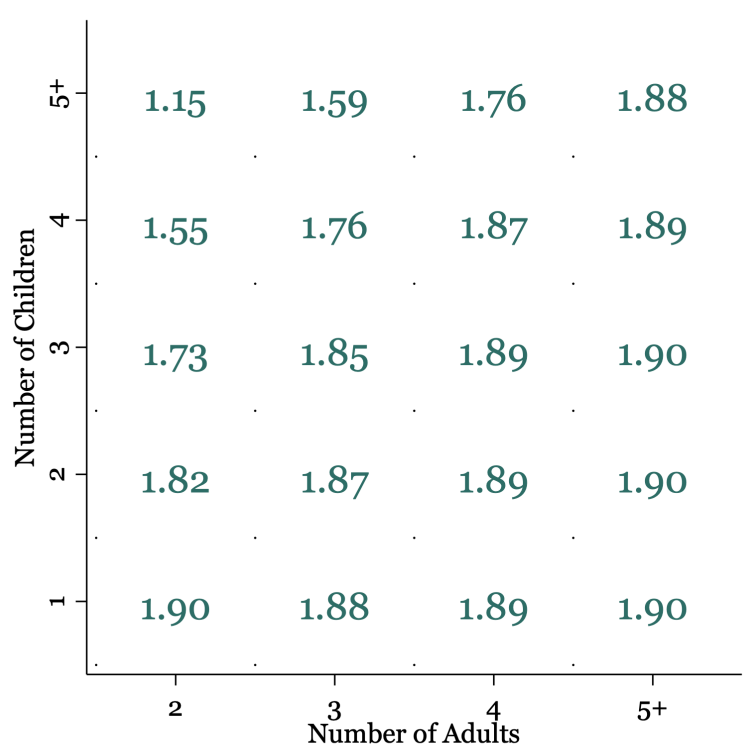

(A) Bangladesh

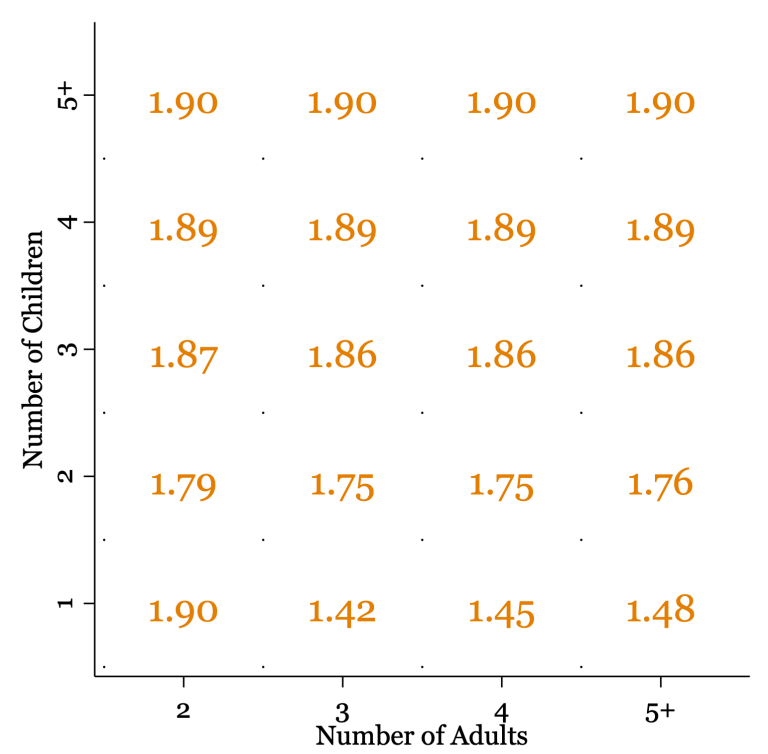

(B) Mexico

Note: The figure shows how the poverty lines for Bangladesh (Panel A) and Mexico (Panel B) should vary by number of children and adults to account for joint consumption based on our estimates. In the figure, for each household composition, the US $\$ 1.90 /$ day poverty line is multiplied by the average level of scale economies $\widehat{s}_{\tau}$. 
Figure A9: Per Capita Expenditure and Consumption

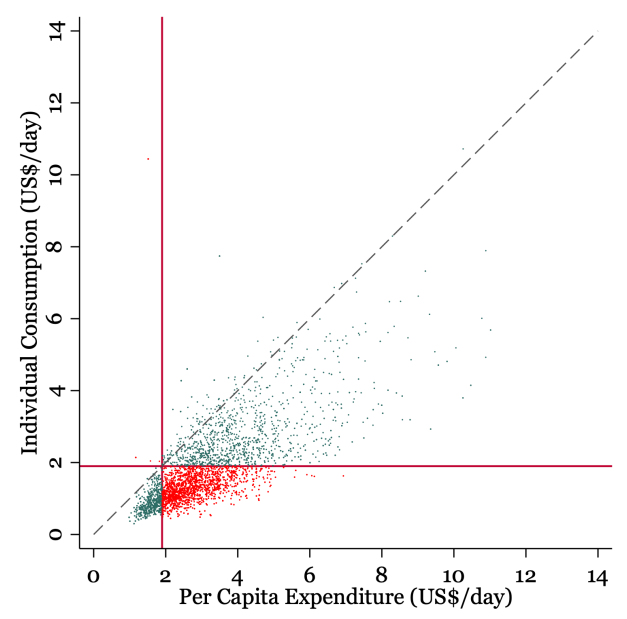

(A) Bangladeshi Children

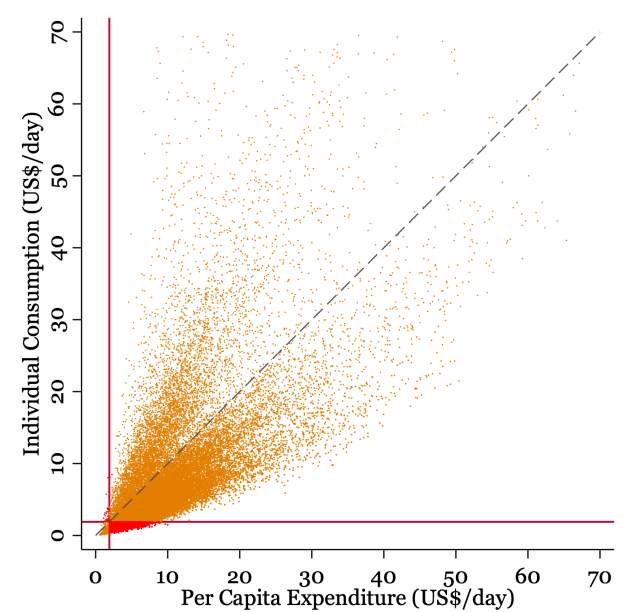

(D) Mexican Children

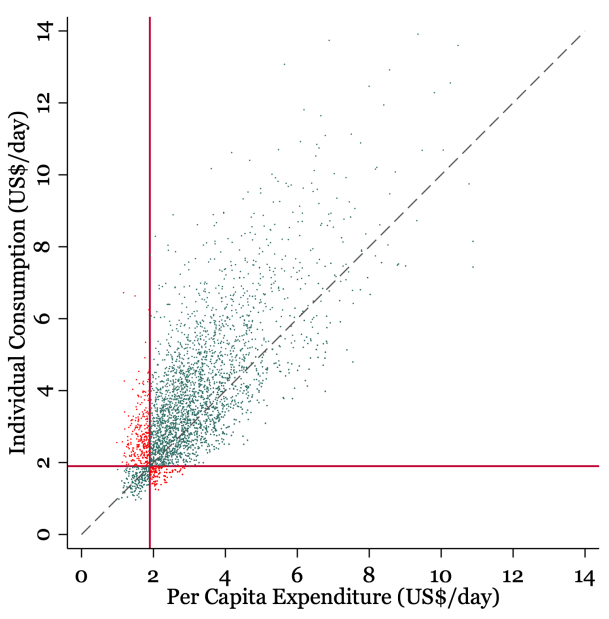

(B) Bangladeshi Women

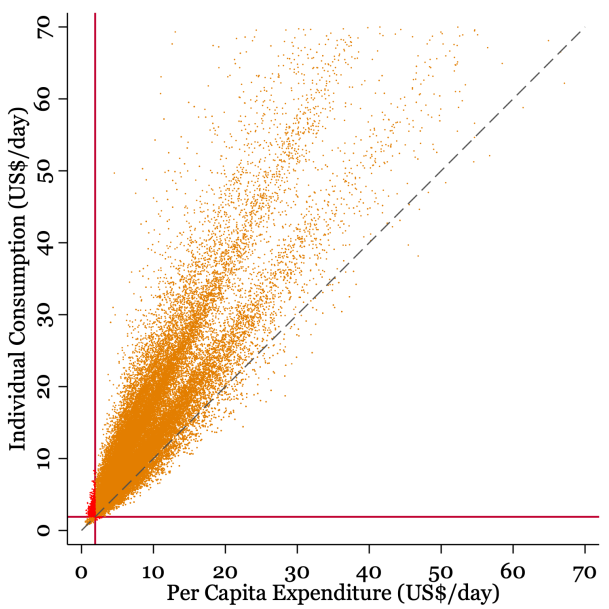

(E) Mexican Women

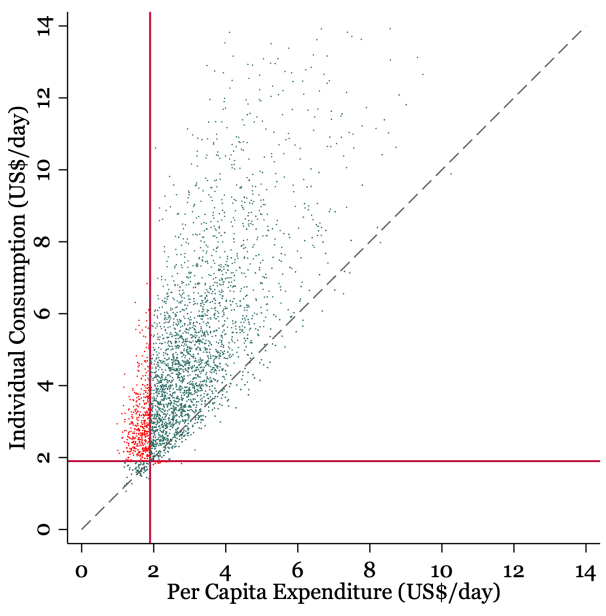

(C) Bangladeshi Men

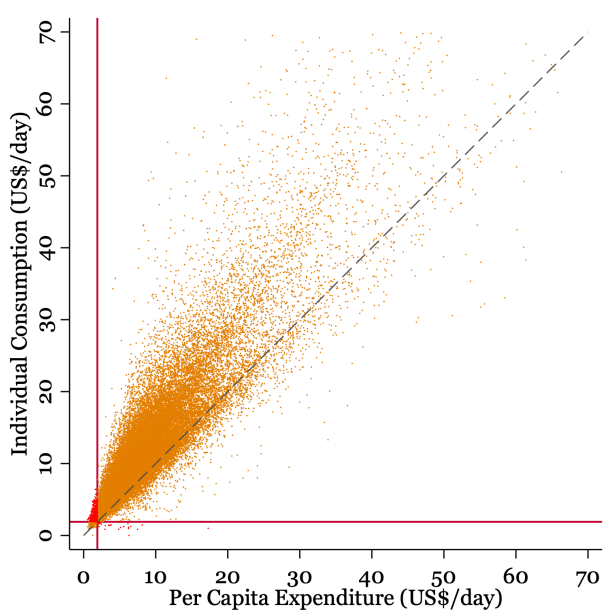

(F) Mexican Men

Note: Per capita expenditure is obtained by dividing total annual household expenditure (PPP dollars) by household size. Individual consumption is obtained by dividing individual expenditure by scale economies. In Bangladesh, only households surveyed in 2015 are included. Reference lines correspond to the 1.90 dollar/day poverty line. Dash lines identify the 45 degree lines. 
Figure A10: Per Equivalent Expenditure and Consumption

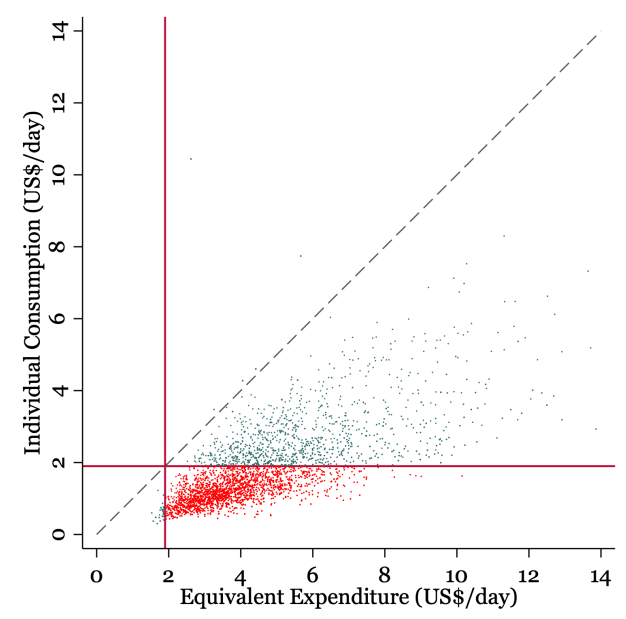

(A) Bangladeshi Children

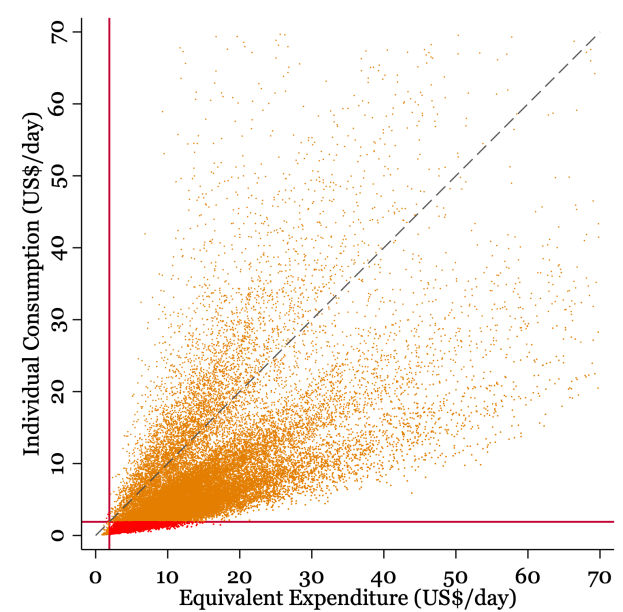

(D) Mexican Children

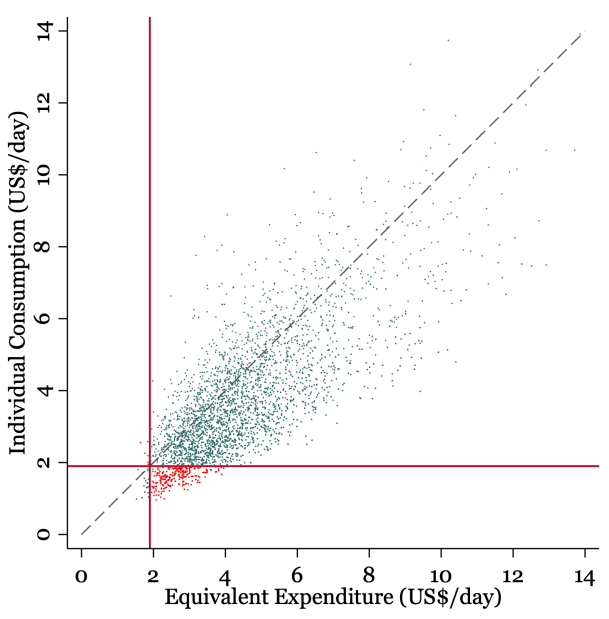

(B) Bangladeshi Women

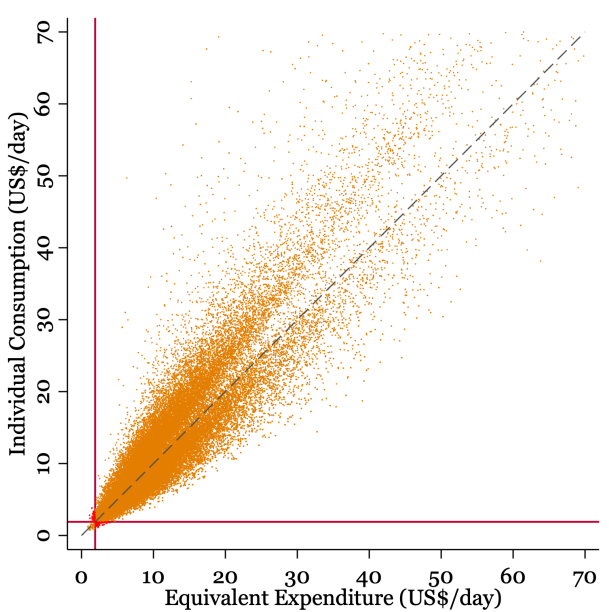

(E) Mexican Women

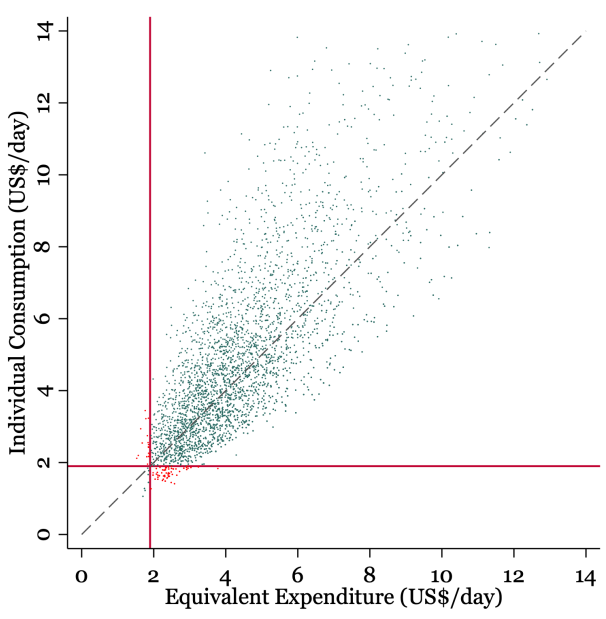

(C) Bangladeshi Men

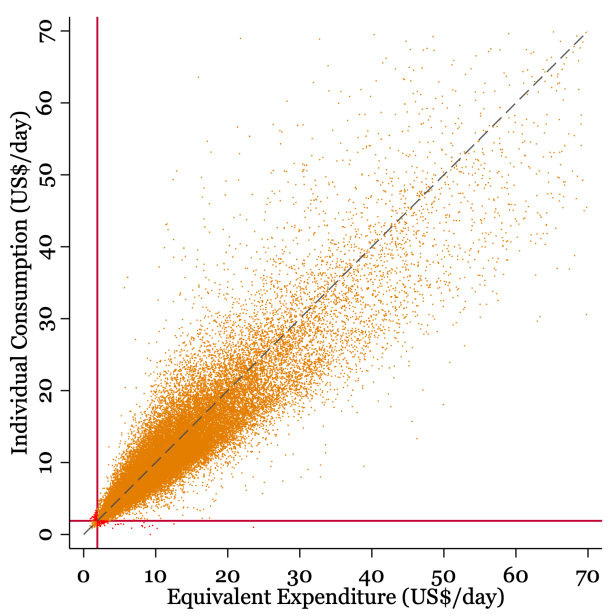

(F) Mexican Men

Note: Per equivalent expenditure is obtained by dividing total annual household expenditure (PPP dollars) by equivalent household size $\left(1+0.7 *\left(n_{m}+\right.\right.$ $\overline{\left.n_{w}\right)+} 0.5 * n_{c}$ ). Individual consumption is obtained by dividing individual expenditure by scale economies. In Bangladesh, only households surveyed in 2015 are included. Reference lines correspond to the 1.90 dollar/day poverty line. Dash lines identify the 45 degree lines. 
Figure A11: Individual Expenditure and Consumption

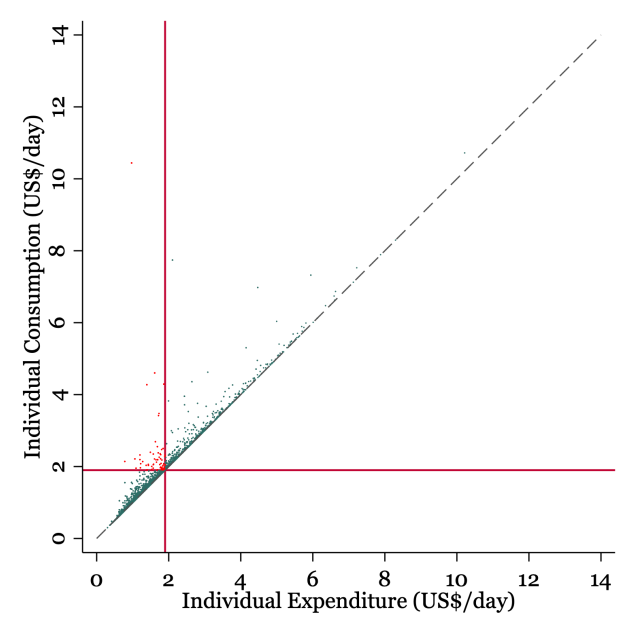

(A) Bangladeshi Children

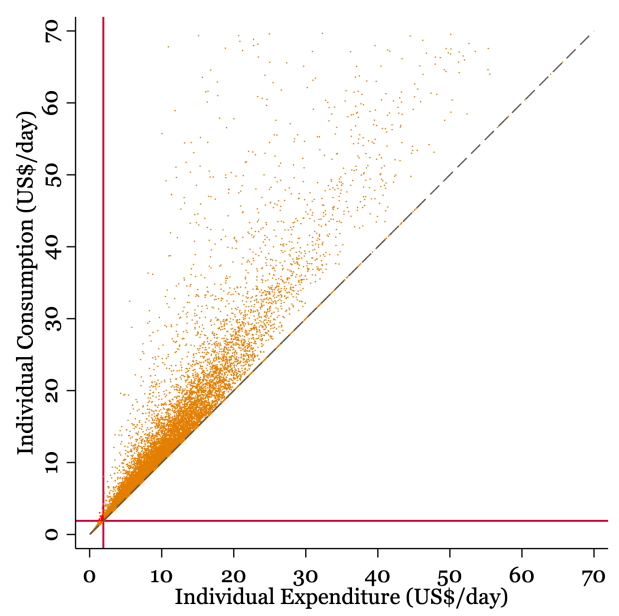

(D) Mexican Children

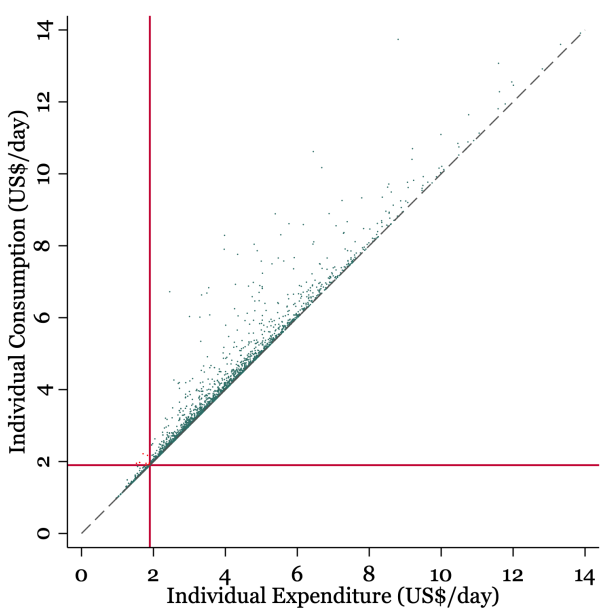

(B) Bangladeshi Women

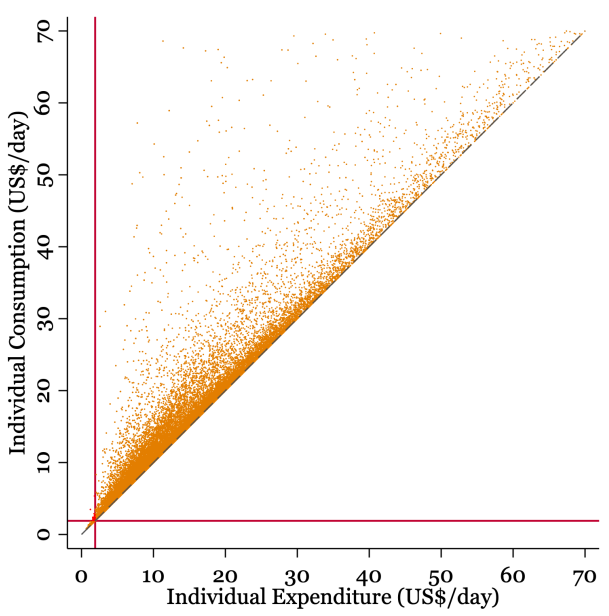

(E) Mexican Women

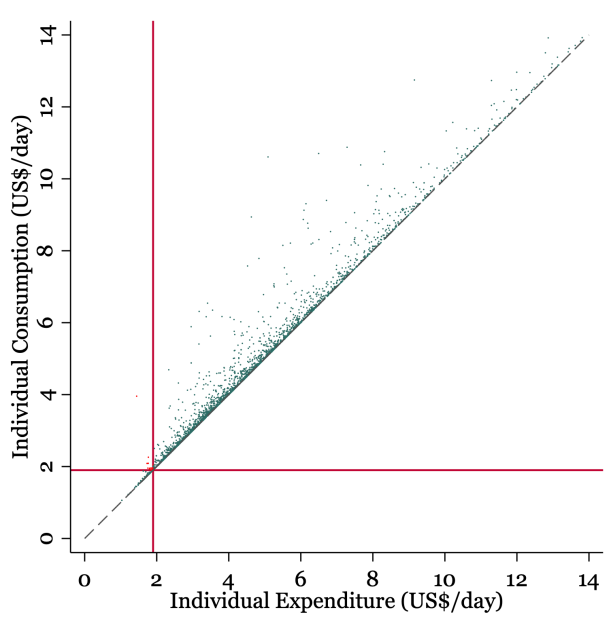

(C) Bangladeshi Men

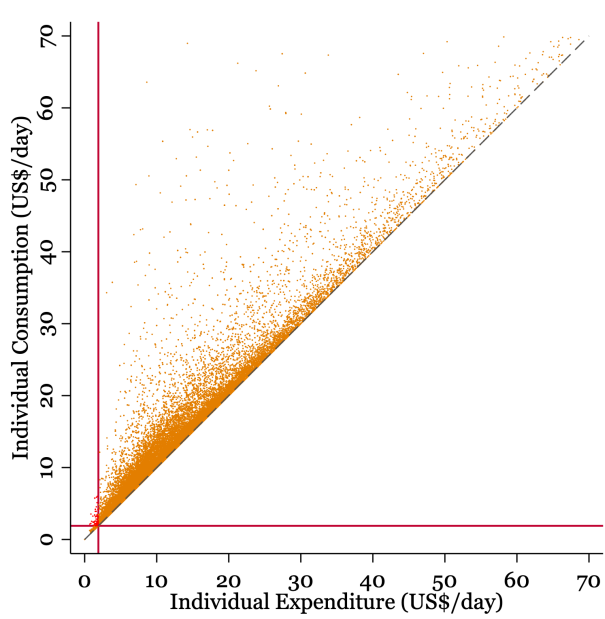

(F) Mexican Men

Note: Individual expenditure is obtained multiplying total annual household expenditure (PPP dollars) by individual resource shares. Individual consumption is obtained by dividing individual expenditure by scale economies. In Bangladesh, only households surveyed in 2015 are included. Reference lines correspond to the 1.90 dollar/day poverty line in Bangladesh. The poverty line is computed as 50 percent of the sample median per-capita expenditure in Mexico. Dash lines identify the 45 degree lines. 